PNL-8281

UC-602

CERCLA Treatability Test Report

\title{
In Situ Vitrification of a Mixed- Waste Contaminated Soil Site: The 116-B-6A Crib at Hanford
}

J. Luey

S. S. Koegler

W. L. Kuhn
P. S. Lowery

R. G. Winkelman

September 1992

Prepared for the U.S. Department of Energy under Contract DE-AC06-76RLO 1830

Pacific Northwest Laboratory Operated for the U.S. Department of Energy by 8 attelle Memorial Institute 


\title{
DISCLAIMER
}

This report was prepared as an account of work sponsored by an agency of the United States Government. Neither the United States Government nor any agency thereof, nor Battelle Memorial Institute, nor any of their employees, makes any warranty, expressed or implied, or assumes any legal liability or responsibility for the accuracy, completeness, or usefulness of any information, apparatus, product, or process disclosed, or represents that its use would not infringe privately owned rights. Reference herein to any specific commercial product, process, or service by trade name, trademark, manufacturer, or otherwise does not necessarily constitute or imply its endorsement, recommendation, or favoring by the United States Government or any agency thereof, or Battelle Memorial Institute. The views and opinions of authors expressed herein do not necessarily state or reflect those of the United States Government or any agency thereof.

\author{
PACIFIC NORTHWEST LABORATORY \\ operated by \\ BATTELLE MEMORIAL INSTITUTE \\ for the \\ UNITED STATES DEPARTMENT OF ENERGY \\ under Contract DE-ACO6-76RLO 1830
}

Printed in the United States of America

Available to DOE and DOE contractors from the

Office of Scientific and Technical Information, P.O. Box 62, Oak Ridge, IN 37831 ; prices available from (615) 576-8401. FTS 626-8401.

Available to the public from the National Jechnical information Service, U.S. Department of Commerce, 5285 Port Royal Rd., Springfield, VA 22161. 
PNL-828I

UC -602

\section{CERCLA TREATABILITY TEST REPORT}

IN SITU VITRIFICATION OF A MIXED-WASTE CONTAMINATED SOIL SITE: THE 116-B-6A CRIB AT HANFORD
J. Luey
S. S. Koeglera
W. L. Kuhn
P. S. Lowery
R. G. Winkelmanb

September 1992

Prepared for the U.S. Department of Energy under Contract DE-ACO6-76RLO 1830

Pacific Northwest Laboratory Richland, Washington

a Currently with Siemens Nuclear Power Company. Richland, Washington.

b Currently with Geosafe Corporation, Richland, Washington. 


\section{SUMMARY}

The first large-scale mixed-waste test of in situ vitrification (ISV) has been completed. The large-scale test was conducted at an actual contaminated soil site, the 116-B-6A crib. on the Department of Energy's Hanford Site. The large-scale test was a demonstration of the ISV technology and not an interim action for the 116-B-6A crib. Performance of the test was done under Section 6 of the Office of Solid Waste Emergency Response (OSWER) Directive 9335.3-01 [Environmental Protection Agency (EPA) guidance for Remedial Investigation/ Feasibility Study (RI/FS) treatability tests under the Comprehensive Environmental Response, Compensation, and Liability ACt (CERCLA)]. The test had four primary objectives:

1) Demonstrate at least $99 \%$ immobilization efficiency of hazardous metals and radionuclides in the vitrified, contaminated soil.

2) Demonstrate the ability of the ISV off-gas treatment system to process a soil containing significant quantities of combustible materials.

3) Demonstrate the ability of ISV to vitrify the site to depths that are practical within the context of actual waste site remediation work.

4) Produce a high-quality glass product comparable in leach resistance to previous ISV glass products and high-level waste glass.

This demonstration has provided technical data to evaluate the ISV process for its potential in the final disposition of mixed-waste contaminated soil sites at Hanford. Because of the test's successful completion, technical data on the vitrified sojl are available on how well the process incorporates transuranics and heavy metals into the waste form, how well the form resists leaching of transuranics and heavy metals, how well the process handles sites with high combustible loadings, and the important site parameters which may affect the achievable process depth.

The ISV demonstration on the 116-B-6A crib was completed in April 1990 after 288 hours of operation. The demonstration consumed 550 Mwh of electrical energy and resulted in a 850 ton block of vitrified soil. The primary contaminants vitrified during the demonstration were chromium, lead. and cesium-137. Data show that the retention in the vitrified block of chromium and lead was greater than $99.99 \%$ and the retention for cesium-137 was greater than $99.98 \%$. This high retention is similar to previous ISV tests and 
illustrates the efficiency of the process. Due to the extremely high immobilization efficiency. the off-gas treatment system is required to process only minor concentrations of contaminants in the gas stream.

Data show that the off-gas treatment system performed within design criteria and successfully handled the high-combustible loadings (the wooden crib timbers) of the contaminated soil site. The processing of the wooden timbers did not increase temperatures within the off-gas hood and treatment system above normal operating conditions observed for previous large-scale tests. The vacuum within the off-gas hood was maintained throughout the demonstration, indicating that the off-gas system compensated for the increased off-gassing from the processing of the wooden timbers.

Results of core drilling conducted in April 1991 revealed that the melt growth during processing was more lateral than predicted. The depth achieved during the 116-B-6A crib ISV demonstration was $4.3 \mathrm{~m}$, which was $1.8 \mathrm{~m}$ short of the depth necessary to vitrify the contaminated soil below the crib. The 4.3-m vitrified depth coincided with a cobble layer detected below the crib during the core drilling (pre-test characterization of the crib did not indicate such a layer). Prior to encountering the cobble layer, the rate of melt progression was satisfactory, indicating that greater depths are achievable if the site is homogenous and/or devoid of stratification.

Analysis of the vitrified core samples collected in Aprii 1991 indicate a homogeneous distribution of elements within the ISV block. Product quality tests on the core samples show the product to be comparable to previously produced ISV products and comparable in chemical durability to natural analogs. TCLP analysis of the core samples show a low leachability for chromium and lead cquantities of chromium and lead in the leach solution were below detection 1 imits).

This report describes the 116-B-6A crib site, the objectives of the ISV demonstration, the results in terms of the objectives, and the overall process performance. 


\section{CONTENTS}

SUMMARY ..............................

1.0 INTRODUCTION . . . . . . . . . . . . . . . . . . . . . . . . 1

1.1 OESCRIPTION OF ISV TECHNOLOGY . . . . . . . . . . . . . . 2

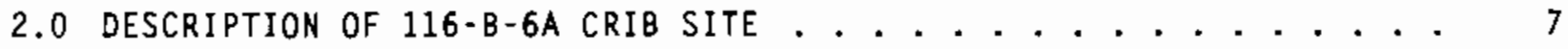

2.1 ESTIMATED CHEMICAL AND RADIOLOGICAL INVENTORY . . . . . . . . . 9

2.2 SITE CHARACTERIZATION DATA . . . . . . . . . . . . . . 9 9

2.3 SITE GROUNDWATER CHARACTERIZATION . . . . . . . . . . . . . 17

2.4 SITE GEOLOGY ANO HYDROLOGY . . . . . . . . . . . . . . . 20

3.0 OBJECTIVES . . . . . . . . . . . . . . . . . . . . . . 23

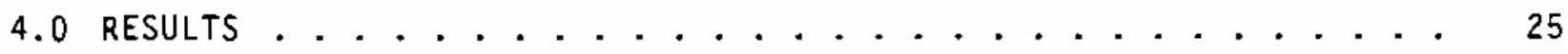

4.1 OBJECTIVE 1 - IMMOBILIZATION EFFICIENCY . . . . . . . . . . 27

4.1.1 Compositional Analysis of the Glass Product . . . . . 28

4.1.2 Compositional Analysis of the Scrub Solution...... 35

4.1.3 Analysis of Off-Gas-Treatment HEPA Filters....... 36

4.1.4 Overall Immobilization Efficiency . . . . . . . . . 37

4.2 OBJECTIVE 2 - EFFECT OF COMBUSTIBLES ON OFF-gAS TREATMENT SYSTEM . . . . . . . . . . . . . . . . . . . . 39

4.3 OBJECTIVE 3 - ISV PROCESSING DEPTH . . . . . . . . . . . . 44

4.3.1 Engineering-Scale Testing of the 116-8-6A Crib. . . . 45

4.3.2 Depth for the 116-B-6A Large-Scale Test ....... 47

4.3.3 Factors Affecting Melt Depth: Particle Size...... 48

4.3.4 Factors Affecting Melt Depth: Composition....... 51

4.3.5 Factors Affecting Me1t Depth: Moisture Content . . . . 51

4.4 OBJECTIVE 4 - PRODUCT OUALITY . . . . . . . . . . . . 53 
5.0 PROCESS PERFORMANCE . . . . . . . . . . . . . . . . . . . 57

5.1 OFF-GAS TREATMENT SYSTEM . . . . . . . . . . . . . . 57

5.2 LARGE-SCALE POWER SYSTEM . . . . . . . . . . . . . . . 58

5.2.1 Power Limitation: Carbon Monoxide Levels . . . . . . 59

5.2.2 Power Limitation: Upper Current Limit. . . . . . . . 61

5.2.3 Power Limitation: Transformer Temperature Limit . . . . 62

5.3 CONTROL OF LATERAL GROWTH: BARRIER WALL . . . . . . . . . 64

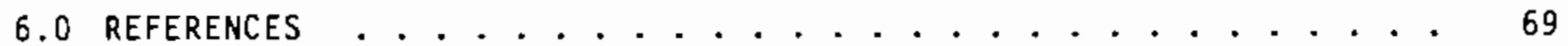

APPENDIX A - 100 AREA MONITORING WELLS, GEOLOGY, HYDROLOGY. AND WATER CHEMISTRY . . . . . . . . . . . . . . . . . A.1

APPENDIX B - EVALUATION OF FACTORS THAT MAY INFLUENCE MELT DEPTH AND SHAPE ....................... B.1 


\section{EIGURES}

1.1 ISV Operating Progression . . . . . . . . . . . . . . . 2

1.2 Aerial View of the Large-Scale ISV Unit . . . . . . . . . . . 3

1.3 Process Trailers for the Large-Scale ISV Unit . . . . . . . . . . 4

1.4 Large-Scale In Situ Vitrification Off-Gas System . . . . . . . 5

2.1 116-B-6A Crib in Relation to the Site Marker . . . . . . . . 7

2.2 Representative Timber Crib Structure . . . . . . . . . . . . 8

2.3 Map of the 116-B-6A Crib Site Showing Borehole and Monitoring Well

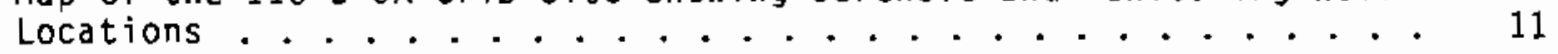

2.4 Lead Analys is for Borehole 2 . . . . . . . . . . . . . . I6

2.5 X-Ray Fluorescence Analysis for Lead - Boreholes 1, 2, 3 . . . . 16

2.6 Location of Probes for 1989 Soil Gas Monitoring . . . . . . . . . 18

2.7 Location of 1990 Soil Gas Monitoring Probes Relative to the
Off-Gas Hood ... 19

2.8 Water Table Map of the 100-B Area Heasured on February 7, 1989 . . 21

4.1 Initial Boring Points for Samples from the 116-B-6A Crib ISV Block 29

4.2 Approximate Locations of Samples Taken for Analysis . . . . . . 30

4.3 Temperature Profile of the Off-Gas Hood Roof . . . . . . . . . . 40

4.4 Temperature Profile of the Off-Gas Hood Wall . . . . . . . . . . . 41

4.5 Temperature Profile for the Off-Gas Exit - 45-second Average . . . 42

4.6 Temperature Profile for the Off-Gas hood Plenum . . . . . . . . . 43

4.7 Off-Gas Hood Vacuum - 45 -second Average . . . . . . . . . . . 44

4.8 Engineering-Scale Test Setup - 116-B-6A Crib Test . . . . . . . 46

4.9 Depth Profile for the 116-B-6A Crib Engineering-Scale Test Conducted in

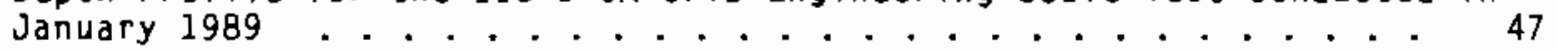

4.10 Depth Profile for 116-B-6A Crib ISV Treatability Test . . . . . 48

4.11 Cobble Layer Detected During Core Sampling of the ISV Block . . . . 50

4.12 water Balance for the 116-B-6A Crib ISV Treatability Test . . . . 52 
5.1 Standard Volumetric Flowrate through the Off-Gas Treatment Stack . 58

5.2 Power Profile for the 116-B-6A Crib ISV Treatability Test . . . . 59

5.3 Cumulative Energy Profile for the 116-B-6A Crib ISV Treatability Test . . . . . . . . . . . . . . . 60

5.4 Carbon Monoxide Concentration Profile: Off-Gas Stack . . . . . . 61

5.5 Current Profile for the "A" Phase Scott-Tee Transformer Output . . 62

5.6 Air Space Temperature Profile for the Scott-Tee Transformer Winding 63

5.7 Barrier Wall and Cooling System Installation - Plan View . . . . 65

5.8 Barrier Wall and Cooling System Installation - Elevation View . . . 66 


\section{IABLES}

2.1 116-B-6A Crib Waste Inventory . . . . . . . . . . . . . 10

2.2 Drill Log Data and Radionuclide Analysis . . . . . . . . . . 10

2.3 Drill Log and Field Sample Measurements for the 116-B-6A Crib Characterization ....................... 13

2.4 Borehole Chemical Anatyses . . . . . . . . . . . . . . 14

2.5 In Situ Radionuclide Analyses for Boreholes . . . . . . . . . . 15

2.6 Soil Gas Samples - Compounds Analyzed . . . . . . . . . . . 19

4.1 Summary of 116-B-6A ISV Treatability Test Events . . . . . . . . 25

4.2 Compositional Analysis for Core 非, Run \#2, Sample \#1 . . . . . . 31

4.3 Compositional Analysis for Core \#1, Run \#14, Sample \#3 . . . . . 32

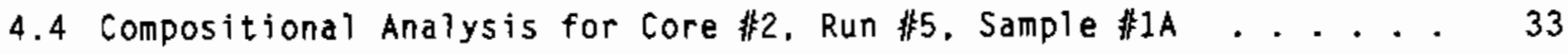

4.5 Estimated Content of Nonradioactive Inorganic Elements in the 116-B-6A ISV Block....................... . . . . . 34

4.6 Radionuclide Concentrations Within the 116-B-6A ISV B1ock . . . 35

4.7 Pre- and Post-Test Analytical Results for 116-B-6A Scrub Solution. 37

4.8 Selected 1mmobilization Efficiencies for the 116-B-6A Crib ISV

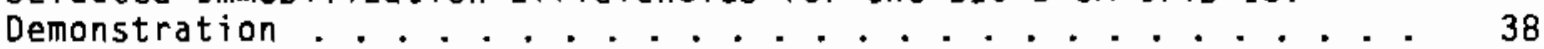

4.9 MCC-1 Test Results for the 116-B-6A Crib ISV Block ........ 54 4.10 TCLP Results for 116-B-6A Block Samples............. . 56 


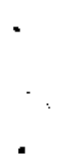




\subsection{INTRODUCTION}

Pacific Northwest Laboratory(a) (PNL) conducted a treatability test of the in situ vitrification (ISV) process in April 1990 at the 116-B-6A Crib site in Hanford's 100-B Area. The Hanford Site is located in south-central Washington state. The test was performed under Section 6 of the Office of Solid Waste Emergency Response (OSWER) Directive 9335.3-01 [Environmental Protection Agency (EPA) guidance for Remedial Investigation/Feasibility Study (RI/FS) treatability tests under the Comprehensive Environmental Response, Compensation, and Liability Act (CERCLA)]. This ISV treatability test was a technology demonstration and not a remedial action; in accordance with this designation, work to characterize the site was limited to those activities necessary to successfully implement and evaluate the demonstration and to ensure minimal impact of the test on the environment.

In situ vitrification technology was developed by PNL as a means to stabilize contaminated soils in situ without exhuming the soils. More than 100 tests of the ISV process, ranging from laboratory-scale to full-scale tests, have been conducted, generating vitrified blocks from 1 to $720,000 \mathrm{~kg}$. These tests have been conducted on a wide range of actual and simulated waste types and soils, and have repeatedly demonstrated the utility of the ISV process as an effective means of immobilizing hazardous chemical and radioactive contaminated soils. The large-scale test at the 116-B-6A site extends the ISV technology by demonstrating the ISV process on a site containing soil contaminated with heavy metals (chrome and lead) and radionuclides. plus combustible wooden timbers. The objectives of this treatability test were to demonstrate immobilization of the radioactive and hazardous materials, verify the ISV system's capacity for handing combustible material, determine the depth capability of the ISV process, and produce a high-quality glass product comparable in leach resistance to other ISV glass products and high-level waste glass.

(a) Pacific Northwest Laboratory is operated by Battelle Memorial Institute for the U.S. Department of Energy under Contract DE-AC06-76RLO 1830. 


\subsection{DESCRIPTION OF ISV TECHNOLOGY}

In situ vitrification is a thermal treatment process that converts contaminated soil into a chemically inert and stable glass and crystalline product. PNL uses three processing systems (engineering, pilot, and large scale) in their developmental work. New applications for the ISV process and modifications to the operating systems are first tested on the engineeringscale system, then on the pilot-and large-scale systems.

Figure 1.1 illustrates the ISV process. Four electrodes are inserted into the ground to the desired treatment depth. Because soil is not electrically conductive once its moisture is driven off, a conductive mixture of flaked graphite and glass frit is placed among the electrodes to act as a conductive starter path. An electrical current is established in the starter path by applying an electrical potential to the electrodes. The resultant. power heats the starter path and surrounding soil up to $2000^{\circ} \mathrm{C}$, well above the typical initial melting temperatures of soil $\left(1100^{\circ} \mathrm{C}\right.$ to $\left.1400^{\circ} \mathrm{C}\right)$. The graphite starter path is eventually consumed by oxidation, and the current is transferred to the molten soil. which is now electrically conductive. As the molten zone grows, it incorporates nonvolatile hazardous elements, such as heavy metals, and destroys organic compounds by pyrolysis. The pyrolyzed

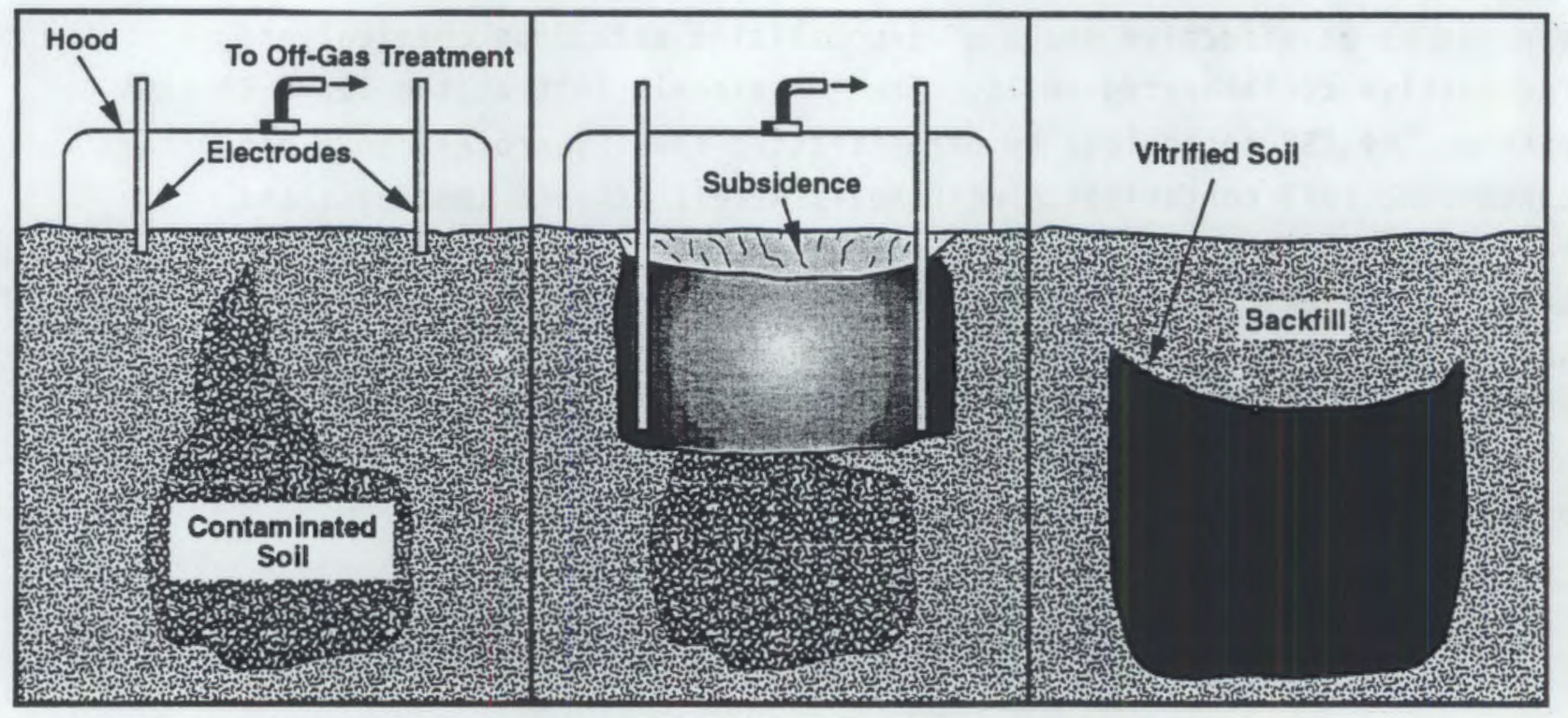

FIGURE 1.1. ISV Operating Progression 
by-products migrate to the surface of the vitrified zone where they burn in the presence of oxygen. A stainless steel hood placed over the area being vitrified directs the gaseous effluent to an off-gas treatment system.

Figure 1.2 shows the large-scale process equipment used for ISV. Controlled electrical power is distributed to the electrodes, and multiple stage off-gas treatment equipment processes the gaseous effluent. The process equipment required to perform these functions can be divided into six major components consisting of an electrical power supply, off-gas hood, off-gas treatment system, glycol cooling system, process control station, and off-gas support equipment.

Except for the off-gas hood, all the components are contained in three transportable trailers. Figure 1.3 illustrates the three different trailers used in the large-scale ISV system (an off-gas treatment trailer, a process control trailer. and a trailer containing the electrical equipment and glycol cooling system). All three trailers can be transported to any site over graded surfaces. The off-gas hood and off-gas 1 ine are dismantled and placed on a flatbed trailer for transport. The entire process is monitored and controlled from the process control station in the process control trailer.

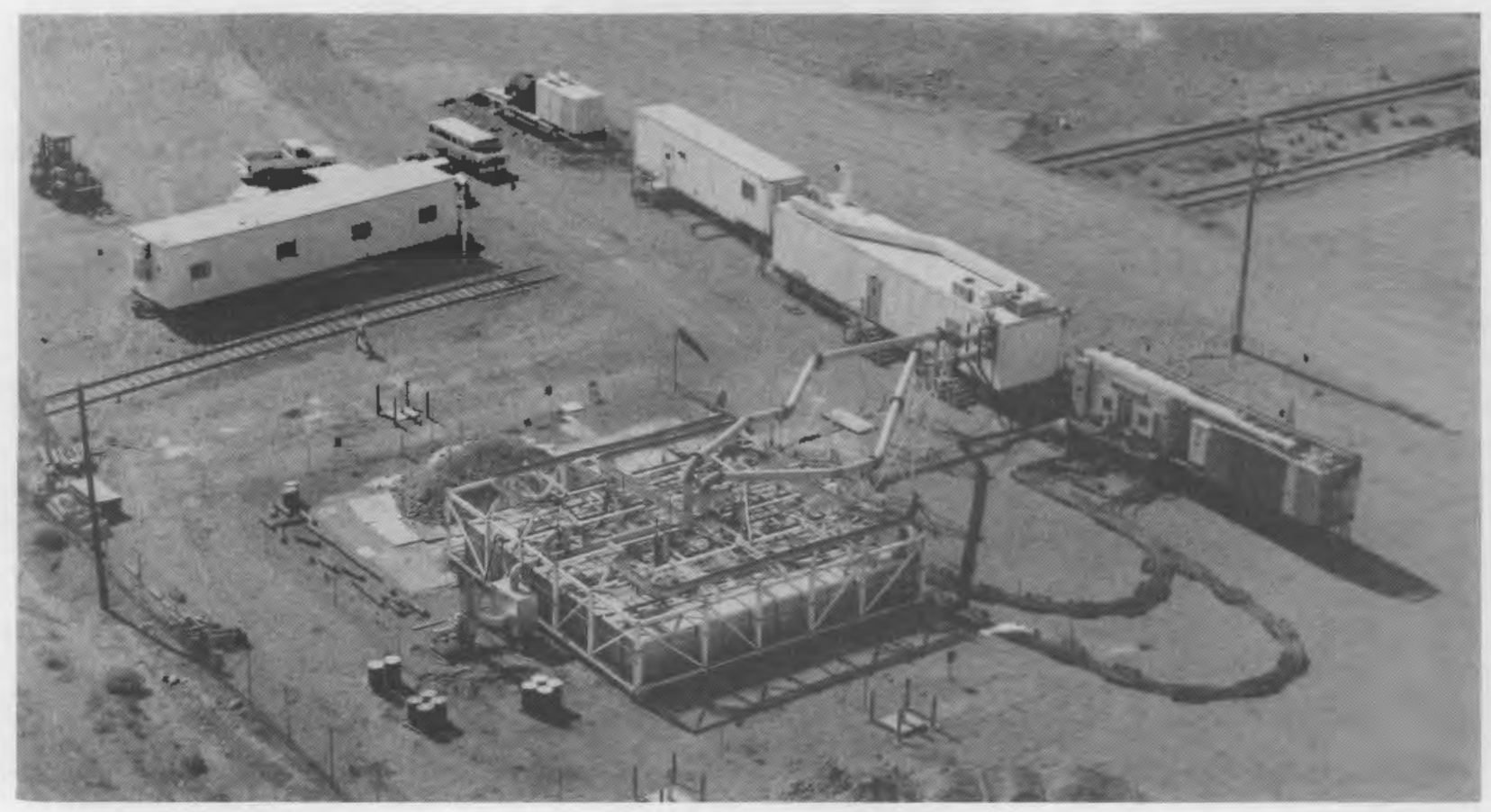

FIGURE 1.2. Aerial View of the Large-Scale ISV Unit 

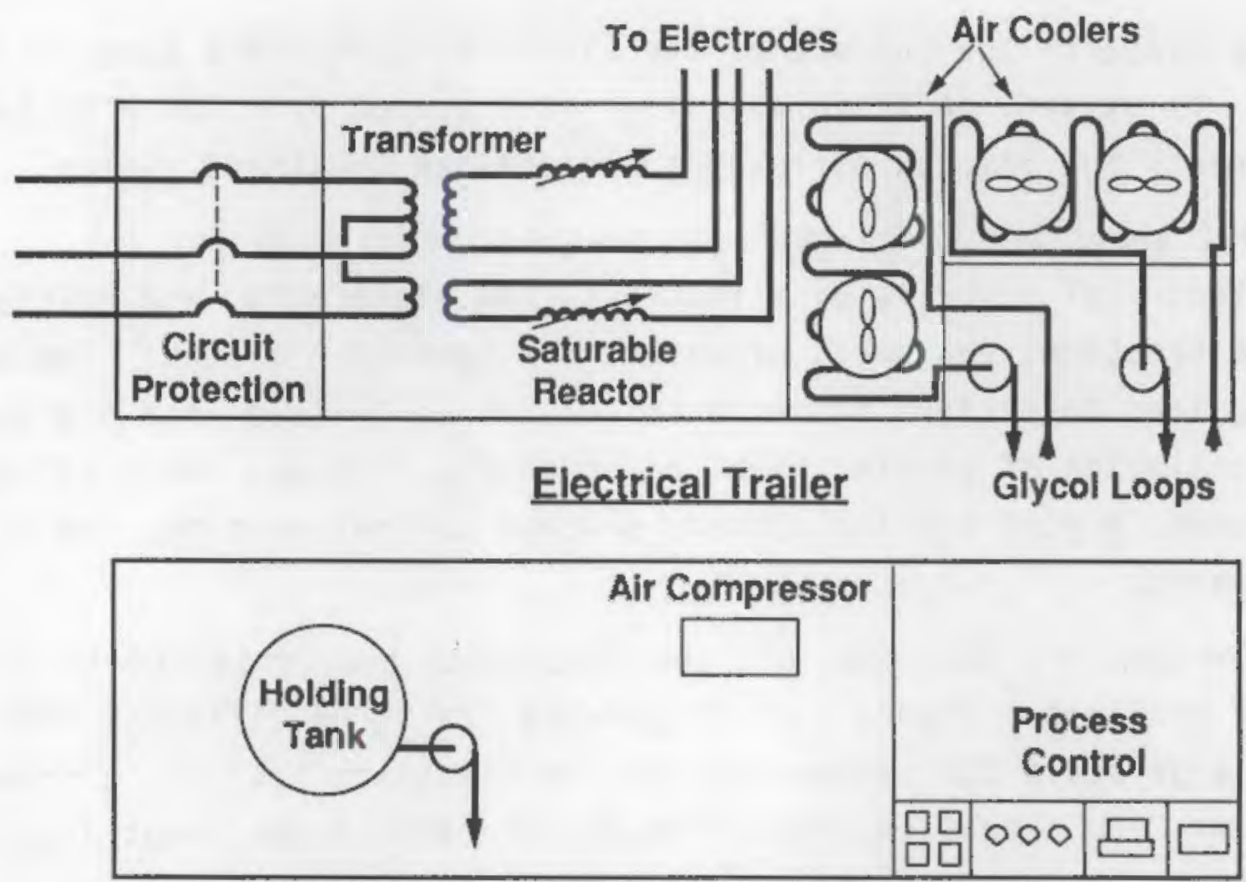

Process Control Trailer
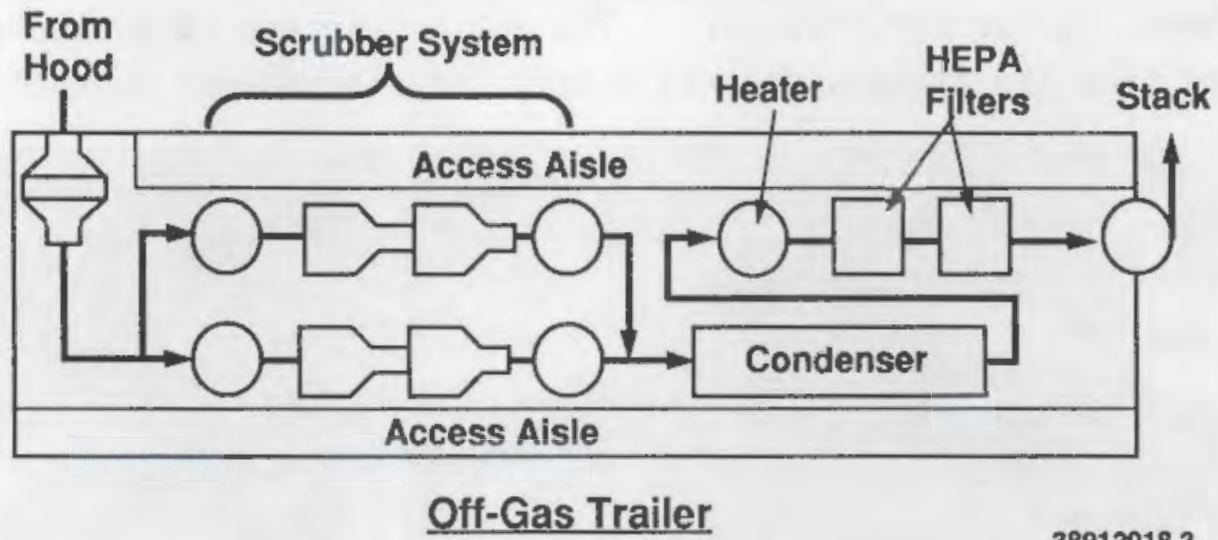

38912018.3

FIGURE 1.3. Process Trailers for the Large-Scale ISV Unit

Figure 1.4 illustrates the systems contained within the off-gas trailer. The system contains dual off-gas treatment trains that can be operated individually or in parallel. The off-gas system is fitted with a gas cooler. two quench towers, hydrosonic tandem nozzle scrubbers, two heat exchangers, three vane-separated mist eliminators, two scrub solution tanks, two pumps, a condenser, a heater, and high-efficiency particulate air (HEPA) filters. The 


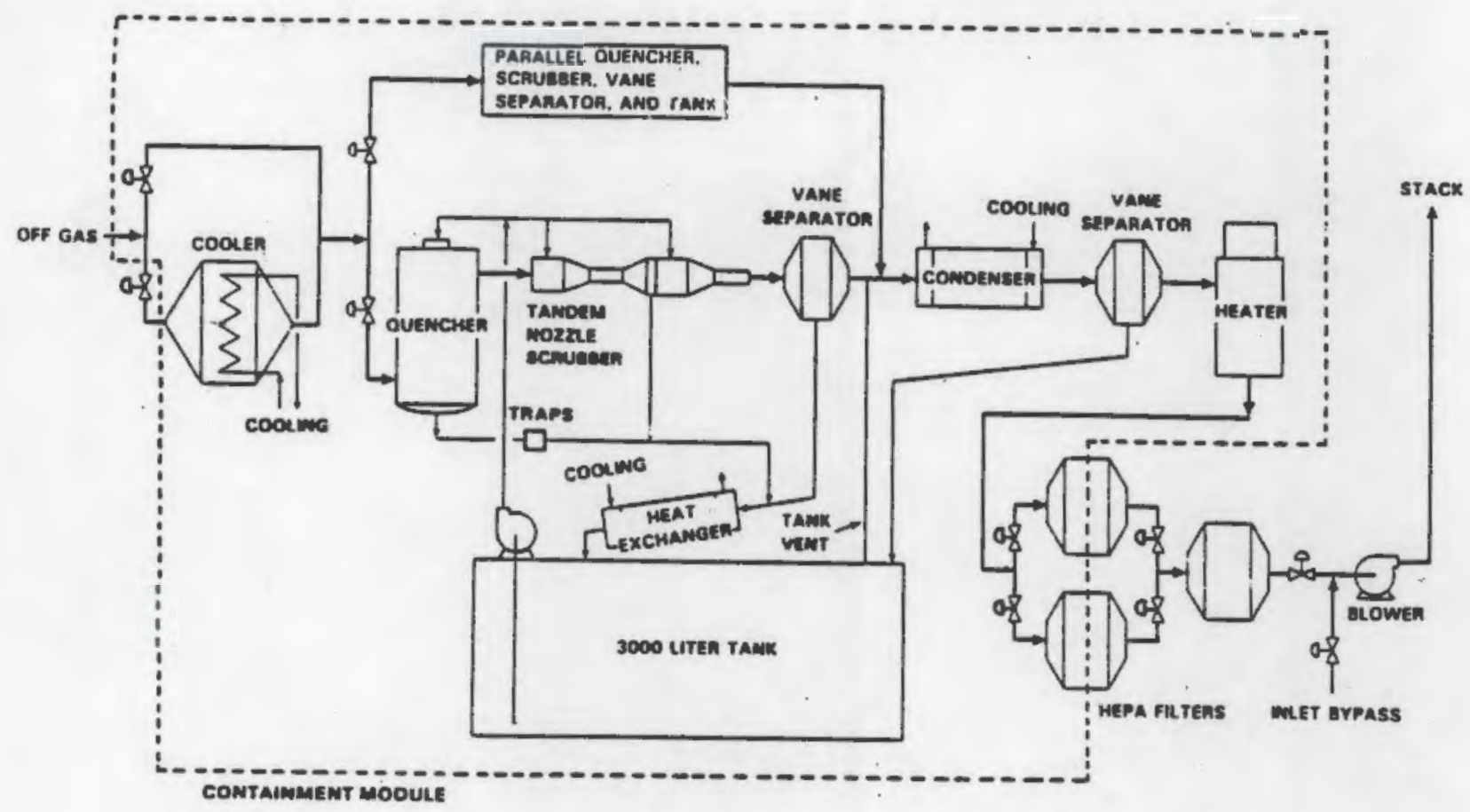

FIGURE 1.4. Large-Scale In Situ Vitrification Off-Gas System

quenchers remove $90 \%$ of the particulate and semi-volatile radionuclides: the scrubbers are designed to remove $90 \%$ of particulate greater than $0.5 \mu \mathrm{m}$ in diameter and condenses the remaining semi-volatile components. The off-gas system is continuously monitored for radionuclides and chemicals at several locations and is controlled from the process control trailer. Typically. operation of the off-gas treatment system, along with the post-test decontamination operations, result in 12 used HEPA filters and approximately $6000 \mathrm{~L}$ of scrub solution that will require disposal.

- The areas occupied by operating personnel in the off-gas and control trailers are ventilated by their own heating, ventilating, and air conditioning (HVAC) systems and duct work designed to maintain comfortable work conditions. The access aisles in the off-gas trailer are monitored by a continuous air monitor (CAM), both for alpha-bearing contaminants and beta/gamma-bearing contaminants. The process effluent stack is monitored continuousiy by a CAM unit. In addition, the process off-gas system contains environmental monitors that detect $\mathrm{NO}_{x}, \mathrm{SO}_{x}, \mathrm{CO}$ and $\mathrm{O}_{2}$. 



\subsection{DESCRIPIION OF $116-B-6 A$ CRIB SITE}

Figure 2.1 shows the crib location in relation to the site marker and the 111-B foundation and pad. The 116-B-6A Crib. located in the 100-B Area of the Hanford Site at Hanford coordinates 68620 north by 80335 west, is an inactive, mixed waste site that historically received liquid radioactive wastes from the 111-B Building. The waste resulted from the decontamination of equipment and fuel element spacers. The 111-B Building has subsequently been leveled and the demolition debris removed. so that only a concrete foundation and loading dock area remain. The waste site was operated from 1951 through 1968, when it was retired.
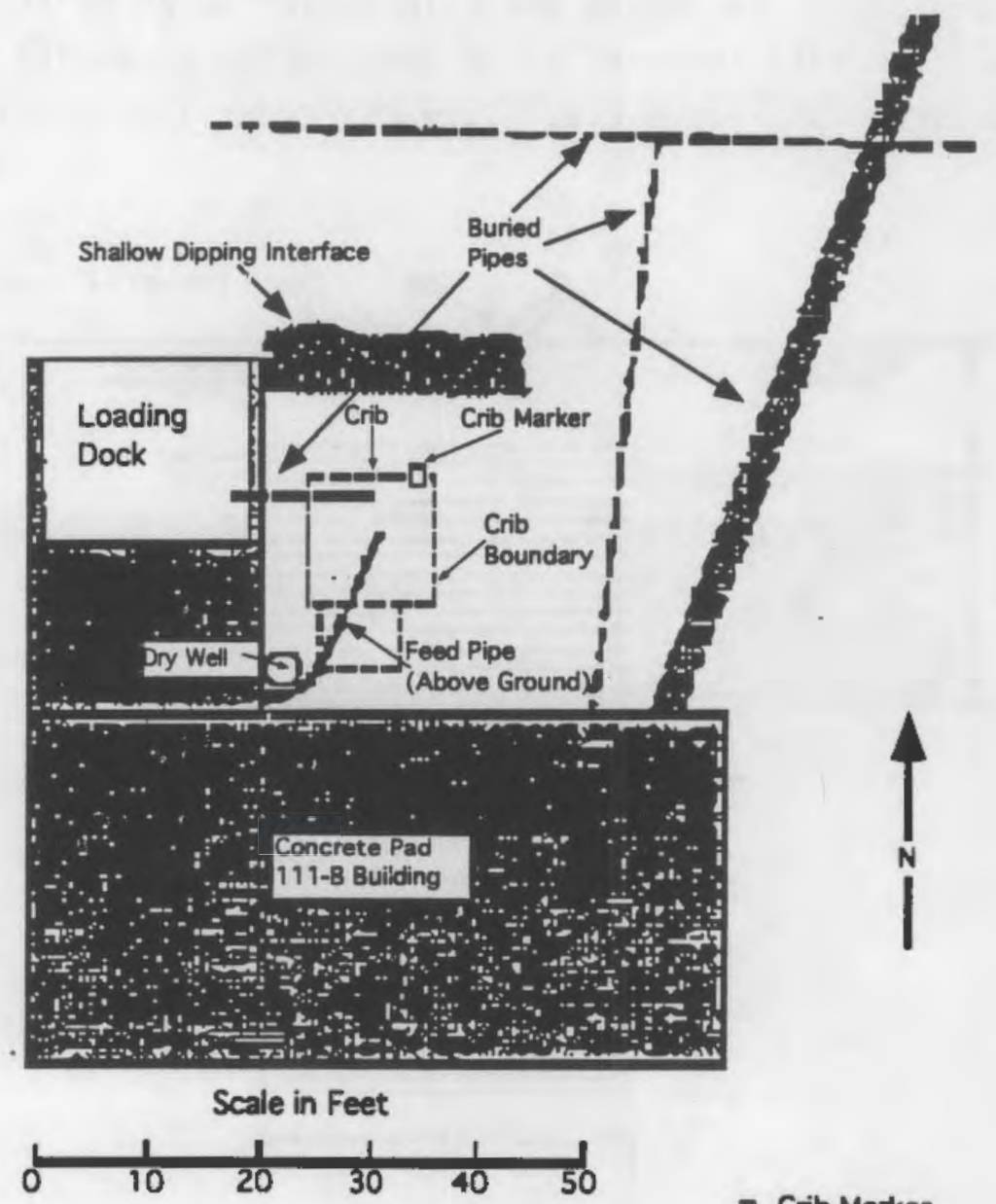

- Crib Marker

FIGURE 2.1. 116-B-6A Crib in Relation to the Site Marker 
A crib is defined as "an earth-covered structure for liquid disposal. with box(es). horizontal pipe, or uniform gravel to provide distribution and surge space" (Clukey 1956). Initial investigations found conflicting information on the geometry of the 116-B-6A Crib, and detailed drawings could not be located. In a 1954 document on radioactive liquid waste disposal facilities (Clukey 1954), the structure was described as $12-\mathrm{ft}$ square by $8-\mathrm{ft}$ high, buried $6 \mathrm{ft}$ underground. The surface elevation was reported as $474 \mathrm{ft}$ and the bottom elevation as $460 \mathrm{ft}$ (a difference of $14 \mathrm{ft}$ ). measurements that agree with the $8-\mathrm{ft}$ crib height plus the $6-\mathrm{ft}$ burial depth. Because of the lack of detailed characterization information, a preliminary site survey using ground-penetrating radar (GPR) was performed to verify the crib boundaries, size, and materials of construction. The GPR survey confirmed the crib dimensions and depth and showed the crib marker to be on the northeast corner of the crib. The crib appeared to be constructed of wooden timbers with rocky backfill, as shown in Figure 2.2. Site characterization drilling in April
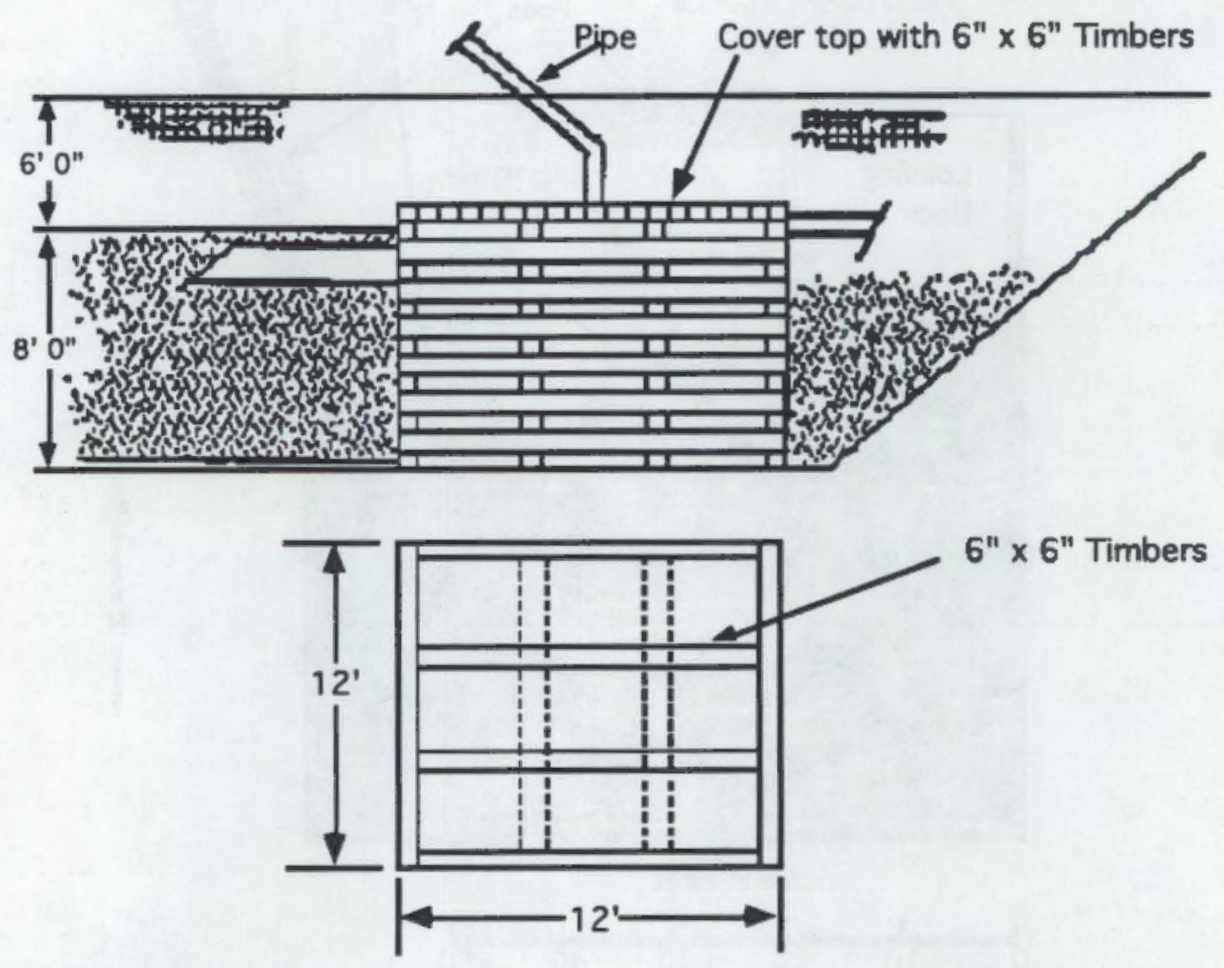

EIGURE 2.2. Representative Timber Crib Structure 
1989 yielded small pieces of wood in the drilling samples, confirming the presence of timbers.

A search of the records found no conclusive information about the buried pipes that are shown in Figure 2.1. A review of engineering drawings for the adjacent facilities indicated that the lines running in a north-south direction and located just east of the crib are most likely inactive 1.5-in.diameter water service lines. The pipe that appears to connect the loading dock sump with the crib is probably a drain line used to drain contaminated sump water into the crib. The "dry well" indicated in the figure is actually a steam drain, formerly used to collect and drain process steam and condensate from the building.

\subsection{ESTIMATEO CHEMICAL AND RADIOLOGICAL INVENTORY}

It is estimated that approximately $5000 \mathrm{~L}$ of chemical wastes were disposed of in the crib. The principal chemicals disposed are sodium dichromate, sodium oxalate, and sodium sulfamate. The inventory of chemicals and radionuclides, based on historical records, is presented in Table 2.1.

\subsection{SITE CHARACTERIZATION DATA}

In 1976, a sample hole was drilled into the site about 2-ft south of the crib marker: results from sampling activities are presented in Table 2.2. Essentially no radioactivity was detected in samples obtained from less than 15-ft deep. The lack of radioactivity in those samples supports the fact that the bottom of the crib is reportedly $14 \mathrm{ft}$ below the surface, as activity is typically concentrated in the soil below the crib. Radionuclides were found from 15 to $22.5 \mathrm{ft}$, and the activity at $25 \mathrm{ft}$ was at background ievels.

In April 1989, two additional characterization boreholes were drilled into the crib, and a third was drilled approximately 10-ft north of the crib. The locations of these boreholes (labeled $\mathrm{BH}-1, \mathrm{BH}-2$, and $\mathrm{BH}-3$ ) are shown in Figure 2.3. The boreholes were used to characterize the type, concentration, and vertical and lateral extent of contamination within the zone to be vitrified and to determine the lithology of the area affected by ISV operations. The cable-tool drilling method was used for drilling the three characterization boreholes. Soil samples were collected from the three boreholes at 2-ft intervals. Surface samples were also collected at boreholes 
TABLE 2.1. 116-B-6A Crib Waste Inventory

\begin{tabular}{cc} 
Chemical & Inventory $(\mathrm{kg})$ \\
\hline Sodium Dichromate $\left(\mathrm{Na}_{2} \mathrm{Cr}_{2} \mathrm{O}_{7} \cdot 2 \mathrm{H}_{2} \mathrm{O}\right)$ & 50 \\
Sodium Oxalate $\left(\mathrm{Na}_{2} \mathrm{C}_{2} \mathrm{O}_{4}\right)$ & 100 \\
Sodium Sulfamate $\left(\mathrm{NaNH}_{2} \mathrm{SO}_{3}\right)$ & 100 \\
Radionuclide & Inventory $(\mathrm{Ci}) \quad$ (a) \\
Sr -90 & 0.9000 \\
$\mathrm{Cs}-137$ & 0.1490 \\
Eu -155 & 0.0023 \\
$\mathrm{Co}-60$ & 0.0022 \\
$\mathrm{Pu}-239$ & 0.0018 \\
$\mathrm{U}-238$ & 0.0009 \\
$\mathrm{Pu}-240$ & 0.0002 \\
Eu -152 & 0.0001 \\
Eu -154 & 0.0001 \\
Total - & 1.0566 \\
\hline
\end{tabular}

(a) Decayed through $04 / 01 / 86$.

IABLE 2.2. Orill Log Data and Radionuclide Analysis (1976)

\begin{tabular}{|c|c|c|c|c|c|c|c|c|c|}
\hline \multirow{2}{*}{$\begin{array}{l}\text { Depth } \\
(\mathrm{ft})\end{array}$} & \multirow{2}{*}{$\begin{array}{l}\text { Count } \\
(\mathrm{c} / \mathrm{m})\end{array}$} & \multicolumn{8}{|c|}{ Radionuclides $(\mathrm{pC} / \mathrm{g})(0)$} \\
\hline & & $90 S r$ & $137 \mathrm{Cs}$ & $155 \mathrm{Eu}$ & $60 \mathrm{Co}$ & $239 / 240 \mathrm{Pu}$ & $238 \mathrm{U}$ & 152Eu & ${ }^{154} \mathrm{Eu}$ \\
\hline 0 & $<100$ & -- & - & -- & - & -- & -- & $\cdots$ & $\cdots$ \\
\hline 5 & $<100$ & -- & $-\cdot$ & -. & -- & - & $-\cdot$ & - & -- \\
\hline 10 & $<100$ & $-\cdot$ & -- & -- & - & -. & -. & - & -- \\
\hline 15 & 1000 & 1400 & 210 & 15 & 6.1 & 3.6 & 1.0 & 0.29 & 0.41 \\
\hline 17.5 & 800 & - & - & - & - & - & - & - & $\cdots$ \\
\hline 20 & 600 & 2200 & 370 & 8.6 & 15 & 3.0 & - & - & 0.18 \\
\hline 22.5 & 200 & 34 & 21 & 0.87 & 0.78 & 0.19 & - & -. & 0.27 \\
\hline 25 & $<100$ & -. & - & - & - & - & - & - & - \\
\hline
\end{tabular}

(a) Samples with (--) were not analyzed. 


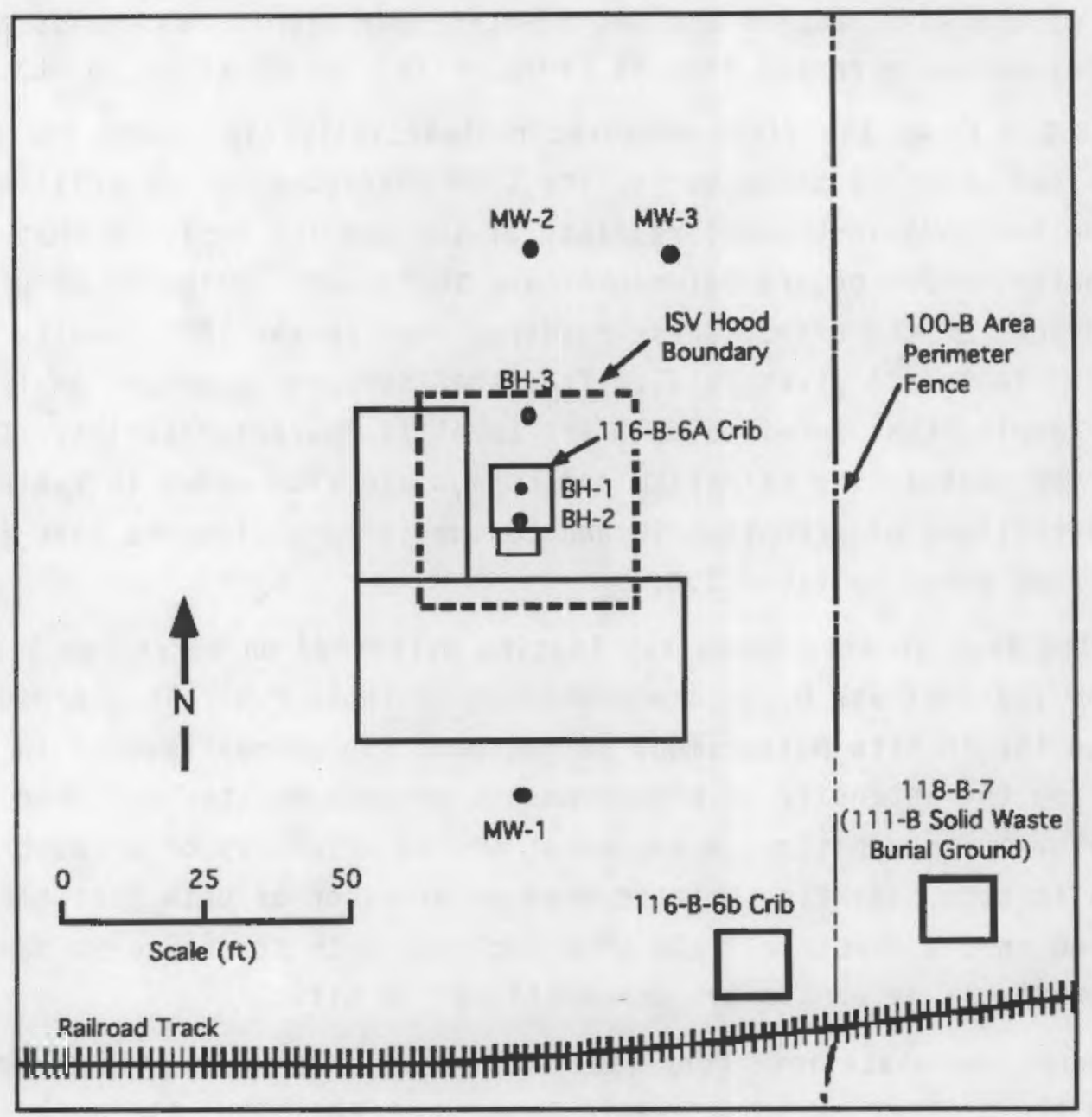

FIGURE 2.3. Map of the 116-B-6A Crib Site Showing Borehole and Monitoring Well Locations

BH-2 and BH-3 using a drive barrel or, during hard-tool drilling, a bailer. The coarseness of the material encountered precluded the use of split-spoon sampling methods. Differences between Tables 2.2 and 2.3 may be attributed to the different sampling locations and the fact that the two sets of data were collected approximately 13 years apart.

The lithology and texture encountered was relatively homogenous at all of the characterization boreholes, consisting of an unconsolidated, poorly sorted, sandy gravel to silty sandy gravel, averaging approximately $50-60 \%$ gravel, 30-45\% sand, and 5-10\% mud (silt and clay). The approximate average petrologic composition was $60-90 \%$ basalt and other volcanics, and $10-40 \%$ quartz, quartzite, and other silicon-rich rock fragments. Moisture content 
analysis of the soil samples did not identify any significant moist zones. The percent moisture ranged from $4 \%(B H-2,4 \mathrm{ft})$ to $15 \%(\mathrm{BH}-2,8 \mathrm{ft})$.

Table 2.3 shows the field-measured radioactivity (in counts per minute) and $\mathrm{pH}$ of soil samples taken during the 1989 characterization drilling. Geiger-Mueller (GM) instrument readings of the samples indicate that the bulk of the contamination occurs between 6 - and 18-ft deep, between the upper and lower confines of the crib. These readings confirm the 1976 results shown in Table 2.2. Table 2.4 gives results from the inorganic chemical analysis for the soil samples that received full EPA Level IV characterization. Selected analysis for radioactive strontium and cesium are also shown in Table 2.5. The concentrations of strontium-90 and cesium-137 are close to that for the 1976 analyses shown in Table 2.2.

Results from in situ gamma-ray logging performed on boreholes 1 and 2 before the ISV test was begun are presented in Table 2.5. This procedure applies to the in situ measurement of radionuclide concentrations in sediments by measuring the intensity of monochromatic photons emitted by those radionuclides. In addition, measurement of the intensity of bremsstrahlung radiation (photon radiation emitted when an electron or beta particle is accelerated in the electric field of a nucleus) from strontium-90 can be used to quantitatively determine its concentration in situ.

Although the waste inventory (see Table 2.1) indicates that chromium should be the primary hazardous waste concern at the site, the soil analyses show that chromium levels in the crib soil were close to the background concentrations of chromium in soil. Nevertheless, the chromium concentrations were high enough to provide data on chromium retention during ISV processing and in the glass product. The soil analyses did indicate, however, that lead is present in concentrations above those found in background soil samples. As with the radioactivity measurements. the lead analyses showed lead to be deposited mainly within the confines of the crib. Analyses of soil samples for sulfamate indicated levels below $3 \mathrm{ppm}$ for the boreholes at all depths. and sulfamate levels below $300 \mathrm{ppm}$ for the "dry well" soil samples. Analyses for oxalate in soil samples from the boreholes indicated levels below $0.5 \mathrm{ppm}$ except between 6 and $12 \mathrm{ft}$ from borehole 3 . where levels average $2 \mathrm{ppm}$. Samples from the "dry well" indicated oxalate levels below $50 \mathrm{ppm}$. The soil 
IABLE 2.3. Drill Log and Field Sample Measurements for the 116-B-6A Crib Characterization (1989)

\begin{tabular}{|c|c|c|c|c|}
\hline $\begin{array}{r}\text { Depth } \\
(\mathrm{ft}) \\
\end{array}$ & $\begin{array}{l}\text { GM Measurements } \\
(\mathrm{cDm})\end{array}$ & $\mathrm{DH}$ & $\begin{array}{r}\text { Depth } \\
(\mathrm{ft})\end{array}$ & $\begin{array}{l}\text { GM Measurements } \\
(\mathrm{cpm})\end{array}$ \\
\hline $\begin{array}{l}\text { BH-1 } \\
2.0(a) \\
4.0 \\
7.0 \\
9.5 \\
11.5(c) \\
14.0 \\
16.0 \\
18.0 \\
20.0 \\
22.0 \\
24.0\end{array}$ & $\begin{array}{l}\text { Background }(<100) \\
\text { Background } \\
150 \\
150 \\
2000 \\
1000 \\
500 \\
500 \\
200 \\
200 \\
100\end{array}$ & $\begin{array}{l}-. \\
-- \\
\cdots \\
-- \\
8.2 \\
7.8 \\
8.3 \\
7.9 \\
8 \\
8.1 \\
7.8\end{array}$ & $\begin{array}{l}\text { Surface } \\
2.0(\mathrm{~b}) \\
4.0 \\
6.0 \\
8.0 \\
10.0 \\
12.0 \\
14.0 \\
16.0 \\
18.0 \\
20.0 \\
22.0 \\
24.0 \\
26.0 \\
28.0 \\
30.0\end{array}$ & $\begin{array}{l}\text { BH-3 } \\
\text { Background } \\
\text { Background } \\
\text { Background } \\
\text { Background } \\
\text { Background } \\
\text { Background } \\
\text { Background } \\
\text { Background } \\
\text { Background } \\
\text { Background } \\
\text { Background } \\
\text { Background } \\
\text { Background } \\
\text { background } \\
\text { Background } \\
\text { Background }\end{array}$ \\
\hline
\end{tabular}

$\mathrm{BH}-2$

Surface

2.0

4.0

6.0

8.0

$10.0(d)$

12.0

14.0

16.0

18.0

20.0

22.0

24.0

26.0

28.0

$\begin{array}{cl}\text { Background } & - \\ \text { Background } & -. \\ \text { Background } & - \\ 5500 & 7.3 \\ 2000 & 7.2 \\ 500 & 7 \\ 700 & 8 \\ 1000 & 8 \\ 300 & 7-8 \\ 800 & 9 \\ 400 & 7 \\ 200 & 12 \\ 300 & 11 \\ 150 & 10 \\ \text { Background } & 9\end{array}$

(a) All pH measurements from $\mathrm{BH}-1$, and the 6- and 8-ft measurements from $\mathrm{BH}$ 2. were taken using a portable pH meter. The remaining pH measurements were taken using $\mathrm{pH}$ paper.

(b) Switched to hard tool after 2-ft sample.

(c) Switched to hard tool after 9-ft sample.

(d) Switched to hard tool after 11.5-ft sample. 
IABLE 2.4. Borehole Chemical Analyses (1989)

Chemical Analysis (ug/g)

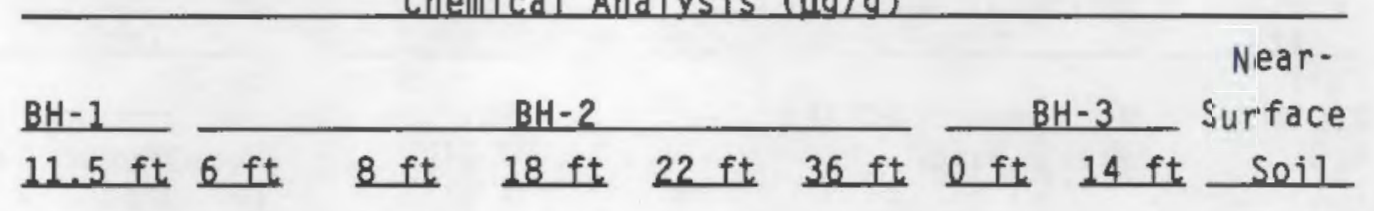

$\begin{array}{llllllllll}\text { Cyanide } & <25.0 & <25.0 & <25.0 & <25.0 & \ldots & & & & \\ \text { Silver } & 2.0 & 2.0 & <1.0 & <1.0 & <1.0 & <1.0 & <1.0 & <1.0 & <1.0 \\ \text { Aluminum } & 5580 & 4480 & 3980 & 3750 & 3770 & 3810 & 4480 & 4600 & 4100 \\ \text { Arsenic } & 1.2 & <1.0 & <1.0 & <1.0 & <1.0 & <1.0 & <1.0 & <1.0 & <1.0 \\ \text { Barium } & 106 & 70 & 60 & 50 & 50 & 60 & 80 & 70 & 50 \\ \text { Beryllium } & 0.3 & 0.2 & 0.1 & <1.0 & 0.2 & <1.0 & <1.0 & <1.0 & <1.0 \\ \text { Calcium } & 6520 & 4840 & 4960 & 5350 & 6020 & 5750 & 3800 & 6780 & 3460 \\ \text { Cadmium } & 0.21 & 0.92 & 0.35 & 0.19 & <0.1 & <0.1 & 0.23 & <0.1 & <0.1 \\ \text { Cobalt } & 10 & 8.0 & 7.0 & 9.0 & 6.0 & 9.0 & 8.0 & 11 & 6.0 \\ \text { Chromium } & 0.1 & <0.1 & 0.2 & <0.1 & <0.1 & <0.1 & 0.2 & <0.1 & 0.1 \\ \text { (hexavalent) } & & & & & & & & & \\ \text { Chromium } & 7.0 & 24.0 & 4.0 & 5.0 & 3.0 & 4.0 & 7.0 & 2.0 & 5.0 \\ \text { Copper } & 26 & 92 & 26 & 38.0 & 19 & 24 & 16 & 26 & 12 \\ \text { Iron } & 22800 & 18400 & 16100 & 22800 & 20300 & 24600 & 10600 & 23300 & 11200 \\ \text { Mercury } & 0.1 & 0.13 & 0.07 & 0.09 & <0.04 & <0.04 & <0.04 & <0.04 & 0.11 \\ \text { Potassium } & 980 & 964 & 825 & 569 & 439 & 585 & 968 & 771 & 982 \\ \text { Magnesium } & 3260 & 2640 & 2350 & 2980 & 2340 & 2680 & 2400 & 3150 & 2210 \\ \text { Manganese } & 355 & 293 & 259 & 298 & 231 & 282 & 282 & 359 & 311 \\ \text { Sodium } & 321 & 247 & 297 & 478 & 405 & 474 & 1.9 & 686 & 141 \\ \text { Nickel } & 20 & 10 & <10 & 10 & <10 & <10 & 10 & <10 & 10 \\ \text { Lead } & 48.0 & 94.0 & 56.0 & 21.0 & 3.5 & 1.6 & 23.0 & 4.2 & 16.0 \\ \text { Antimony } & <1.0 & <1.0 & <1.0 & <1.0 & <1.0 & <1.0 & <1.0 & <1.0 & <1.0 \\ \text { Selenium } & <1.0 & <1.0 & <1.0 & <1.0 & <1.0 & <1.0 & <1.0 & <1.0 & <1.0 \\ \text { Tin } & <5.0 & <5.0 & <5.0 & <5.0 & <5.0 & <5.0 & <5.0 & <5.0 & <5.0 \\ \text { Thallium } & <1.0 & <1.0 & <1.0 & <1.0 & <1.0 & <1.0 & <1.0 & <1.0 & <1.0 \\ \text { Vanadium } & 15 & 13 & 13 & 9.0 & 9.0 & 16 & 10 & 12 & 12 \\ \text { Zinc } & 60 & 2500 & 1140 & 40 & 30 & 30 & 70 & 30 & 42 \\ & & & & & & & & & \end{array}$


IABLE 2.5. In Situ Radionuclide Analyses for Boreholes ( $\mathrm{pCi} / \mathrm{g}$ )

\begin{tabular}{|c|c|c|c|c|}
\hline & Depth (ft) & Cs -137 & $S r-90$ & Co-60 \\
\hline \multirow[t]{4}{*}{ Borehole 1} & 11.5 & 11 & $N / A(a)$ & 122 \\
\hline & 14 & 574 & 138 & 0.76 \\
\hline & 16 & 450 & $--(b)$ & $\mathrm{N} / \mathrm{A}$ \\
\hline & 20 & 140 & -- & $\mathrm{N} / \mathrm{A}$ \\
\hline \multirow[t]{9}{*}{ Borehole 2} & 4 & 3.9 & $N / A$ & N/A \\
\hline & 6 & 3402 & $N / A$ & $N / A$ \\
\hline & 8 & 245 & N/A & $N / A$ \\
\hline & 12 & $\mathrm{~N} / \mathrm{A}$ & $N / A$ & 0.58 \\
\hline & 14 & 787 & 162 & $\mathrm{~N} / \mathrm{A}$ \\
\hline & 18 & 394 & $N / A$ & $N / A$ \\
\hline & 20 & 169 & -- & $N / A$ \\
\hline & 26 & 16 & -- & $\mathrm{N} / \mathrm{A}$ \\
\hline & 28 & 10.4 & $N / A$ & $N / A$ \\
\hline Borehole 3 & 20 & 2.3 & -- & $N / A$ \\
\hline
\end{tabular}

(a) N/A indicates not analyzed.

(b) - indicates below detection limit.

analyses for oxalate and sulfamate confirmed the disposal of oxalate and sulfamate into the crib, and suggested that oxalate has migrated outside of the crib over time.

Figure 2.4 shows results from the lead analysis for borehole 2 . The highest lead concentration is near the top of the crib ( 6 to $8 \mathrm{ft}$ ), and then the concentration drops to background levels below $20 \mathrm{ft}$. There also appears to be a concentration spike at $18 \mathrm{ft}$. near the bottom of the crib. The figure shows both PNL $x$-ray fluorescence results and results for the contract Laboratory Program (CLP) Method 239.2. The $x$-ray fluorescence method measures total lead (both soluble and insoluble), whereas the CLP analysis measures only acid-soluble lead. Figure 2.5 illustrates a comparison of the lead concentration values for each of the three borehole locations. Except for a spike at the surface, lead concentrations for borehole 3 are at background (the lead concentration spike at the surface may be attributed to other characterization activities under way in the area). 


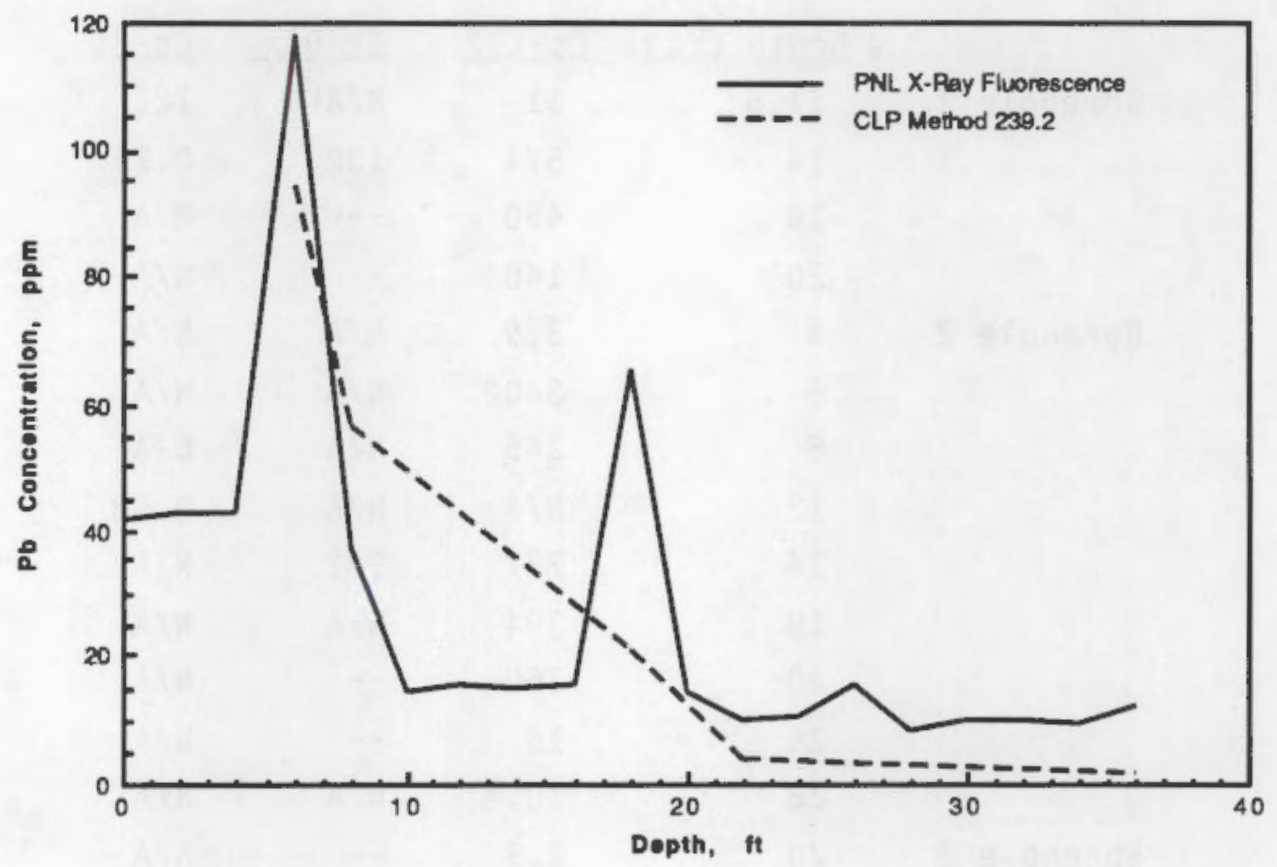

FIGURE 2.4. Lead Analysis for Borehole 2

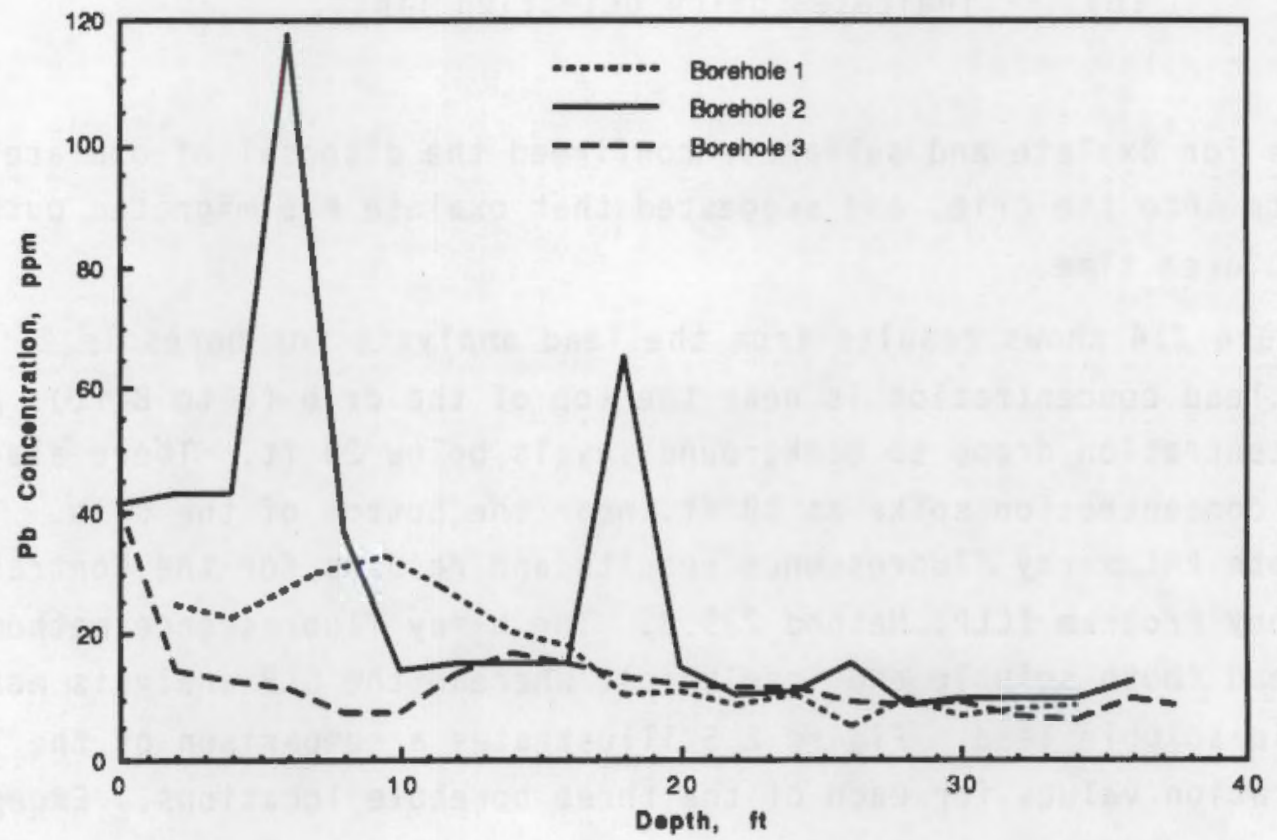

FIGURE 2.5. X-Ray Fluorescence Analysis for Lead - Boreholes 1,2, 3 
The lateral distribution of the 116-B-6A plume appears to be 1 imited. Borehole 3, which was placed $10 \mathrm{ft}$ outside the crib. produced soil samples that did not show any radioactive contamination or elevated concentrations of chemical constituents to the maximum depth of $36 \mathrm{ft}$.

Soil samples were also taken at the steam trap and background soil samples were taken from two near-surface locations near the site. Samples were collected from the steam trap using a manually operated hand auger. The background soil samples collected from the near surface were obtained at depths of 1 to $1.4 \mathrm{ft}$ at the locations using a shovel. None of these samples showed radioactive contamination or elevated levels of hazardous chemicals.

Soil gas monitoring was performed on the area surrounding the crib to monitor for volatile organic compounds in the soil. Samples were taken in June 1989. February and March 1990, and during the April 1990 test. Figure 2.6 illustrates the location of the soil gas probes used for the sampling performed in 1989. The probes were placed at the perimeter; 40 and $80 \mathrm{ft}$ from the crib on the north, south, and east sides of the crib; and at the perimeter and at $40 \mathrm{ft}$ from the crib on the west side of the crib. The soil gas was analyzed for the ten chemicals shown in Table 2.6. Results from the 1989 sampling show that concentrations in all four samples adjacent to the crib were below the detection limits for all ten chemicals. Traces of trichloroethylene (TCE) at concentrations slightly above detection limits were found in three soir samples north and south of the crib and in one sample east of the crib. The soil gas samples collected in 1989 indicate that no significant amounts of volatile organics are present at the site. Figure 2.7 illustrates the location of the soil gas probes used for the sampling performed in 1990. TCE was observed in samples from the north probe locations and from the two east probe locations closest to the off-gas containment hood. The TCE may be due to surface contamination from other activities in the area.

\subsection{SITE GROUNDWATER CHARACTERIZATION}

Prior to the ISV technology demonstration test, there were eight existing groundwater monitoring wells in the 100-B Area. All but one of these wells monitor the upper portion of the unconfined aquifer. The locations and monitoring intervals of these wells are provided in Appendix $A$. The well nearest the 116-B-6A $\mathrm{Crib}$ is Well 199-B4-4, approximately $350 \mathrm{ft}$ away from the crib. Wells 199-B9-1 and 199-B4-3 are approximately 1200 and $1250 \mathrm{ft}$ away 


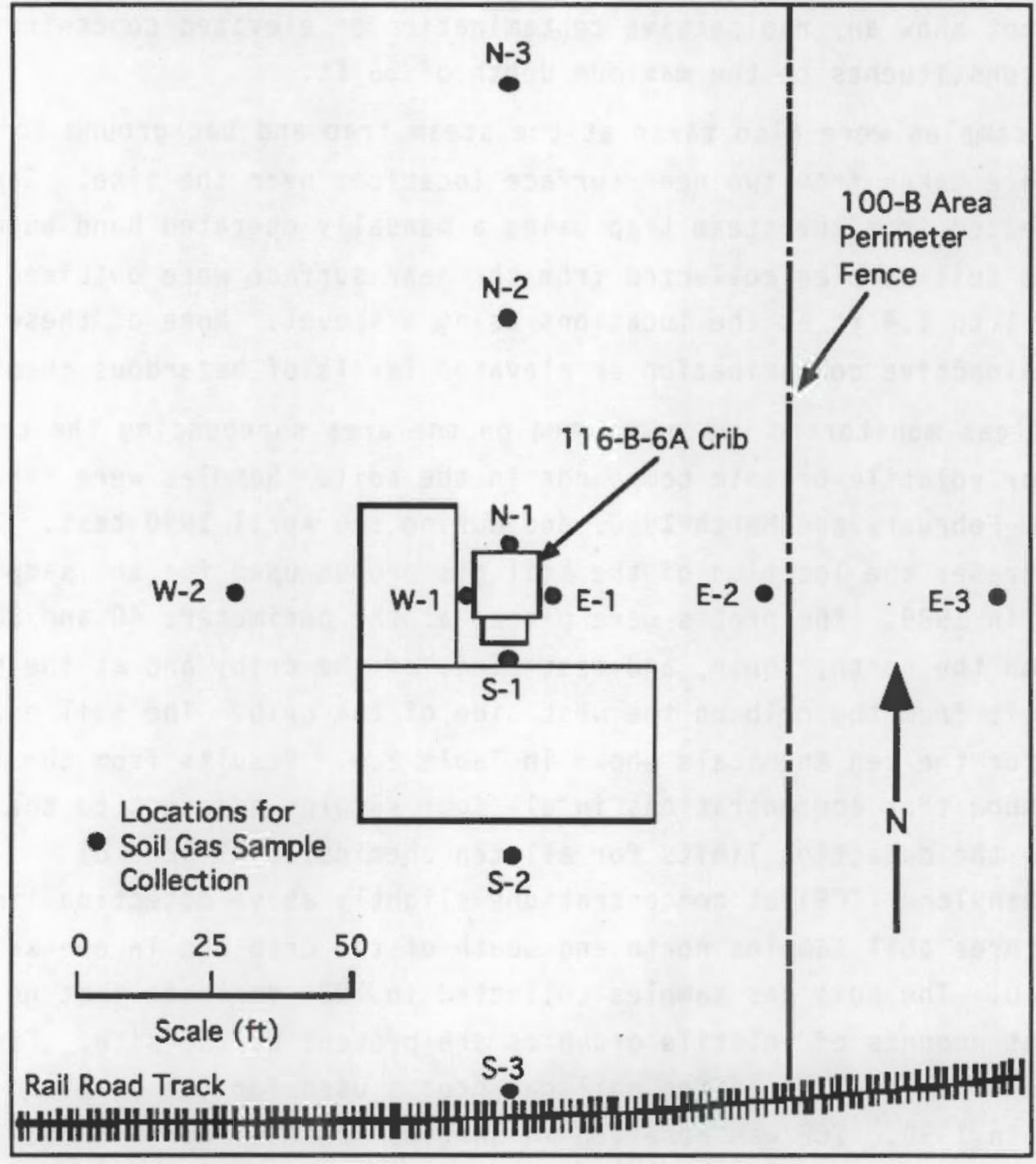

EIGURE 2.6. Location of Probes for 1989 Soil Gas Monitoring 
IABLE2.6. Soil Gas Samples - Compounds Analyzed

Benzene Compound
Toluene
Xylenes
Octane
1.1 .1 . Trichloroethane
1.1 Dichloroethane
Trichloroethylene
Perchloroethylene
Trans Dichloroethylene
Cis Dichloroethylene
1,1 Dichloroethylene
Carbon tetrachloride
Chloroform
Methylene Chloride

\begin{tabular}{c}
$\begin{array}{c}\text { Detection Limit } \\
(\mu \mathrm{g} / \mathrm{m} \mathrm{l})\end{array}$ \\
\hline 0.2 \\
0.2 \\
0.2 \\
0.2 \\
0.01 \\
0.05 \\
0.01 \\
0.0002 \\
0.5 \\
0.3 \\
1.0 \\
0.002 \\
0.05 \\
2.0
\end{tabular}

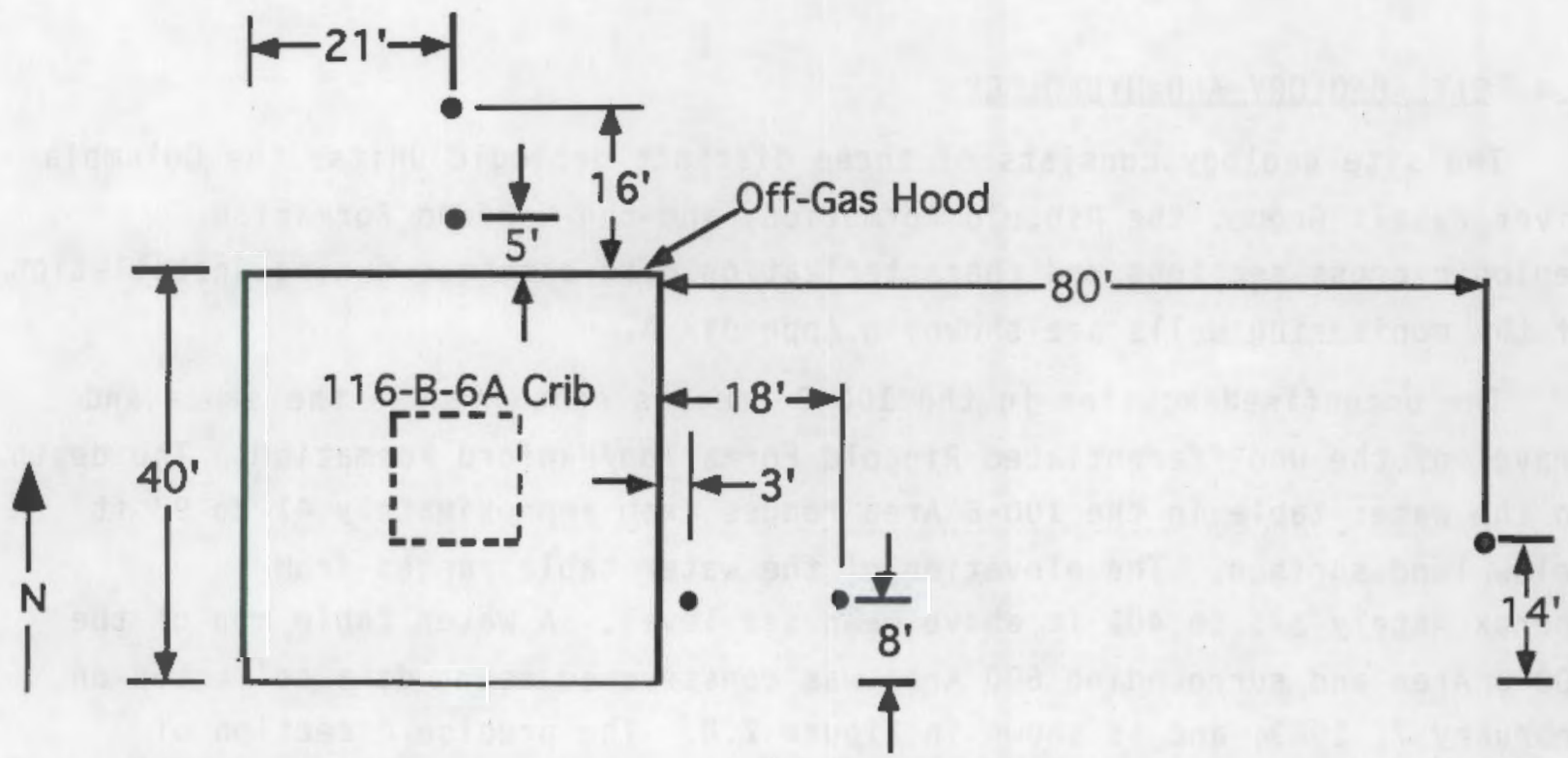

- Indicates location of soil gas monitoring probes

EIGURE 2.7. Location of 1990 Soil Gas Monitoring Probes Relative to the OffGas Hood 
from the crib. respectively. Appendix A also gives a summary of the groundwater quality data from these monitoring wells from 1984 to 1988.

In addition to the existing groundwater monitoring wells, three groundwater monitoring wells were installed in the immediate vicinity of the test site. These wells, labeled MW-1, MW-2, and MW-3 and shown in Figure 2.3. were used to monitor the effects (if any) of the ISV process on the chemical composition of the groundwater immediately adjacent to the vitrification site. The wells were installed prior to the ISV demonstration and were developed according to Washington State Department of Ecology guidelines for groundwater monitoring wells. Samples taken prior to the ISV demonstration, along with historical groundwater quality data collected over the past five years from existing wells in the 100-B Area, were used to establish baseline water quality levels. Analyses of groundwater samples conducted following vitrification were compared to these baseline levels to determine the impact of vitrification processing on the groundwater. This comparison is discussed in Section 5.0 .

\subsection{SITE GEOLOGY AND HYDROLOGY}

The site geology consists of three distinct geologic units: the Columbia River Basalt Group, the Ringold Formation, and the Hanford Formation. Geologic cross sections and characterization data obtained during installation of the monitoring wells are shown in Appendix $A$.

The unconfined aquifer in the 100-B Area is contained in the sands and gravel of the undifferentiated Ringold Formation/Hanford Formation. The depth to the water table in the 100-B Area ranges from approximately 41 to $93 \mathrm{ft}$ below land surface. The elevation of the water table ranges from approximately 395 to $401 \mathrm{ft}$ above mean sea level. A water table map of the 100-B Area and surrounding 600 Area was constructed using data collected on February 7. 1989, and is shown in Figure 2.8. The precise direction of groundwater flow beneath the 116-B-6A Crib is unknown. Figure 2.8 suggests that it is predominantly northward. 


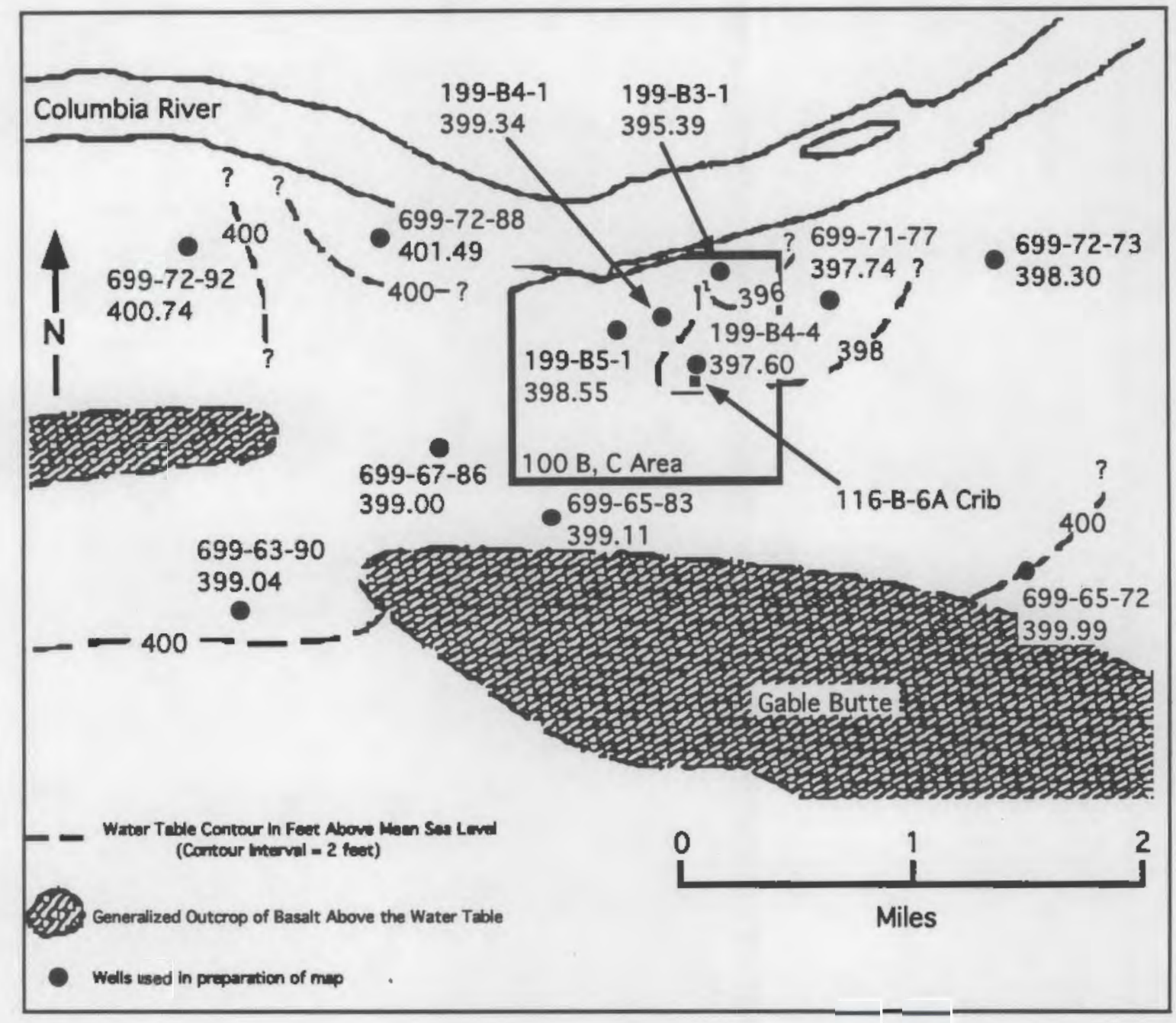

EIGURE 2.8. Water Table Map of the 100-B Area Measured on February 7, 1989 



\subsection{OBJECTIVES}

A treatability test demonstration of the large-scale ISV process was performed at the 116-B-6A Crib site in April 1990 using the existing DOE large-scale ISV equipment. This test was a technology demonstration, not a remedial action. The objectives of the test were as follows:

1. Demonstrate at least $99 \%$ immobilization efficiency of hazardous metals and radionuclides in the vitrified. contaminated soil. This efficiency was to be determined on the basis of the total waste inventory in the site that is vitrified. Specifically, the efficiency of the process was to be determined by comparing the amount of contaminant in the final vitrified block with the total inventory processed (the sum of levels in the ISV block and in the off-gas treatment system).

2. Demonstrate the ability of the ISV off-gas treatment system to process a soil containing significant quantities of combustible materials. Performance against this objective was to be determined by the ability of the system to perform within equipment design specifications during vitrification of the wooden crib support structure. The site contained an estimated 190 to $250 \mathrm{ft}^{3}$ (6000 to $90001 \mathrm{~b})$ of wood.

3. Demonstrate the ability of ISV to vitrify the site to depths that are practical within the context of actual waste site remediation work. Performance was to be determined on the basis of post-test drilling and analysis to determine both the vertical and lateral extent of the vitrified zone. The primary measure of success was to vitrify the site to a depth at which radionuclide contamination dropped to a level below background soil concentrations, i.e., about 20-ft deep.

4. Produce a high-quality glass product comparable in leach resistance to previous ISV glass products and high-level waste glass. The ISV test was to be considered successful if the normalized element release rates for strontium, cesium, lead, and chromium from the glass product were in the range of rates for other ISV glasses. 


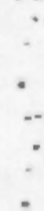




\subsection{RESULTS}

Table 4.1 provides a chronological summary of events associated with this test. Processing of the 116-B-6A Crib began 11 April 1990 at 2:30 p.m. and ended 23 April 1990 at 2:25 p.m., a total run time of about 288 hours. As shown in Table 4.1, there were a significant number of time periods for the test during which power was not supplied to the electrodes. The impact of these down times will be discussed in greater detail in the following sections. However, it should be noted that many of the causes for these down times have been remedied, either through changes in the operating procedures or improvements in the system itself.

The large-scale run reached a depth of $14 \mathrm{ft}$ from grade, producing an ISV block between 35 and $40 \mathrm{ft}$ in diameter, approximately $12 \mathrm{ft}$ high, and weighing between 800 and 900 tons. After cooling for a year, two sets of core samples from the block were collected and used for compositional analyses and product quality testing. The following sections summarize the test results in terms of the objectives described in section 3.0 .

TABLE 4.1. Summary of 116-B-6A ISV Treatability Test Events

\begin{tabular}{|c|c|c|c|}
\hline Date & Iime & $\begin{array}{l}\text { Run Time, } \\
\text { hours }\end{array}$ & Event \\
\hline \multirow[t]{4}{*}{$4 / 11 / 90$} & 1432 & 0.00 & $\begin{array}{l}\text { Start of } 116-B-6 \mathrm{~A} \text { Crib ISV treatability test. } \\
\text { Power to the electrodes initially at } 40 \mathrm{~kW} \text { per }\end{array}$ \\
\hline & 2017 & 5.75 & $\begin{array}{l}\text { First observation of molten soil around } \\
\text { electrodes. }\end{array}$ \\
\hline & 2220 & 7.80 & $\begin{array}{l}\text { Process control system shut down scrub system } 1 \\
\text { and started scrub system } 2 \text {. High DP recorded in } \\
\text { filter housing. Power shut down for } 20 \text { minutes } \\
\text { before restart. }\end{array}$ \\
\hline & 2320 & 8.80 & $\begin{array}{l}\text { The stack CO level exceeded } 500 \mathrm{ppm} \text { for } \\
\text { approximately } 1 \text { hour. Concentration then } \\
\text { decreased to } 425 \mathrm{ppm} \text {. }\end{array}$ \\
\hline $4 / 12 / 90$ & 0200 & 11.47 & $\begin{array}{l}\text { Co level up to } 3000 \mathrm{ppm} \text {. Total power decreased } \\
\text { from } 440 \mathrm{~kW} \text { to } 300 \mathrm{~kW} \text { to slow event causing high } \\
\text { levels. }\end{array}$ \\
\hline & 0945 & 19.22 & $\begin{array}{l}\text { HEHF personnel provided CO sampling. No } C O \\
\text { found in off-gas trailer. control trailer. } \\
\text { office trailer, or outside electrical trailer. }\end{array}$ \\
\hline $4 / 13 / 90$ & $\begin{array}{l}1826 \\
0020\end{array}$ & $\begin{array}{l}27.90 \\
33.83\end{array}$ & $\begin{array}{l}\text { Total power increased to } 2.6 \mathrm{MW} \text {. } \\
\text { co levels up to } 5000 \mathrm{ppm} \text {, power shut down. }\end{array}$ \\
\hline
\end{tabular}


TABLE 4.1. (contd)

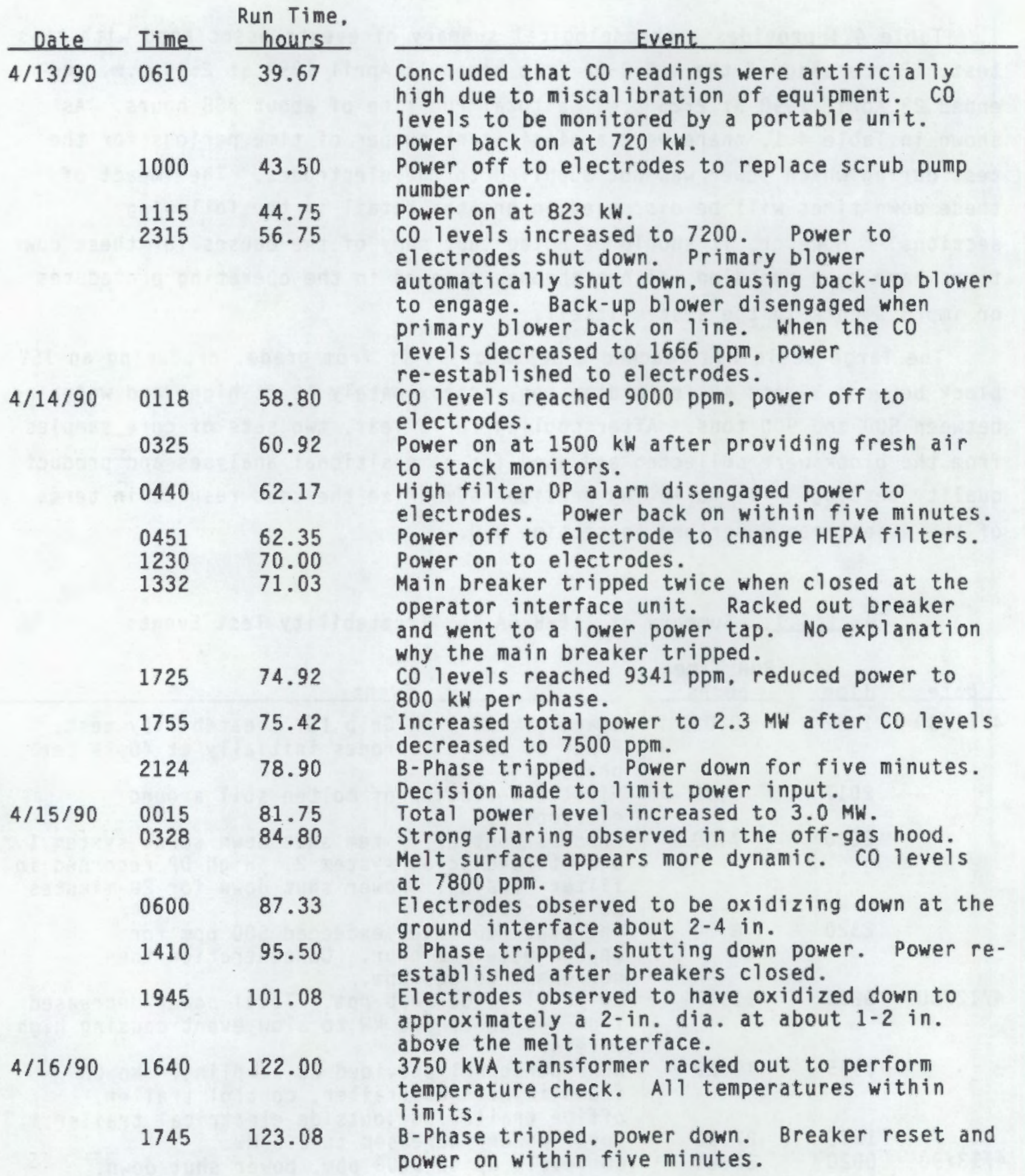


TABLE 4.1. (contd)

\begin{tabular}{ccc} 
Date & Iime & $\begin{array}{r}\text { Run Tim } \\
\text { hours }\end{array}$ \\
\cline { 1 - 1 } $4 / 17 / 90$ & 0335 & 130.92 \\
& 0340 & 131.00 \\
& 0800 & 135.33 \\
& & \\
& 1045 & 138.08 \\
& 1745 & 145.08 \\
& 2145 & 149.08 \\
$4 / 18 / 90$ & 0400 & 155.33
\end{tabular}

Event

Batch logic de-energized electrodes and started parallel scrubbing system. Hood vacuum increased to 1.3-in. water column. Power restored within five minutes.

Process control system de-energized electrodes due to wet HEPA alarm. Power back on at 0440 . All electrodes observed to be showing bare molybdenum. Graphite collar has been oxidized away.

Power shut down to replace NW electrode. HEPA filters were also changed.

Power back on at 2.7 MW. total.

Power shut down to electrodes due to high $O P$ across the HEPAs. Power back on at 2200.

Process control unit 2, multi-functional controller 3 temporarily failed, causing false data reading in almost every area. All alarms acknowledged and in about 30 seconds, a 11 data values appeared normal. Power turned back on to electrodes.

$\begin{array}{lll} & 0900 & 160.33 \\ & 1100 & 162.33 \\ & 1523 & 166.72 \\ 4 / 19 / 90 & 1050 & 189.17 \\ & 1650 & 195.17 \\ & 1700 & 195.34 \\ 4 / 20 / 90 & 1329 & 215.82 \\ & & \\ 4 / 21 / 90 & 1930 & 221.84 \\ 4 / 22 / 90 & 1054 & 261.23 \\ & 1300 & 263.33 \\ 4 / 23 / 90 & 1010 & 284.50 \\ & 1142 & 286.03 \\ & 1425 & 288.75\end{array}$

Power reduced to $2.0 \mathrm{MW}$ due to high C Phase amperage. Tap changes made and power increased. Powered down temporarily to lower NW electrode. Power increased at 1230 .

Cold cap observed over the entire melt.

Power off to electrodes. Started replacement activities for SW electrode.

Power back on at $3.1 \mathrm{MW}$, total.

Lowered NW electrode approximately 17 in.. electrode now at $11 \mathrm{ft}$ depth.

Power off to electrodes to place metal shoring plates on the north and east sides of the offgas hood to prevent subsidence.

Power on to electrodes.

Power off to electrodes to change out gas

bubbler and lower NW and SW electrodes.

Power on to electrodes.

Power off to lower electrodes.

Power on to electrodes.

Power off to electrodes. End of test.

\subsection{OBJECTIVE 1 - IMMOBILIZATION EFFICIENCY}

An advantage of ISV over other in situ technologies is its ability to treat inorganic materials such as hazardous metals and radionuclides. The ISV process encapsulates the majority of hazardous metals and radionuclides within 
the glass matrix and minimizes the extent to which these materials enter the off-gas treatment system. To this end, an objective of this test was to demonstrate at least $99 \%$ immobilization efficiency of hazardous metals and radionuclides in the vitrified contaminated soil--specifically, of the total amount of metals and radionuclides treated by the ISV process, at 1east $99 \%$ of the material would be retained in the ISV block.

Samples from the ISV melt were collected for use in compositional and durability analyses of the vitrified material. The Environmental Field Services Group of Westinghouse Hanford Company obtained samples from the vitrified mass during April 1991. Figure 4.1 illustrates the two drilling locations for the cores drilled into the ISV block. Samples of the vitrified mass were taken from selected points along the cores. Diamond bits were used during drilling operations, and drilling progressed at an average penetration rate of $0.5 \mathrm{in./min}$ for both cores. A split barrel assembly was used to allow easy recovery of the ISV block samples.

Figure 4.2 illustrates the approximate locations from which various ISV block samples were collected for use in compositional and/or durability testing. The run numbers depicted in the figure correspond to individual penetrations of the drill into the vitrified block. Core number 1 required more runs in the early stages of the drilling operation because of unusually slow cutting. Observations of the actual samples did not indicate any apparent difference between samples collected during the early runs and those of later runs. Core 非 was 19.1-ft long and core 非 was 19.13-ft long.

\subsubsection{Compesitional Analysis of the Glass Product}

Tables 4.2 .4 .3 , and 4.4 contain results from the compositional analysis

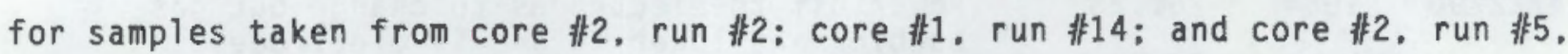
respectively. The samples were analyzed by $\mathrm{PNL}^{\prime}$ 's Analytical Chemistry Laboratory. Inductively coupled plasma (ICP) spectroscopy was used to identify the metals present within the samples. Prior to measurement by ICP, the samples were first prepared using either a $\mathrm{KOH}$ fusion or acid digestion technique. The $\mathrm{KOH}$ fusion technique provides a better identification of the major constituents, while the acid digestion technique leads to better resolution of minor impurities. As shown by the data from Tables 4.2. 4.3, and 4.4. silicon is the most prevalent element present in the ISV block. 


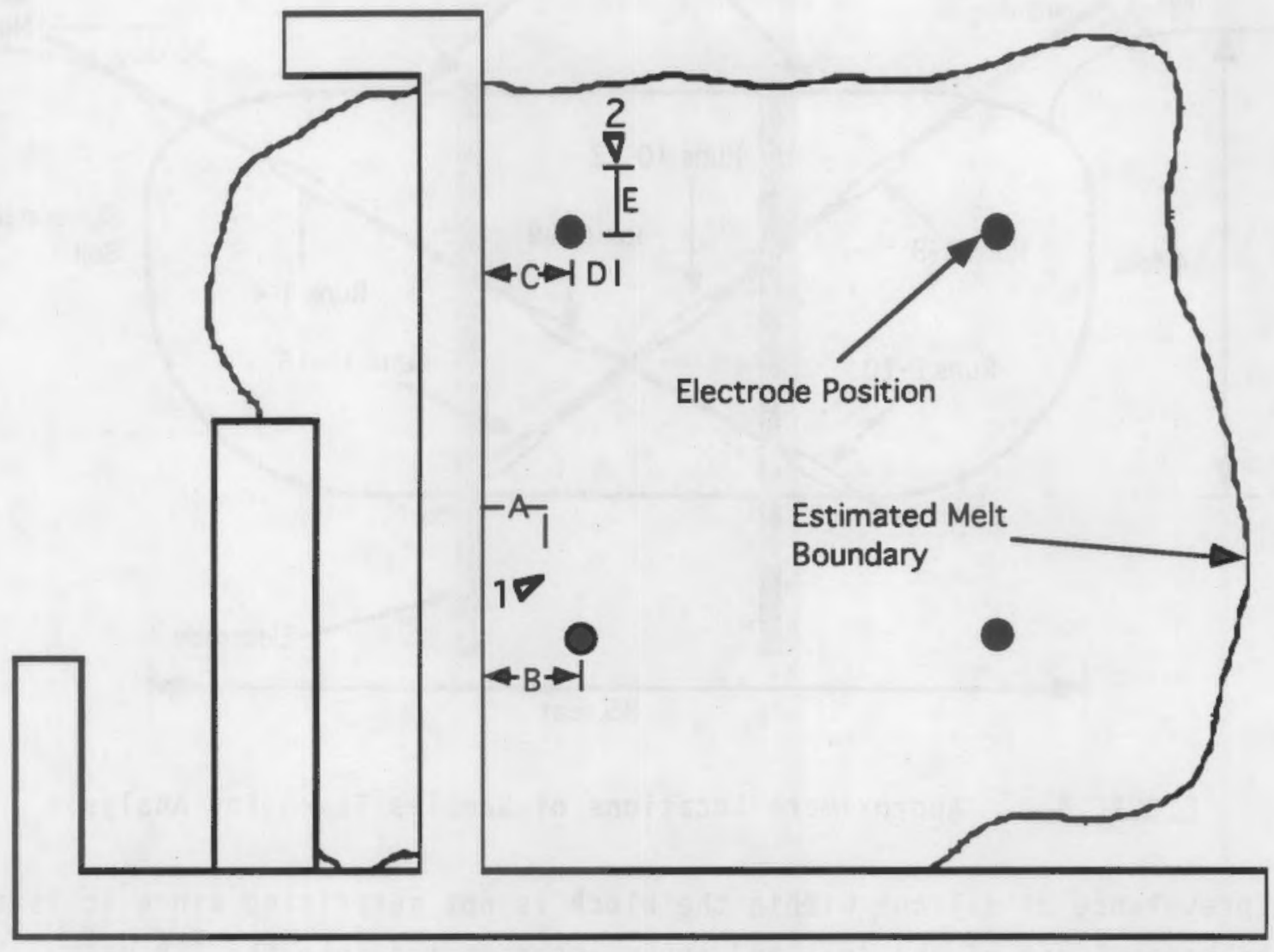

NOT TO SCALE

\section{LEGEND}

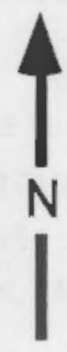

- Electrodes

$\triangle$ Sample Boring Location (arrow designates direction)

1 Sample boring is $\mathbf{4 0 . 5}$ degrees from horizontal with a vitrified mass penetration depth of 19.10 feet
2 Sample boring is 30.5 degrees from horizontal with a vitrified mass penetration depth of 19.13 feet

$$
\begin{aligned}
& A-3.2 \mathrm{ft} ; B-5.5 \mathrm{ft} \\
& C-2.4 \mathrm{ft} ; D-5.0 \mathrm{ft} \\
& E-3.0 \mathrm{ft}
\end{aligned}
$$

FIGURE 4.1. Initial Boring Points for Samples from the 116-B-6A Crib ISV Block. ISV block contour shown is observed boundary at the surface. Detail of the melt boundary below grade is not available. 


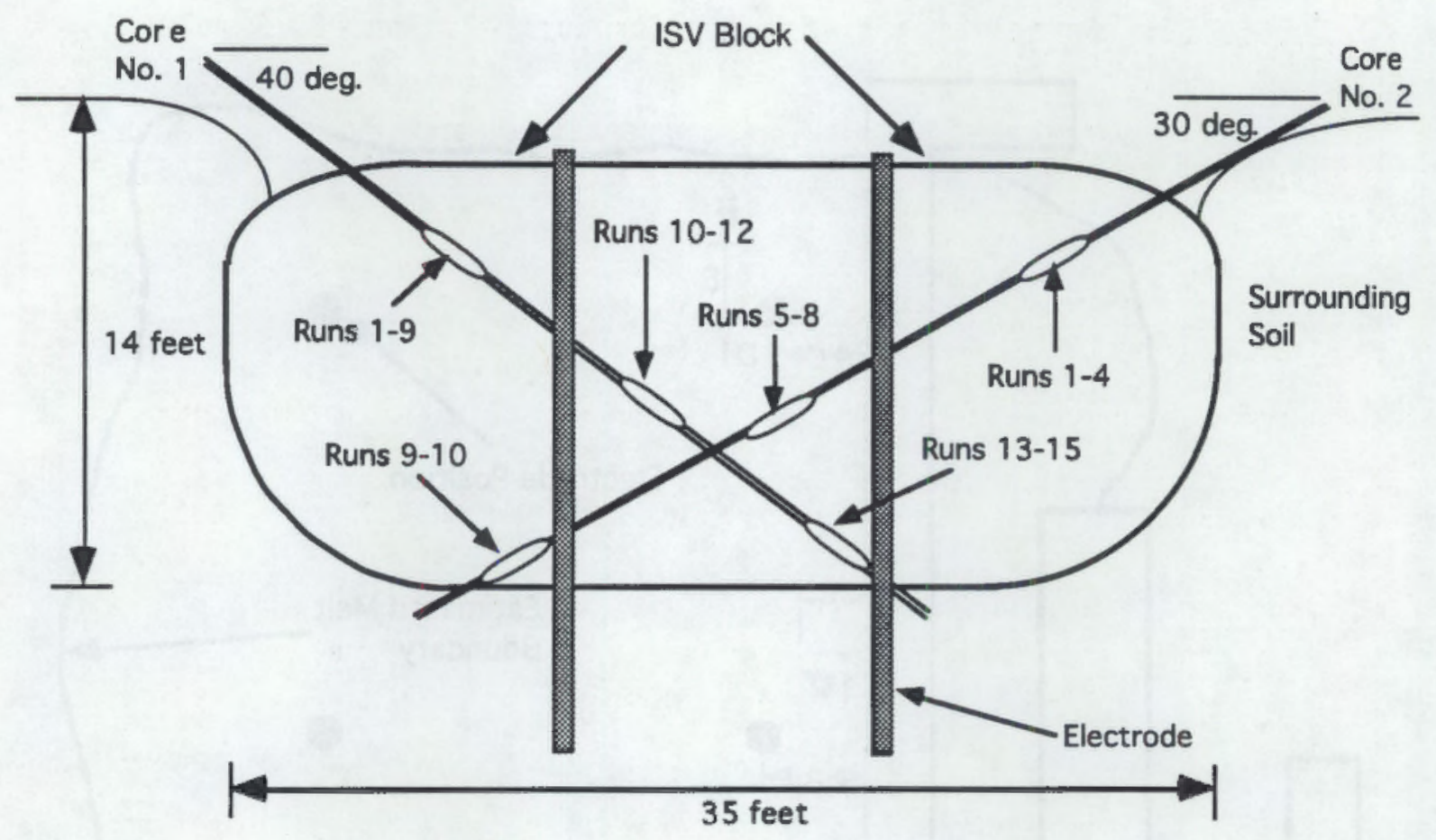

FIGURE 4.2. Approximate Locations of Samples Taken for Analysis

The prevalence of silicon within the block is not surprising since it is the major constituent of the soil and rocks incorporated into the ISV melt. In addition, elemental weight percentages for the three samples were very similar. indicating a relatively homogeneous distribution of material within the block.

Two elements of particular interest were lead and chromium. Both are included on the EPA's target analyte 1 ist and were found within the confines of the 116-B-6A Crib during pre-test site characterization activities. PNL's Analytical Chemistry Laboratory analyzed the samples for lead and chromium using atomic adsorption (AA) spectroscopy for the metal analysis after preparing the samples by an acid digestion technique (interference by other metals during an ICP analysis makes AA the method of choice when analyzing for chromium and lead). Results from the $A A$ analysis indicate metal weight percents of $0.0018 \%$ and $0.0040 \%$ for lead and chromium, respectively. In addition, the amounts of lead and chromium in the three samples analyzed were consistent with each other, indicating a homogeneous distribution of these elements in the ISV block. 
IABLE 4.2. Compositional Analys is for Core $\# 2$, Run 非, Sample \#1

\begin{tabular}{|c|c|c|c|c|c|c|}
\hline & $\begin{array}{c}\mathrm{KOH} \\
\text { Fusion } \\
\end{array}$ & $\begin{array}{l}\text { Normalized } \\
\text { Weight \% }\end{array}$ & $\begin{array}{l}\mathrm{HF}: \mathrm{HNO}_{3} \\
\text { Digestion }\end{array}$ & $\begin{array}{l}\text { Norma } 1 \text { ized } \\
\text { Weight \% }\end{array}$ & $\begin{array}{l}\text { Combined } \\
\text { Results } \\
\end{array}$ & $\begin{array}{l}\text { Normalized } \\
\text { Weight } \%\end{array}$ \\
\hline $\mathrm{Al}_{2} \mathrm{O}_{3}$ & 15 & 14.91 & 15 & 14.12 & 15 & 14.507 \\
\hline $\mathrm{B}_{2} \mathrm{O}_{3}$ & 0.01 & 0.010 & $\cdots$ & $\cdots$ & 0.01 & 0.010 \\
\hline $\mathrm{BaO}$ & 0.061 & 0.061 & 0.072 & 0.068 & 0.067 & 0.064 \\
\hline $\mathrm{CaO}$ & 5.9 & 5.865 & 6.2 & 5.838 & 6.05 & 5.851 \\
\hline $\mathrm{CeO}_{2}$ & 0.008 & 0.008 & - & -- & 0.008 & 0.008 \\
\hline $\mathrm{CO}_{2} \mathrm{O}_{3}$ & 0.008 & 0.008 & 0.006 & 0.006 & 0.007 & 0.007 \\
\hline $\mathrm{Cr}_{2} \mathrm{O}_{3}$ & 0.004 & 0.004 & $\cdots$ & $\cdots$ & 0.004 & 0.004 \\
\hline CuO & 0.002 & 0.002 & $\cdots$ & $-\cdot$ & 0.002 & 0.002 \\
\hline $\mathrm{Fe}_{2} \mathrm{O}_{3}$ & 9.3 & 9.245 & 9.3 & 8.757 & 9.3 & 8.994 \\
\hline $\mathrm{Li}_{2} \mathrm{O}$ & 0.017 & 0.017 & $\because$ & - & 0.017 & 0.016 \\
\hline MgO & 2.9 & 2.883 & 3.1 & 2.919 & 3.0 & 2.901 \\
\hline $\mathrm{MnO}_{2}$ & 0.16 & 0.159 & 0.18 & 0.169 & 0.17 & 0.164 \\
\hline $\mathrm{Na}_{2} \mathrm{O}$ & 4.4 & 4.374 & 3.4 & 3.202 & 3.9 & 3.772 \\
\hline $\mathrm{P}_{2} \mathrm{O}_{5}$ & 0.3 & 0.298 & 0.3 & 0.282 & 0.3 & 0.290 \\
\hline $\mathrm{PbO}$ & 0.02 & 0.020 & - & $\cdots$ & 0.02 & 0.019 \\
\hline $\mathrm{SiO}_{2}$ & 61 & 60.63 & 67 & 63.089 & 64 & 61.89 \\
\hline sro & 0.047 & 0.047 & 0.055 & 0.052 & 0.051 & 0.049 \\
\hline $\mathrm{TiO}_{2}$ & 1.4 & 1.392 & 1.5 & 1.412 & 1.45 & 1.402 \\
\hline $\mathrm{V}_{2} \mathrm{O}_{3}$ & 0.03 & 0.030 & 0.03 & 0.028 & 0.03 & 0.029 \\
\hline $\mathrm{Y}_{2} \mathrm{O}_{3}$ & 0.003 & 0.003 & $\cdots$ & $-\cdot$ & 0.003 & 0.003 \\
\hline Zno & 0.01 & 0.010 & $\cdots$ & $\cdots$ & 0.01 & 0.010 \\
\hline $\mathrm{ZrO}_{2}$ & 0.03 & 0.030 & 0.02 & 0.019 & 0.025 & 0.024 \\
\hline SUM & 100.6 & 100.0 & 106.2 & 100.0 & 103.4 & 100.0 \\
\hline
\end{tabular}

- Indicates below detection limits. 
IABLE 4.3. Compositional Analysis for Core 非, Run \#14, Sample \#3

\begin{tabular}{|c|c|c|c|c|c|c|}
\hline & $\begin{array}{c}\mathrm{KOH} \\
\text { Fusion } \\
\end{array}$ & $\begin{array}{l}\text { Normal ized } \\
\text { Weight } \%\end{array}$ & $\begin{array}{l}\mathrm{HF}: \mathrm{HNO}_{3} \\
\text { Digestion }\end{array}$ & $\begin{array}{l}\text { Normal ized } \\
\text { Weight } \%\end{array}$ & $\begin{array}{l}\text { Combined } \\
\text { Results } \\
\end{array}$ & $\begin{array}{l}\text { Normalized } \\
\text { Weight \% }\end{array}$ \\
\hline $\mathrm{Al}_{2} \mathrm{O}_{3}$ & 15 & 15 & 15 & 13.575 & 15 & 14.27 \\
\hline $\mathrm{B}_{2} \mathrm{O}_{3}$ & 0.023 & 0.023 & -- & - & 0.023 & 0.022 \\
\hline $\mathrm{BaO}$ & 0.058 & 0.058 & 0.075 & 0.068 & 0.067 & 0.063 \\
\hline $\mathrm{CaO}$ & 7.4 & 7.4 & 8.8 & 7.964 & 8.1 & 7.700 \\
\hline $\mathrm{CeO}_{2}$ & 0.01 & 0.01 & $\therefore$ & $\cdots$ & 0.01 & 0.010 \\
\hline $\mathrm{CO}_{2} \mathrm{O}_{3}$ & 0.008 & 0.008 & 0.01 & 0.009 & 0.009 & 0.009 \\
\hline $\mathrm{Cr}_{2} \mathrm{O}_{3}$ & -- & -- & $\cdots$ & $-\cdot$ & $\cdots$ & -- \\
\hline CuO & 0.004 & 0.004 & $\cdots$ & $\cdots$ & 0.004 & 0.004 \\
\hline $\mathrm{Fe}_{2} \mathrm{O}_{3}$ & 13 & 13 & 14 & 12.670 & 13.5 & 12.84 \\
\hline $\mathrm{K}_{2} \mathrm{O}$ & & & 1 & 0.905 & 0.905 & 0.905 \\
\hline $\mathrm{Li}_{2} \mathrm{O}$ & 0.015 & 0.015 & 0.001 & 0.001 & 0.008 & 0.008 \\
\hline $\mathrm{MgO}$ & 3.5 & 3.5 & 4.2 & 3.801 & 3.85 & 3.660 \\
\hline $\mathrm{MnO}_{2}$ & 0.2 & 0.2 & 0.26 & 0.235 & 0.23 & 0.219 \\
\hline $\mathrm{MoO}_{3}$ & 0.003 & 0.003 & $\cdots$ & $\cdots$ & 0.003 & 0.003 \\
\hline $\mathrm{Na}_{2} \mathrm{O}$ & 3.7 & 3.7 & 3 & 2.715 & 3.35 & 3.184 \\
\hline $\mathrm{P}_{2} \mathrm{O}_{5}$ & 0.41 & 0.41 & 0.5 & 0.452 & 0.455 & 0.433 \\
\hline $\mathrm{PbO}$ & 0.02 & 0.02 & 0.02 & 0.018 & 0.02 & 0.019 \\
\hline $\mathrm{SiO}_{2}$ & 54.3 & 54.3 & 61 & 55.204 & 57.65 & 54.83 \\
\hline sro & 0.034 & 0.034 & 0.044 & 0.040 & 0.037 & 0.035 \\
\hline $\mathrm{TiO}_{2}$ & 2.2 & 2.2 & 2.5 & 2.262 & 2.231 & 2.122 \\
\hline $\mathrm{V}_{2} \mathrm{O}_{3}$ & 0.04 & 0.04 & 0.05 & 0.045 & 0.043 & 0.041 \\
\hline $\mathrm{Y}_{2} \mathrm{O}_{3}$ & 0.004 & 0.004 & $\cdots$ & - & 0.004 & 0.004 \\
\hline Zno & 0.02 & 0.02 & $\cdots$ & - & 0.02 & 0.019 \\
\hline $\mathrm{ZrO}_{2}$ & 0.03 & 0.03 & 0.03 & 0.027 & 0.029 & 0.028 \\
\hline SUM & 100.0 & 100.0 & 110.5 & 100.0 & 105.2 & 100.0 \\
\hline
\end{tabular}

\footnotetext{
- Indicates below detection limit.
} 
IABLE 4.4. Compositional Analys is for Core \#2, Run \#5, Sample \#1A

\begin{tabular}{|c|c|c|c|c|c|c|}
\hline & $\begin{array}{c}\mathrm{KOH} \\
\text { Fusion }\end{array}$ & $\begin{array}{l}\text { Normalized } \\
\text { Weight } \%\end{array}$ & $\begin{array}{l}\mathrm{HF}: \mathrm{HNO}_{3} \\
\text { Digestion }\end{array}$ & $\begin{array}{l}\text { Normalized } \\
\text { Weight } \%\end{array}$ & $\begin{array}{l}\text { Combined } \\
\text { Results }\end{array}$ & $\begin{array}{l}\text { Normalized } \\
\text { Weight } \%\end{array}$ \\
\hline $\mathrm{Al}_{2} \mathrm{O}_{3}$ & 15 & 15 & 14 & 13.646 & 14.500 & 14.285 \\
\hline $\mathrm{B}_{2} \mathrm{O}_{3}$ & 0.029 & 0.029 & 0 & 0.000 & 0.029 & 0.029 \\
\hline $\mathrm{BaO}$ & 0.062 & 0.062 & 0.072 & 0.070 & 0.067 & 0.066 \\
\hline $\mathrm{CaO}$ & 7.5 & 7.5 & 8.2 & 7.993 & 7.850 & 7.734 \\
\hline $\mathrm{CeO}_{2}$ & 0.01 & 0.01 & - & - & 0.010 & 0.010 \\
\hline $\mathrm{CO}_{2} \mathrm{O}_{3}$ & 0.008 & 0.008 & 0.01 & 0.010 & 0.009 & 0.009 \\
\hline $\mathrm{Cr}_{2} \mathrm{O}_{3}$ & -- & -- & -- & $-\cdot$ & $-\cdot$ & $-\cdot$ \\
\hline CuO & 0.004 & 0.004 & 0.005 & 0.005 & 0.005 & 0.004 \\
\hline $\mathrm{Fe}_{2} \mathrm{O}_{3}$ & 14 & 14 & 13 & 12.671 & 13.500 & 13.300 \\
\hline $\mathrm{K}_{2} \mathrm{O}$ & & & 1 & 0.975 & .975 & 0.975 \\
\hline $\mathrm{Li}_{2} \mathrm{O}$ & 0.036 & 0.036 & -- & - & 0.036 & 0.037 \\
\hline $\mathrm{MgO}$ & 3.6 & 3.6 & 3.9 & 3.801 & 3.750 & 3.695 \\
\hline $\mathrm{MnO}_{2}$ & 0.21 & 0.21 & 0.24 & 0.234 & 0.225 & 0.222 \\
\hline $\mathrm{MoO}_{3}$ & 0.003 & 0.003 & $-\cdot$ & $-\cdot$ & 0.003 & 0.003 \\
\hline $\mathrm{Na}_{2} \mathrm{O}$ & 4 & 4 & 2.8 & 2.729 & 3.400 & 3.350 \\
\hline $\mathrm{P}_{2} \mathrm{O}_{5}$ & 0.42 & 0.42 & 0.5 & 0.487 & 0.460 & 0.453 \\
\hline Pbo & 0.02 & 0.02 & 0.03 & 0.029 & 0.020 & 0.020 \\
\hline $\mathrm{Sb}_{2} \mathrm{O}_{3}$ & $-\cdot$ & -- & 0.01 & 0.010 & 0.010 & 0.010 \\
\hline $\mathrm{SiO}_{2}$ & 52.8 & 52.8 & 56.3 & 54.876 & 54.150 & 53.349 \\
\hline Sro & 0.036 & 0.036 & 0.041 & 0.040 & 0.039 & 0.038 \\
\hline $\mathrm{TiO}_{2}$ & 2.2 & 2.2 & 2.4 & 2.339 & 2.300 & 2.266 \\
\hline $\mathrm{V}_{2} \mathrm{O}_{3}$ & 0.045 & 0.045 & 0.05 & 0.049 & 0.048 & 0.047 \\
\hline $\mathrm{Y}_{2} \mathrm{O}_{3}$ & 0.004 & 0.004 & -- & $-\cdot$ & 0.004 & 0.004 \\
\hline $2 n 0$ & 0.02 & 0.02 & - & $\cdots$ & 0.020 & 0.020 \\
\hline $\mathrm{ZrO}_{2}$ & 0.039 & 0.039 & 0.03 & 0.029 & 0.035 & 0.034 \\
\hline SUM & 100.0 & 100.0 & 102.6 & 100.0 & 101.5 & 100.0 \\
\hline
\end{tabular}

- Indicates below detection 1 imit. 
Table 4.5 provides an estimate of the total nonradioactive element content of the 116-B-6A ISV block. This estimate is based on the average weight percent for each element within the three glass samples and an estimated mass for the monolith of $750,000 \mathrm{~kg}$, or about 850 tons. The estimated mass for each element listed in Table 4.5 is based on the element being in the oxide form. Because of the nature of the ISV block, the oxide form is the most probable state for the elements contained within the block.

Radionuclide concentrations were not used in the listings in Tables 4.2 through 4.4 for normalization of the weight percent for each element within the ISV block. Radiochemical analysis of samples from the ISV block was performed by $\mathrm{PNL}$ 's Analytical Chemistry Laboratory. Concentrations were determined as follows: total uranium by laser fluorimetry, total plutonium by

IABLE 4.5. Estimated Content of Nonradioactive Inorganic Elements in the 116-B-6A ISV B1ock

Inorganic Element
Aluminum
Boron
Barium
Calcium
Cesium
Cobalt
Chromium
Copper
Iron
Lead
Lithium
Magnesium
Manganese
Molybdenum
Phosphorous
Potassium
Silicon
Sodium
Strontium
Titanium
Vanadium
Yttrium
Zinc
Zirconium

TOTAL
Estimated Amount of Oxide Form $(\mathrm{kg})$

107.655 128 483 53.213 70 63

87,835

152

25,640

1.513

15

2.940

3.670

425,173

25.765

305

14,475

293

28

123

215

749.823 
1 iquid extraction followed by alpha analysis. strontium-90 by liquid extraction and beta analysis, and cesium-137 and cobalt-60 by gamma analysis. Results from the radiochemical analysis are presented in Table 4.6. Except for uranium, the concentrations of radionuclides detected were below, or very close to, instrumentation detection limits. In addition, the radionuclides present were distributed uniformly in the ISV biock.

Based on a mass of $750,000 \mathrm{~kg}$ for the ISV block, the estimated radioactive content within the ISV block would be as follows: $0.54 \mathrm{mCi}$ of $U$. $80.63 \mathrm{mCi}$ of $\mathrm{Cs}-137$, and $2,157.50 \mathrm{mCi}$ of $\mathrm{K}-40$. Estimated values were not determined for $\mathrm{Pu}, \mathrm{Sr}-90$, and $\mathrm{Co}-60$ since the measured values were below detection limits.

\subsubsection{Compositional Analysis of the Scrub Solution}

Because the ISV process operates at a high temperature (typical melt temperatures are about $1700^{\circ} \mathrm{C}$ ), a portion of the volatile and semi-volatile inorganic elements is released to off-gas stream. In addition, inorganic material may attach to particulate that becomes entrained in the off-gas

stream. The off-gas treatment system collects the inorganic material from the off-gas stream by scrubbing the gas stream with a caustic water solution. The water both cools the off-gas stream so that volatilized material is condensed into the liquid phase and traps particulate into the liquid phase. Water containing the inorganic material, referred to as a scrub solution. is collected in two tanks within the off-gas treatment system and then disposed of at the end of the test.

TABLE 4.6. Radionuclide Concentrations Within the 116-B-6A ISV Block

\begin{tabular}{|c|c|c|c|c|c|c|}
\hline $\begin{array}{l}\text { Sample Identification } \\
\text { Core \#2, Run \#2, } \\
\text { Sample \#1 }\end{array}$ & $\begin{array}{l}\text { Uranium } \\
\mu \mathrm{g} / \mathrm{g}\end{array}$ & $\begin{array}{l}\text { Plutonium } \\
\mathrm{DPM} / \mathrm{g}\end{array}$ & $\begin{array}{r}5 r-90 \\
\mathrm{DPM} / \mathrm{g} \\
\end{array}$ & $\begin{array}{l}\begin{array}{l}C s-137 \\
\mu C i / g\end{array} \\
<2.9 E-5\end{array}$ & $\begin{array}{r}K-40 \\
\mu \mathrm{Ci} i / \mathrm{g} \\
\end{array}$ & $\begin{array}{r}\begin{array}{r}C 0-60 \\
\mathrm{HC} i / 9\end{array} \\
<2.8 E-5\end{array}$ \\
\hline $\begin{array}{l}\text { Core 非, Run 非14, } \\
\text { Sample 非 }\end{array}$ & 2.5 & $<2.0 \mathrm{E} 2$ & $<3.2 E 4$ & $9.5 E-5$ & $2.85 E-3$ & $<1.8 E-5$ \\
\hline $\begin{array}{l}\text { Core \#2, Run \#5, } \\
\text { Sample \#1A }\end{array}$ & 2.1 & $<2.5 E 2$ & $<3.1 \mathrm{E} 4$ & $1.2 E-4$ & $3.01 E-3$ & $<3.3 E-5$ \\
\hline Blank & $<0.6$ & $<3.1 E 4$ & $<2.6 \mathrm{E} 2$ & $<2.5 E-5$ & $2.82 E-3$ & $<2.2 E-5$ \\
\hline
\end{tabular}


The scrub solution was analyzed before and after the 116-B-6A Crib test by Controls for Environmental Pollution (CEP. Sante Fe. NM) so the amount of material collected during the test could be determined. Results from CEP's analysis for nonradioactive metals are presented in Table 4.7. In terms of mass, only the amount of sodium increased appreciably between pre- and posttest sampling. The sodium increase is not unexpected since sodium hydroxide is added to the water to make the solution caustic (acid gases from the ISV melt make the scrub solution acidic). The accumulation of the other metals present, except arsenic, likely can be attributed to the ISV melt. The source of arsenic is unclear at this time since soil samples and samples from the ISV block were not found to contain arsenic.

CEP also performed the radiochemical analysis of the final scrub solution samples taken after the completion of the test. Based on a final scrub solution volume of $3754 \mathrm{~L}$, the final radioactive content of the scrub solution was: $\mathrm{Cs}_{5}-137,6.83 \mu \mathrm{Ci}$ : Co-60, $0.04 \mu \mathrm{Ci}$; tritium, $8.87 \mu \mathrm{Ci}$; alpha. $0.19 \mu \mathrm{Ci}$; and beta, $10.36 \mu \mathrm{Ci}$. Relative to historical records for the 116-B$6 \mathrm{~A}$ site, the amount of radioactivity that was volatilized or otherwise transported to the scrub solution was minimal (see Table 2.1 for the historically based estimate of the 116-B-6A (rib contents). In addition, the amount of radioactivity in the scrub solution is negligible compared to estimates of the amount of radioactivity retained in the ISV block.

\subsubsection{Analysis of Off-Gas-Ireatment HEPA Filters}

As a final control to prevent the release of radioactive or hazardous metal-laden particulate to the environment, the off-gas treatment system is equipped with HEPA filters before the point at which the off-gas stream exits the system. Nondestructive assays using high-purity germanium detectors were used to measure the radioactivity contained within the filters. Each HEPA filter was scanned on both sides and the activity recorded was averaged for the two measurements. Cs-137 was the only radionuclide present above background. The total estimated amount of $\mathrm{Cs}-137$ contained within the HEPA filters was $1.67 \mu \mathrm{Ci}$. Of the radionuclides present in the 116-B-6A Crib. cesium is the most volatile. so it is not surprising that only cesium was detected above background levels. 
IABLE 4.7. Pre- and Post-Test Analytical Results for 116-B-6A Scrub Solution

\begin{tabular}{|c|c|c|}
\hline \multirow[b]{2}{*}{$\begin{array}{l}\text { Inorganic } \\
\text { Metal }\end{array}$} & \multicolumn{2}{|c|}{ Pre-test } \\
\hline & Conc. mg/L & $\begin{array}{l}\text { Amount } 1 \\
\text { grams }\end{array}$ \\
\hline Al uminum & 0.1 & 0.22 \\
\hline Arsenic & 2.3 & 4.97 \\
\hline Barium & 0.1 & 0.22 \\
\hline Calcium & 8.4 & 18.14 \\
\hline Cobalt & $<.0$ & 0.00 \\
\hline Chromium & 0.0 & 0.00 \\
\hline Copper & 0.0 & 0.00 \\
\hline Iron & 0.4 & 0.86 \\
\hline Lead & 3.4 & 7.34 \\
\hline Magnesium & 2.9 & 6.26 \\
\hline Manganese & 0.1 & 0.22 \\
\hline Mercury & 0.1 & 0.22 \\
\hline Nickel & 0.1 & 0.22 \\
\hline Potassium & 7.8 & 16.85 \\
\hline Selenium & 0.1 & 0.22 \\
\hline Silver & $<.0$ & 0.00 \\
\hline Sodium & 86.5 & 186.84 \\
\hline Thallium & 0.5 & 1.08 \\
\hline Tin & $<0.1$ & 0.22 \\
\hline Vanadium & $<0.1$ & 0.22 \\
\hline Zinc & 45.1 & 97.42 \\
\hline 1 Based on & 2160 L scrub & \\
\hline 2 Based on & 1849 L scrub & solution. \\
\hline
\end{tabular}

\begin{tabular}{|c|c|c|}
\hline \multicolumn{2}{|c|}{ Post-test } & \multirow{3}{*}{$\begin{array}{l}\text { Accumulated } \\
\text { grams }\end{array}$} \\
\hline & Amount2 & \\
\hline Conc. $\mathrm{mg} / \mathrm{L}$ & grams & \\
\hline 0.1 & 0.18 & $(0.04)$ \\
\hline 15.4 & 28.47 & 23.50 \\
\hline$<0.1$ & 0.18 & $(0.04)$ \\
\hline 7.8 & 14.42 & $(3.72)$ \\
\hline 0.2 & 0.36 & 0.36 \\
\hline 0.2 & 0.36 & 0.36 \\
\hline 1.5 & 2.77 & 2.77 \\
\hline 91.4 & 169.00 & 168.14 \\
\hline 5.2 & 9.61 & 2.27 \\
\hline 1.7 & 3.14 & $(3.12)$ \\
\hline 0.7 & 1.29 & 1.07 \\
\hline 1.3 & 2.40 & 2.18 \\
\hline 1.1 & 2.03 & 1.81 \\
\hline 9.3 & 17.20 & 0.35 \\
\hline 0.1 & 0.18 & $(0.04)$ \\
\hline 0.0 & 0.00 & 0.00 \\
\hline 12600.0 & 23297.40 & 23110.56 \\
\hline 4.8 & 8.88 & 7.80 \\
\hline 2.2 & 4.07 & 3.85 \\
\hline 2.2 & 4.07 & 3.85 \\
\hline 920.0 & 1701.08 & 1603.66 \\
\hline
\end{tabular}

\subsubsection{Overall Immobilization Efficiency}

Using the results from the analysis of the final vitrified product. the off-gas treatment scrub solutions, and the HEPA filters, the immobilization efficiency of the ISV process for contaminants of interest may be determined. The immobilization efficiency is determined by comparing the amount of a contaminant immobilized in the ISV block to the total amount present in the block, scrub solution, and HEPA filters. Table 4.8 illustrates the immobilization efficiency for compounds that showed a significant inventory in the final ISV block. Of note is the immobilization efficiency observed for lead, chromium, and cesium-137 (>99.9\%). These elements were of concern 
IABLE 4.8. Selected Immobilization Efficiencies for the 116-B-6A Crib ISV Demonstration. Percent immobilized equals the amount present in the ISV block divided by the total amount found in the ISV block. scrub solution, and HEPA filters.

\begin{tabular}{|c|c|c|c|c|}
\hline Compound & ISV Block & Scrub Solution & HEPA & $\%$ Immobilized \\
\hline Chromium & $9.58(\mathrm{~kg})$ & $0.00036(\mathrm{~kg})$ & NA & 99.996 \\
\hline Iron & $61434.78(\mathrm{~kg})$ & $0.16814(\mathrm{~kg})$ & NA & 99.999 \\
\hline Lead & $27.85(\mathrm{~kg})$ & $0.00227(\mathrm{~kg})$ & NA & 99.992 \\
\hline Manganese & $956.11(\mathrm{~kg})$ & $0.00107(\mathrm{~kg})$ & NA & 99.999 \\
\hline Zinc & $98.83(\mathrm{~kg})$ & $1.60366(\mathrm{~kg})$ & NA & 98.403 \\
\hline Cesium-137 & $80.60(\mathrm{mCi})$ & $0.00683(\mathrm{mCi})$ & $0.00167(\mathrm{mCi})$ & 99.989 \\
\hline
\end{tabular}

because of the potential toxicity of lead and chromium and the volatile nature of cesium-137.

The relatively low immobilization efficiency $(\approx 98 \%)$ for zinc is unexpected since zinc compounds are of a nonvolatile nature. The calculated amounts of zinc in the ISV block and scrub solution as listed in Table 4.8 suggest that this low efficiency value is due to the unusually high amount of zinc found in the scrub solution. The source for this zinc is not believed to be the ISV melt, and may be the impurities in the caustic solution or the material resolubilized from the scrub tanks present from previous tests after the demonstration was initiated.

The immobilization efficiencies listed in Table 4.8 demonstrate the utility of the ISV process as a remedial action tool that effectively captures inorganic contaminants in a final waste form, the ISV block. The quality of the final waste form will be discussed in the section on product quality (section 4.4). However, although the calculated immobilization efficiencies are very good, the amount of contaminants captured in the ISV block is only a fraction of the total estimated inventory of the 116-B-6A Crib. The crib contents were not completely processed because the vitrification depth was only $14 \mathrm{ft}$ rather than the targeted $20 \mathrm{ft}$. The reasons for this shortfall will be discussed in the section on processing depth (section 4.3). Based on the estimated waste inventory for the 116-B-6A Crib as shown in Table 2.1. it is estimated that $57.5 \%$ of the chromium and $54.1 \%$ of the cesium-137 was treated by the ISV process. 


\subsection{OBJECTIVE 2 - EFFECT OF COMBUSTIBLES ON OFF-GAS TREATMENT SYSTEM}

The off-gas confinement hood for the ISV process is designed to direct gases and particulate evolved from the melt surface into an off-gas treatment system (see Figures 1.3 and 1.4 for details). An objective of this treatability test was to demonstrate the ability of the ISV off-gas treatment system to process soil containing significant quantities of combustible materials. Since the equipment has upper temperature and off-gas flowrate limits, dictated by the design specifications, there is a potential to reach those limits when processing a region with significant amounts of combustibles. The 116-B-6A Crib was an ideal test for the system since the crib is composed of a significant amount of timbers and has a 6-in. solid layer of timbers that acts as a lid (see Figure 2.2).

Pretest calculations estimated that the highest temperature in the offgas hood would occur during processing of the crib lid, which was located approximately $6 \mathrm{ft}$ below grade. Based on a rate of destruction of $8.19 \mathrm{~cm} / \mathrm{hr}$ (determined by engineering-scale studies). it was estimated that processing of the crib lid would require 2 hours and would result in off-gas and hood temperatures of $290^{\circ} \mathrm{C}$ and $285^{\circ} \mathrm{C}$, respectively. These calculated temperatures are well within the $500^{\circ} \mathrm{C}$ design criteria for the off-gas hood and the $750^{\circ} \mathrm{C}$ upper limit for the off-gas temperature.

Figure 4.3 illustrates the average(a) roof temperature for the off-gas hood and shows that predictions were accurate and that there was no significant rise in temperature during the time period that the crib roof was being processed. This confirms the ability of the ISV process to handle contaminated soils with high combustible loadings.

Depth monitoring devices placed into the boreholes before beginning the treatability test indicated that the ISV melt reached $6 \mathrm{ft}$ in depth (the top of the 116-B-6A (rib lid) about 62 hours into the test. Section 4.3 discusses the methods for measuring depth in greater detail. The temperature of the off-gas hood roof did not increase during this time period but did approach $320^{\circ} \mathrm{C}$ later in the test. probably because of the normal steady-state heat transfer of the process.

(a) The roof temperature of the off-gas hood is measured at four different locations. The value illustrated in Figure 4.3 is the average of these four measurements. 


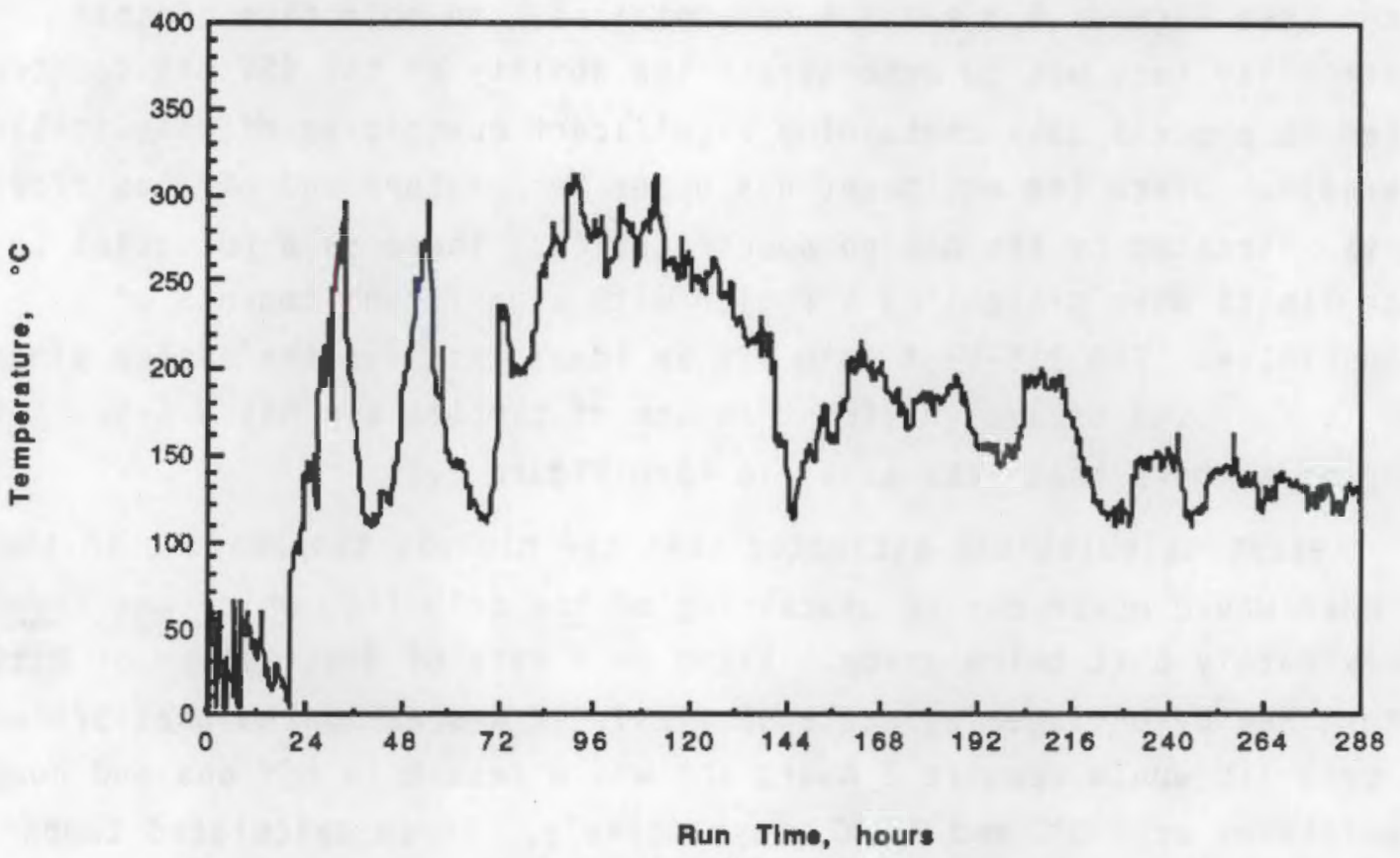

FIGURE 4.3. Temperature Profile of the Off-Gas Hood Roof

Before processing the wooden crib lid. the temperature of the off-gas hood roof approached $300^{\circ} \mathrm{C}$ twice, but subsequently decreased to $100^{\circ} \mathrm{C}$. A comparison of the events listed in Table 4.1 with the increases and decreases in temperature of the off-gas hood roof shows a strong correlation between the trend in power level and the trend in hood roof temperature. Figure 4.4 illustrates the average(a) temperature of the off-gas hood wall and supports the trends observed for the off-gas hood roof. Temperatures on the off-gas hood walls were generally lower because of their distance from the melt and the lesser influence of radiant heat transfer from the surface of the ISV melt.

(a) The wall temperatures of the off-gas hood are measured at four different locations. The average is illustrated in Figure 4.4. 


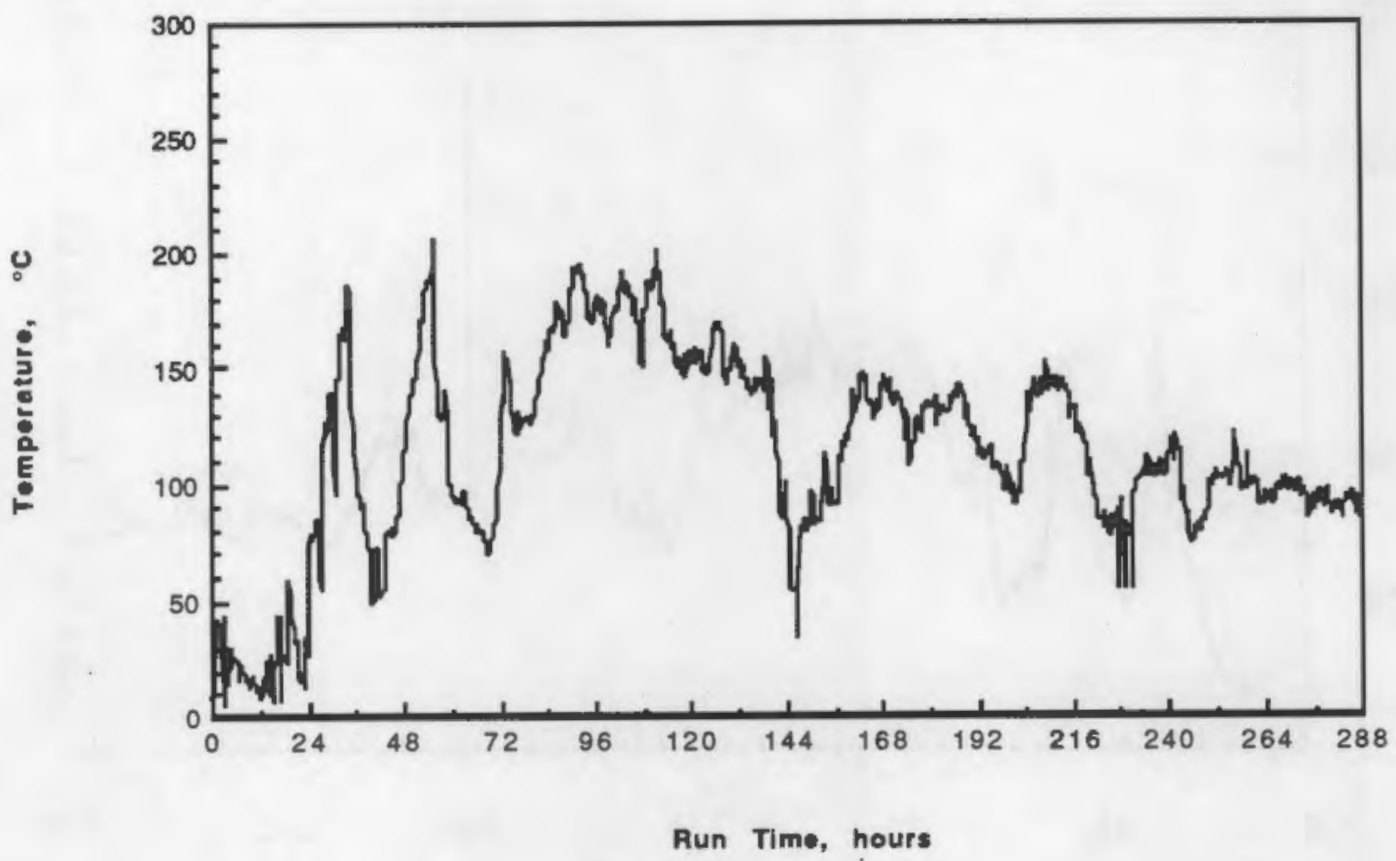

EIGURE 4.4. Temperature Profile of the Off-Gas Hood Wall

Figure 4.5 illustrates the temperature profile for the off-gas exiting the off-gas confinement hood. The temperature profile trends in a similar manner to that of the off-gas hood roof and wall temperatures. Temperatures for the exiting off-gas do not show an increase as a result of processing the crib lid or of processing the crib in general. Although temperatures for the off-gas do approach those calculated to occur from processing the wooden crib timbers, the fact that the temperature approached the calculated value before the crib was processed suggests that it is a result of normal processing operations(a).

Figure 4.6 illustrates the average temperature profile for the off-gas in the hood plenum and supports the conclusion that the spike observed in the

(a) The temperature spike observed in the data 192 hours into the test is likely due to a spurious signal from the thermocouple at that point. No similar spikes are observed in Figures 4.3 and 4.4 , as would be expected if the temperature spike was due to an actual occurrence in the off-gas hood. 


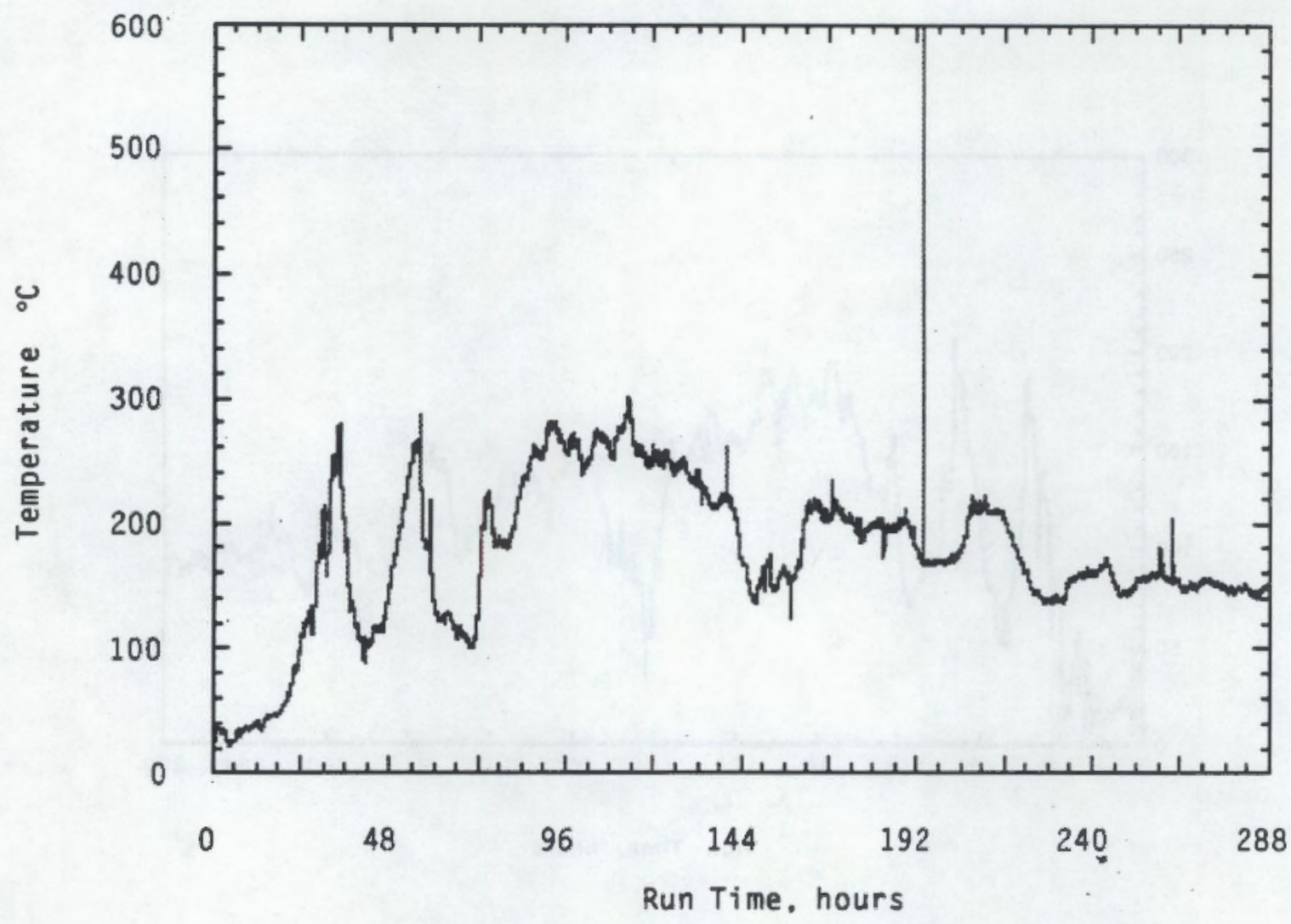

FIGURE 4.5. Temperature Profile for the Off-Gas Exit - 45-second Average

exiting off-gas temperature does not represent a real temperature. The temperatures in the off-gas hood plenum were slightly higher than those measured in the exiting off-gas stream. The higher temperatures in the offgas hood plenum can be attributed to the relative positioning of the thermocouples used for measuring at the respective locations. The thermocouple measuring temperature at the off-gas exit was located downstream from the exit port of the off-gas hood. This location shielded the thermocouple from the effects of radiant heat from the melt surface. In addition, the off-gas cooled somewhat because of heat loss through the piping connecting the off-gas hood with the off-gas treatment trailer. Four thermocouples were used to measure the off-gas plenum temperature, and they could have been influenced by radiant heat from the ISV melt surface. 


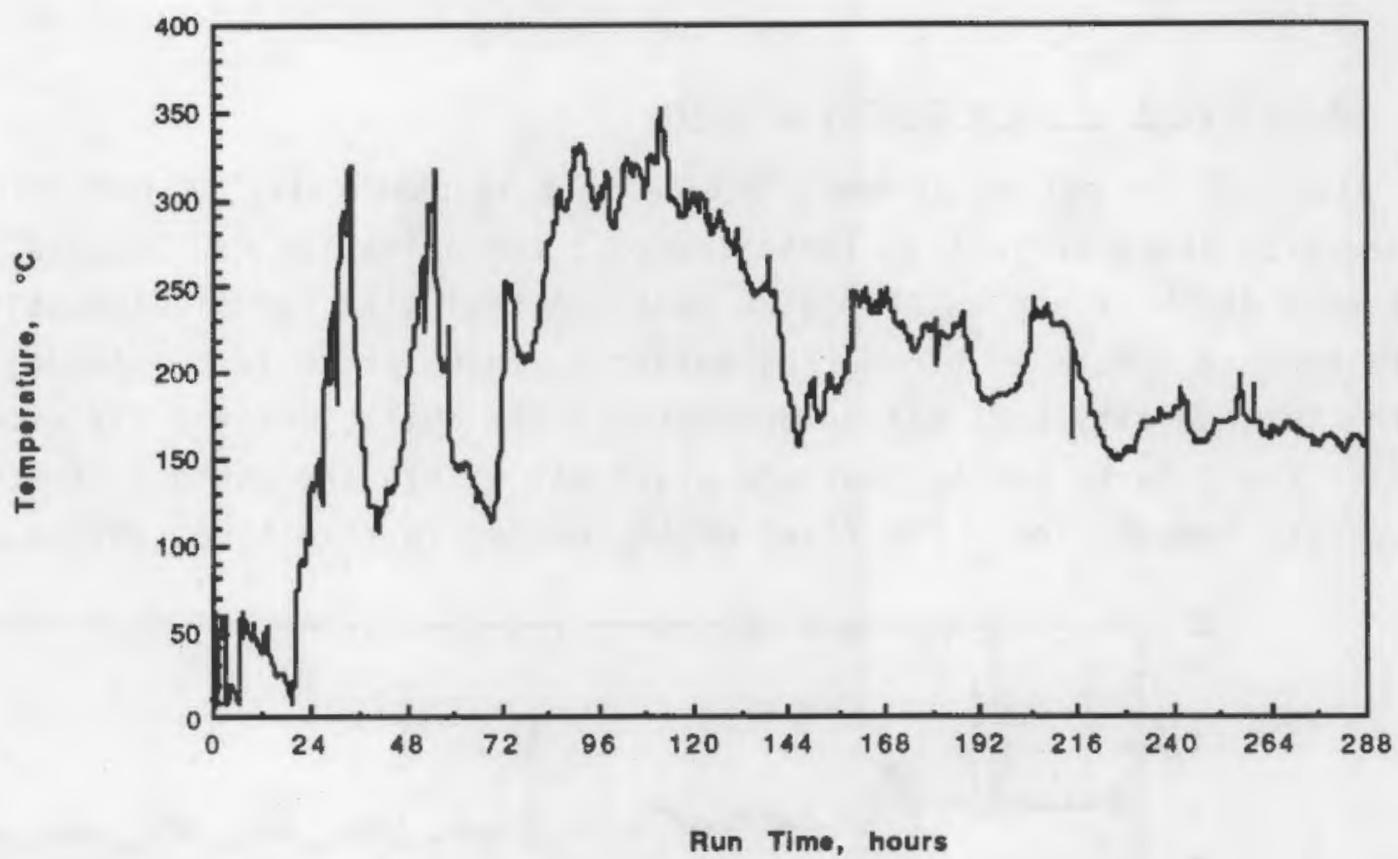

FIGURE 4.6. Temperature Profile for the Off-Gas Hood Plenum

The off-gas system is designed to maintain the off-gas hood at a slightly negative pressure (vacuum) so that gases and particulate evolved from the melt surface are directed into the off-gas treatment system (see Figure 1.4 for an illustration of the off-gas treatment system). Because the off-gas system has an upper off-gas flowrate that is governed by the capacity of the off-gas blower(s) and the pressure drops through the off-gas treatment components. there is the potential that the rate of gas evolution from the melt surface could exceed this capacity. Using a simple balance between what is entering the off-gas hood and what is leaving the off-gas hood, the possibility of more entering the hood than leaving could lead to the off-gas hood becoming positively pressurized. This situation is not desirable because of the possibility that untreated material could then escape from the off-gas hood instead of being directed into the off-gas treatment system.

Figure 4.7 illustrates the vacuum within the off-gas hood during the test. As shown in the figure, a vacuum was maintained within the off-gas hood during the entire test. An apparent pressure spike 156 hours into the test 
has been attributed to an instrument problem because there is no other evidence supporting a conclusion that this signal is real.(a)

\subsection{OBJECTIVE 3 - ISV PROCESSING DEPTH}

Although the bottom of the 116-B-6A Crib is physically 14 feet below grade, site characterization indicated that contamination had leached into the soil to a depth of approximately 20 feet. Actual site remediation using ISV would require treatment of the contamination found at 20 feet. An objective of the treatability test was to demonstrate the ability of the ISV process to vitrify the site to depths that are practical within the context of actual waste site remediation. The final depth reached in this treatability test was

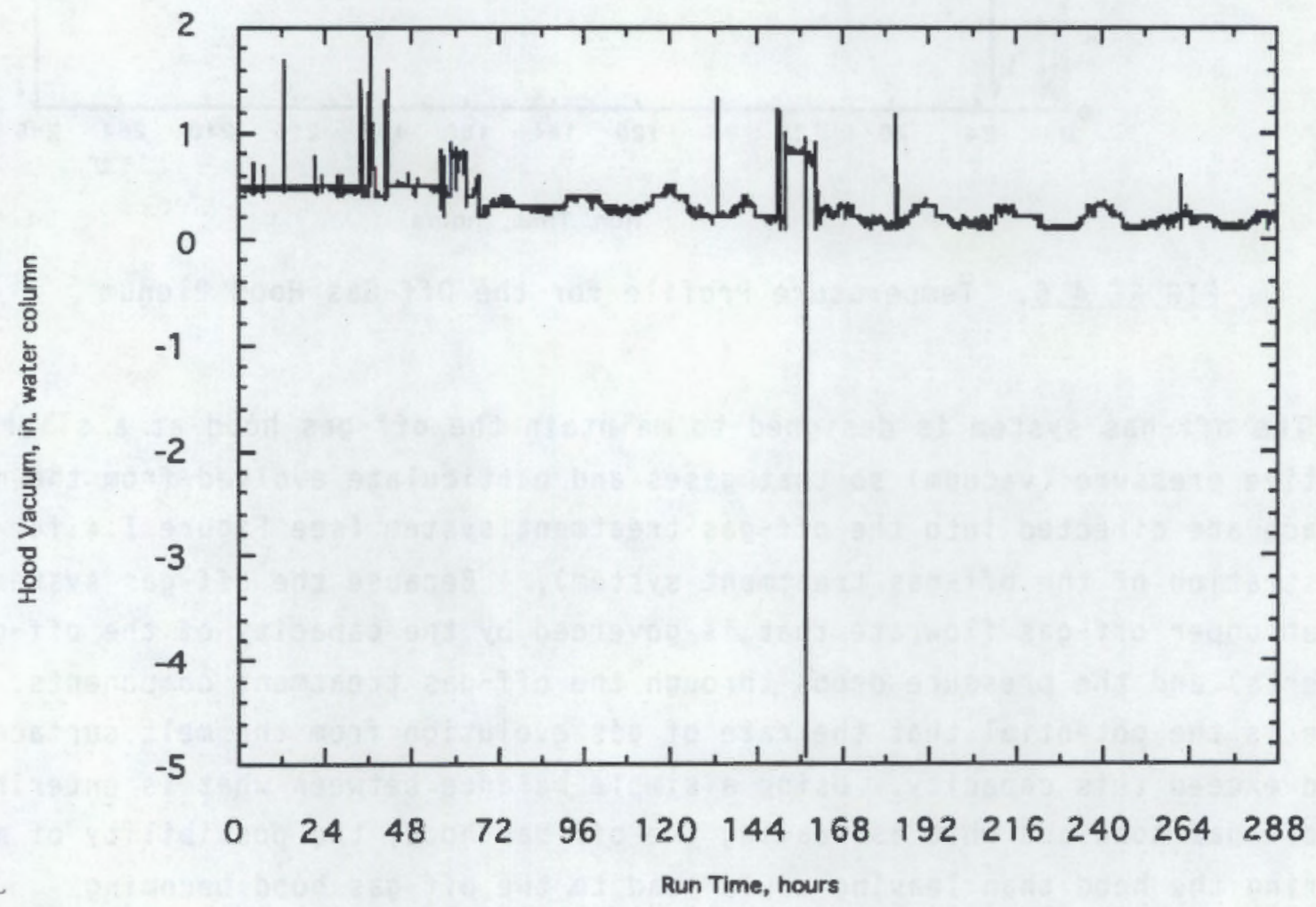

FIGURE 4.7. Off-Gas Hood Vacuum - 45-second Aveiage

(a) The magnitude of such a pressure spike would have damaged the off-gas hood and/or potentially lifted portions of the hood off the ground (not observed). In addition, a sudden release of gas from the melt would have resulted in a corresponding increase in off-gas temperatures (not observed). 
14 feet. The following sections discuss the processing depth issues that pertain to this test.

\subsubsection{Engineering-Scale Testing of the 116-B-6A Crib}

Prior to this large-scale treatability test, an engineering-scale test was performed to estimate the probable effect of the 116-B-6A Crib structure and construction material on the ability of the ISV process to meet the target processing depth of $20 \mathrm{ft}$. Figure 4.8 shows the setup for this engineeringscale test. which was performed in January 1989 . The relative electrode positions, plus the order of material encountered through the first rock layer. were in proportion to the actual layout for the large-scale 116-B-6A treatability test.

Figure 4.9 illustrates the depth profile of the engineering-scale test. The downward melt rate was approximately constant until the melt approached the rock layer that did not contain frit. This observation is consistent with those made during previous ISV tests on Hanford soils during which the melt progression decreased when the melt encountered an unmodified rocky sublayer. A more detailed discussion of the influence of rocky sublayers can be found in section 4.3.3 and Appendix B. Frit containing glass frit sodium carbonate. and smectite was added to the first rock layer as a water suspension. The positive results observed with the use of this frit during the engineeringscale test prompted its use in the large-scale treatability test. Figure 4.9 also indicates that the wooden material was processed at a slightly faster rate than were the soil and rock layers.

Figure 4.8 indicated a frit layer just beneath the wooden structure. This layer was a Hanford soil/suspended frit mixture. The objective in including this layer was to evaluate the effect of the frit on ISV melt growth and processing rates. As Figure 4.9 illustrates, the rate at which depth was achieved was not affected by the presence of the frit material. This result prompted the use of frit to fill the void spaces of the 116-B-6A Crib. 


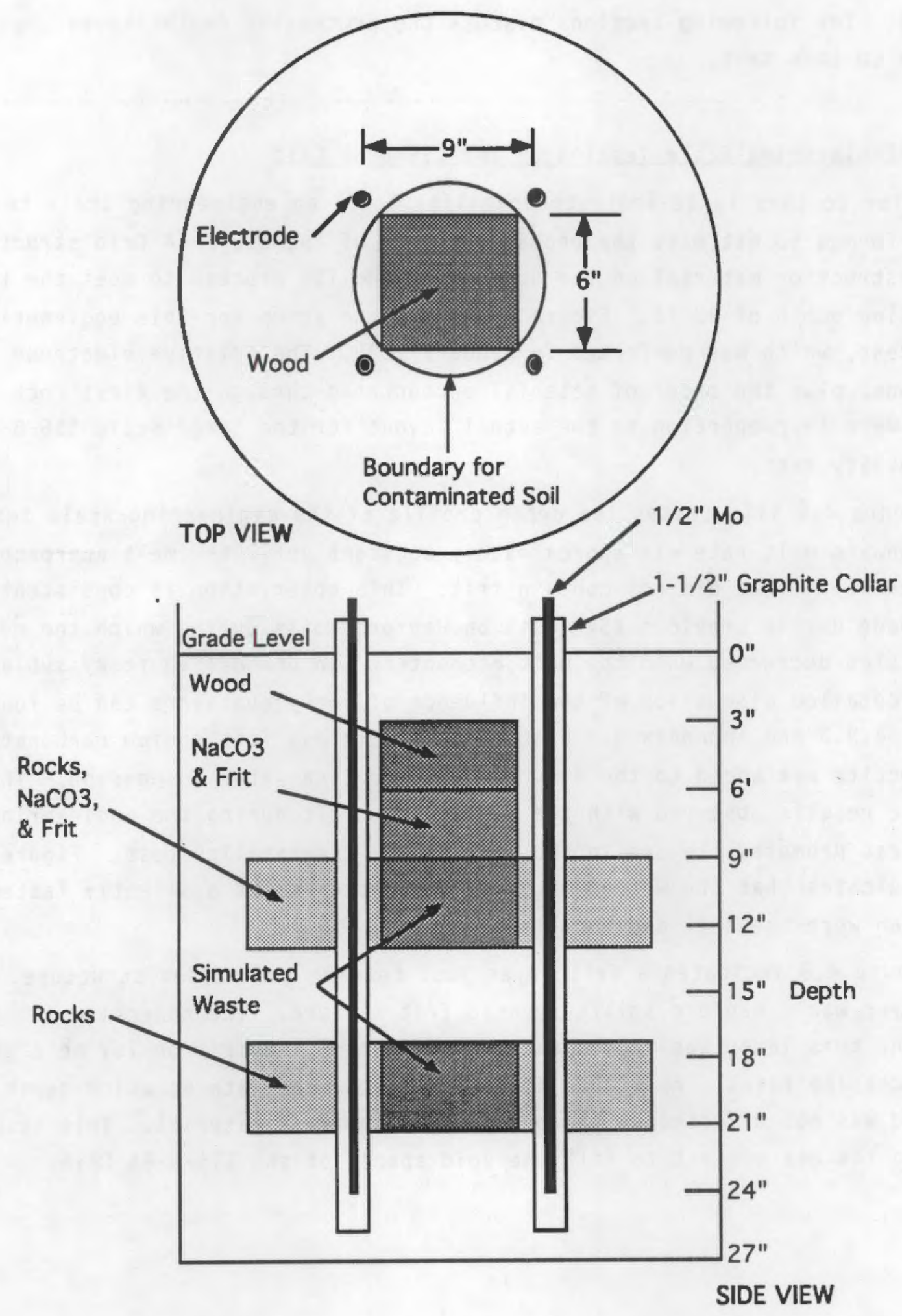

EIGURE 4.8. Engineering-Scale Test Setup - 116-B-6A Crib Test 


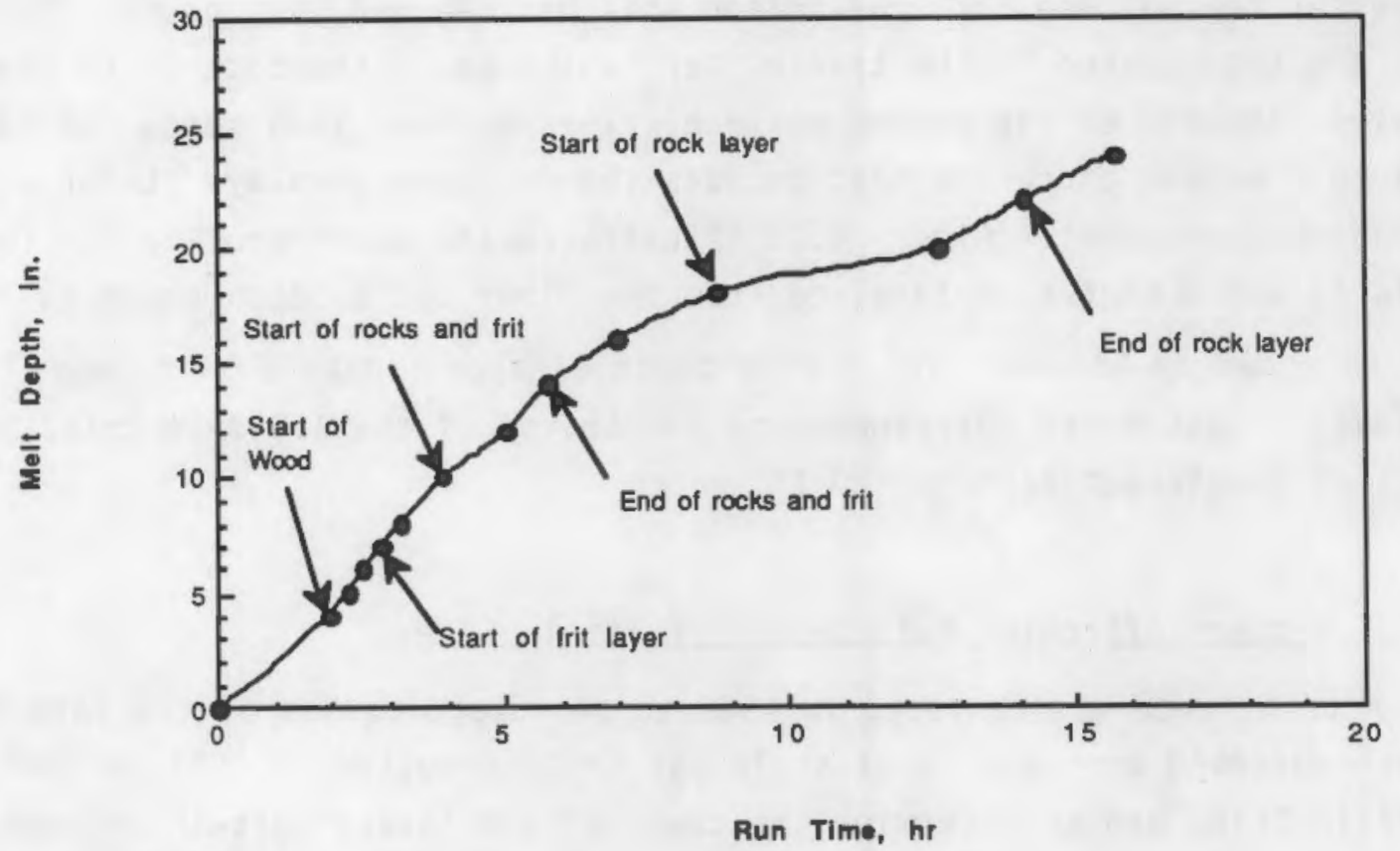

FIGURE 4.9. Depth Profile for the 116-B-6A Crib Engineering-Scale Test Conducted in January 1989

\subsubsection{Depth for the 116-B-6A Large-Scale Test}

During engineering-scale and staged pilot-and large-scale testing. growth of the vitrification zone is monitored by thermocouples placed in the soil at designated positions. However, the installation of the thermocouples at a radioactive and/or hazardous waste site is not feasible. Therefore. depth monitoring using optical fiber sensors was developed and tested successfully in intermediate- and large-scale tests prior to the 116-B-6A Crib treatability test. The optical fiber sensors were used to monitor depth during the 116-B-6A demonstration.(a)

The depth monitoring system consists of a signal processor and transmitter package mounted below one or more of the electrodes. For operation, a series of fiber optic sensors runs from the signal processor

(a) Recent tests with the ISV system have shown the advantage of feeding electrodes into the melt as opposed to pre-placing the electrodes. Depth is now monitored via the length of electrode that has been fed into the melt. 
upward to varying depth levels on the electrode(s). As the ISV process melts downward, the sensors transmit light from the molten soil to the signal processor to indicate that the molten soil has reached that depth. The depth data are then passed to the transmitter. which sends the data on to the receiver located at the ground surface. The receiver then sends the depth data to a second processor that decodes the data and displays it for the operations personnel. Figure 4.10 illustrates the depth profile for the 116-B6 A large-scale test as determined from the fiber optic depth sensors.

As shown by Figure 4.10, a melt depth of approximately $14 \mathrm{ft}$ was achieved. This depth corresponds to the bottom of the 116-B-6A crib, but was short of the target depth of $20 \mathrm{ft}$.

\subsubsection{Factors Affecting Melt Depth: Particle Size}

A task force was convened in 1988 to postulate causes of the lateral growth observed during a large-scale ISV test conducted in 1987 on Hanford's 216-z-12 Crib, and to determine the cause of the lateral growth through

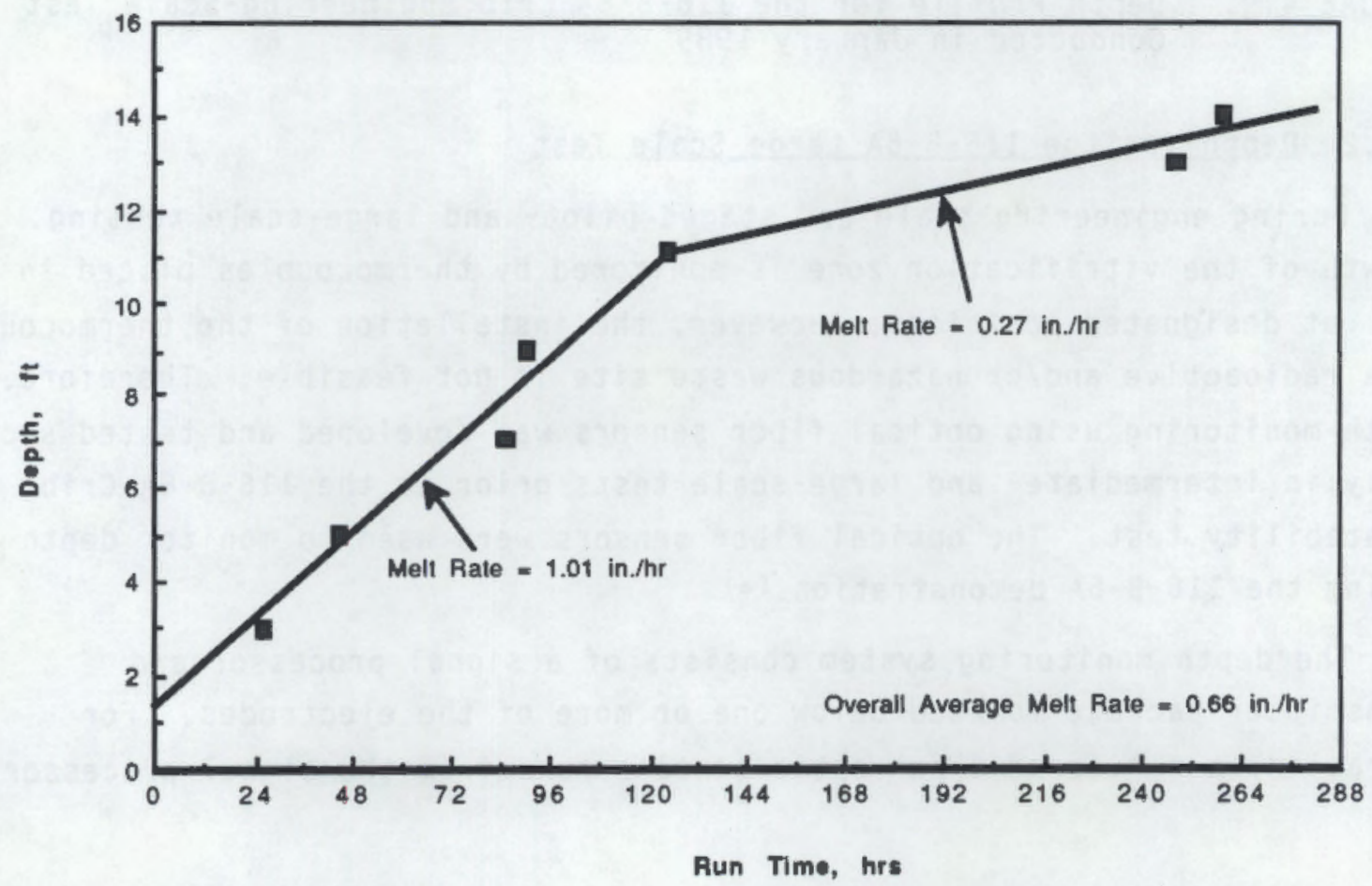

EIGURE 4.10. Depth Profile for 116-B-6A Crib ISV Treatability Test 
analyses and theoretical studies. Some of the task force's findings are applied in the following sections to identify potential factors that may have affected the downward growth rate of the melt during the 116-B-6A Crib test. The task force's findings are summarized in Appendix B.

The cause for the lateral growth during the 1987 test was determined to be the presence of an artificial rock layer placed in the bottom of the 216-Z12 Crib during its construction (the 216-Z-12 Crib differs from the 116-B-6A Crib in that it did not contain large amounts of wooden timbers and was composed almost entirely of graded sizes of gravel). The different particle size of this rock layer relative to the soil at the sides of the melt was the main contributor to preferential lateral growth rather than downward growth. When a large particle size (greater than $2 \mathrm{~cm}$ ) layer or a higher fusion temperature layer is encountered, a higher equilibrium temperature is needed to achieve the same downward progression rate. Otherwise, the molten zone will grow preferentially into soil that allows a lower equilibrium melting temperature.

As shown in Figure 4.10, the downward melt rate for the 116-B-6A Crib test progressed at a relatively constant rate of $1.01 \mathrm{in./hr}$ until the melt reached a depth of $\approx 11 \mathrm{ft}$. A comparison between Figures 4.9 and 4.10 would suggest that the slowed melt rate was due to the presence of a rocky layer within the crib. However, as indicated in section 2.3. when the characterization boreholes were placed in 1989 it was noted that the 1 ithology and texture of the soil layers encountered was relatively homogeneous. The composition consisted of an unconsolidated, poorly sorted, sandy gravel to silty sandy gravel, approximately averaging 50-60\% gravel, 30-45\% sand, and 5$10 \%$ mud (silt and clay). The pre-test characterization suggested homogeneity within the 116-B-6A Crib, greatly reducing the expectations for depth problems (i.e., no rocky cobble layer) during this treatability test.

Subsequent to the test, core samples of the ISV block were taken for compositional and product quality analyses (see Figure 4.2 for locations of core samples). Figure 4.11 illustrates the penetration of core 1 to an area immediately under the 116-B-6A Crib, whereupon it encountered a cobble layer consisting of rocks $1-i n$. to 3 -in. in diameter. Based upon the experience from the 216-z-12 large-scale demonstration and engineering analysis. the presence of the rocky cobble layer was considered to have contributed significantly to the reduced depth. Other potential mechanisms will be discussed in the following sections. 


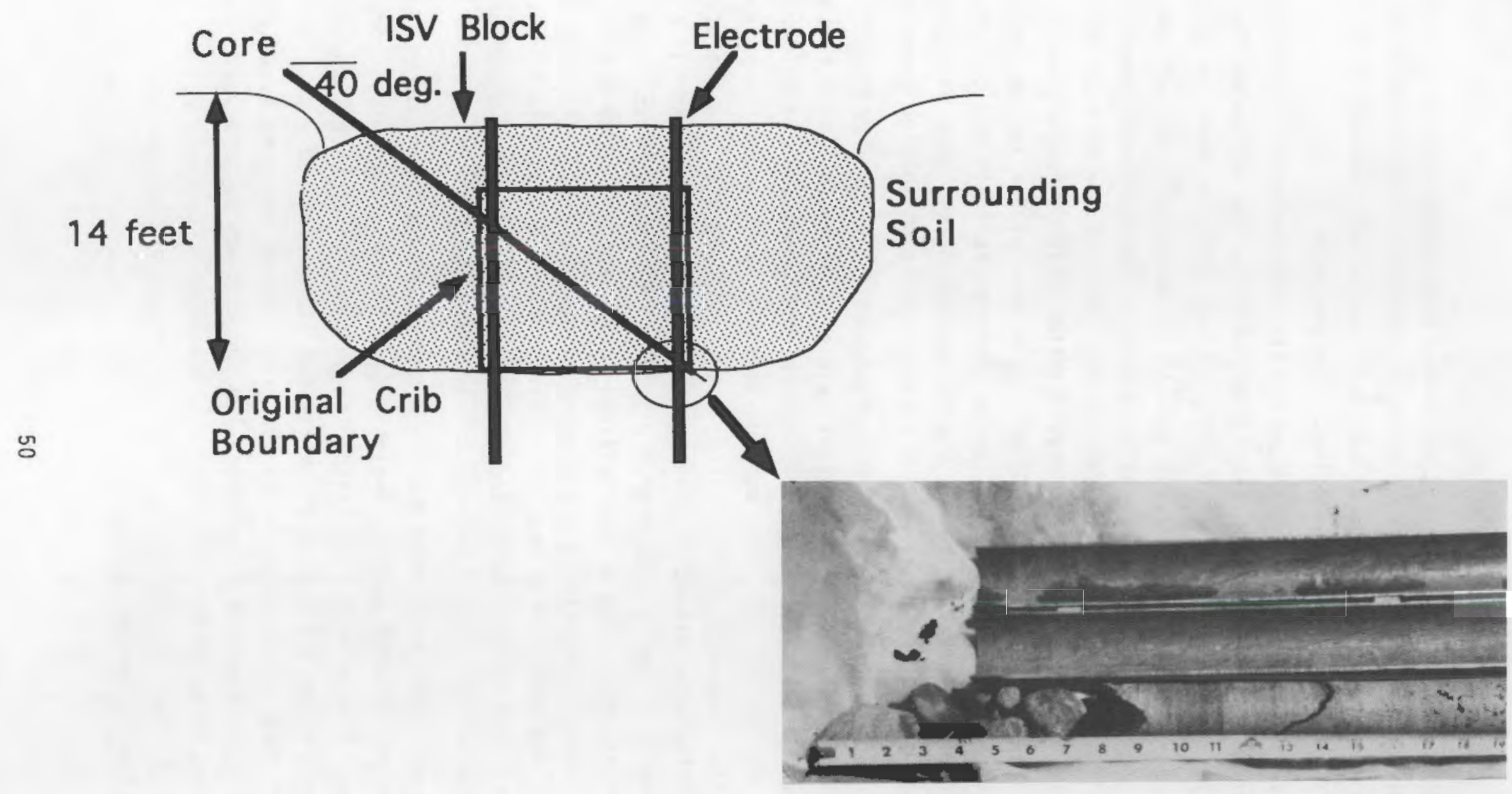

FIGURE 4.11. Cobble Layer Detected During Core Sampling of ISV Block 


\subsubsection{Eactors Affecting Melt Depth: Composition}

The findings associated with encountering layers of larger size rocks also can be applied to heterogenous layers of varying soil compositions. Even if the particle size of the soil throughout the region to be vitrified is uniform, encountering a layer of higher melting temperature soil at the bottom of the melt after a melt has been established with a lower melting point soil will slow the downward growth of the melt. Just as it does upon encountering a rock layer, the ISV melt will preferentially grow laterally instead of downward in this instance.

For the 116-B-6A Crib test, fluxing agents similar to those used for the engineering-scale 116-B-6A test were added to the actual crib to reduce the amount of void space and to minimize any effects that a rocky layer may have on the ISV melt rate. Three 4-in.-diameter grout injection wells were placed in the 116-B-6A Crib to a depth of $20 \mathrm{ft}$. A water slurry containing frit. sodium silicate, and smectite was then injected to fill any voids between the $10-\mathrm{ft}$ and $20-\mathrm{ft}$ depths. Compositionally, this material should melt at a lower temperature than would typical Hanford soil: therefore, progression through this region should have been favored over progression through regular soil. The addition of the flux in the crib resulted in an acceptable downward melting rate up to when the cobble layer was reached. However, the addition of the flux ultimately increased the alkali content of the molten soil which makes the molten soil more conductive and effectively lowers the temperature of the melt (Stanek 1977). As a result, the lower melt temperature combined with the presence of the cobble layer retarded the downward melt rate.

\subsubsection{Factors Affecting Melt Depth: Moisture Content}

The presence of a layer of material at the bottom of the ISV melt that has a higher moisture content than that of material on the lateral edges of the melt may also influence melt shape and growth, especially if the water within this layer is recharged from an outside source. Power input for the ISV process must first be used to evaporate the water present in these layers before the ISV melt can progress into the layer of actual material. A layer of material with a higher moisture content requires more time to drive off the moisture before the melt can advance: meanwhile, progression through layers with lower moisture content commences. However, if the water content in a layer is recharged from an outside source (e.g., an aquifer or pipeline), then 
the melt progression into the region of high moisture content can be stalled indefinitely.

As discussed in section 2.0. site characterization and a review of the engineering drawings of adjacent facilities indicated that buried pipes running in a north-south direction and located just east of the crib are most likely inactive 1.5-in.-diameter water service lines (see Figure 2.1). It is possible that one of the buried pipes was breached either by the melt or through thermal-induced stress during the 116-B-6A Crib test and that water flowed into a region near the bottom of the crib. However, analysis of the data does not support the presence of such an amount of moisture over and above that estimated to be contained within the crib and surrounding soil.

Figure 4.12 illustrates the water balance for the 116-B-6A Crib test. The output curve is generated based on the off-gas flowrate out of the off-gas treatment stack and the water content of this stream. This curve is not a straight line because the off-gas treatment system was operated to

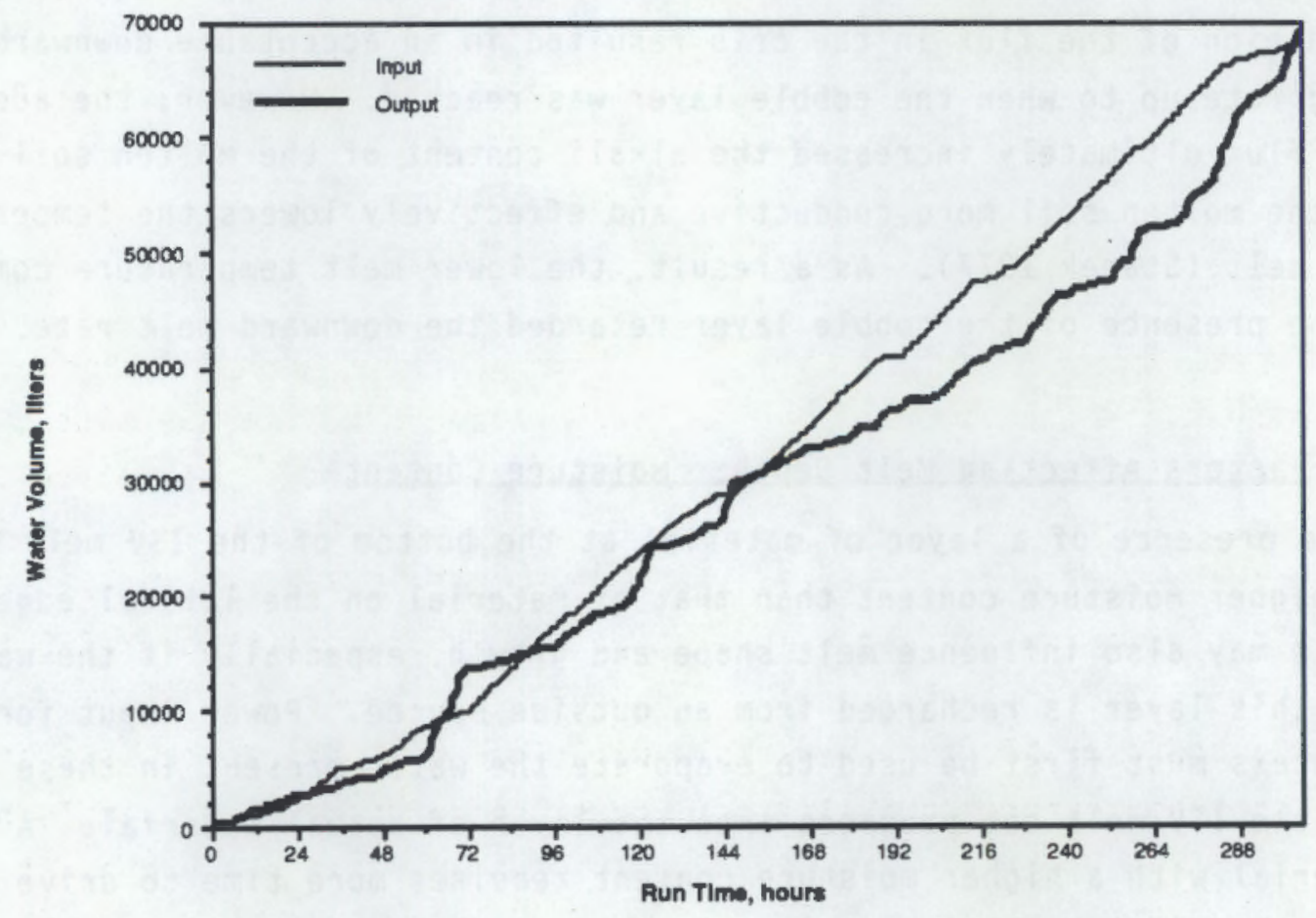

FIGURE 4.12. Water Balance for the 116-B-6A Crib ISV Treatability Test 
evaporate water from the scrub solution tanks only when the need arose. In addition. the water removed from the scrub solution tanks at the end of the test is included in the curve as an output. The only directly measurable amount of water input to the ISV system is the amount added to the scrub solution tanks. Water input from ambient air drawn into the system is based on the calculated humidity of ambient air and a flowrate equivalent to that exiting the stack (inlet air flowrate is not currently measured on the largescale ISV system). However, these two sources of water are minimal compared to the water input from the soil.

The primary source of water is the water evaporated from the soil (or other material) being melted. Computer models of the ISV process show that energy use equivalent to $0.9 \mathrm{kWh}$ is sufficient to melt $1 \mathrm{~kg}$ of soil. Using the energy profile for the 116-B-6A Crib test, the ratio of $0.9 \mathrm{kWh} / \mathrm{kg} \mathrm{soi} 1$, and an average soil moisture content of $7.8 \%$, the water input profile from the ISV melt was developed. The input curve shown in figure 4.12 is the sum of water input contributions from additions to the scrub solution tanks, ambient air, and from the ISV melt. This water balance shows that the amount of water in the output is $108 \%$ of the calculated amount input. This difference is not considered great enough to suggest that a water pipe was breached. Therefore, water recharge is not considered a viabie cause for the slowed downward melt rate and the accompanying increase in lateral growth.

\subsection{OBJECTIYE 4 - PRODUCT QUALITY}

The ISV process converts contaminated soil into a durable glass and crystalline waste form in place. The final waste form, the ISV block, has a chemical durability that is greater than that of commercial high-level waste (HLW) glass. Durability properties of the vitrified block were determined using PNL's Materials Characterization Center (MCC) leach procedures (MCC 1986). The following samples were sent to PNL laboratories for MCC-1 testing: core \#1, run \#11, sample \#3; core \#2, run \#4, sample \#4; core 非, run 非, sample 非: and core 非, run 非, sample 非. The MCC-1 procedure is a static leach test that measures the elemental mass loss of a monolith sample of glass as a function of time. The glass sample is suspended in deionized water inside of a sealed container and maintained at $90^{\circ} \mathrm{C}$. At the end of a predetermined time period ( 28 days for the 116-B-6A samples), the leachant is analyzed using ICP spectroscopy. Results for normalized elemental loss are 
presented in Table 4.9. Results from leach tests of previous ISV blocks and a commercial HLW glass are also tabulated for comparison. As shown in the table, the 116-B-6A block is comparable in durability to previously tested ISV glass and crystalline products. The 116-B-6A block also compares favorably to the commercial HLW glass.

In addition to MCC-1 testing, the samples from the 116-B-6A block were subjected to the Product Consistency Test (PCT). The PCT was originated at the Westinghouse Savannah River Company (WSRC) by C. M. Jantzen and N. R. Bibler (1989). It was designed to require a shorter time period than the MCC1 test and still be able to demonstrate product quality and composition homogeneity of the glass. The test is a modified MCC-3 test, which runs for 7 days and uses crushed $\mathrm{glass}$ in the size range -100 to +200 mesh. The

IABLE 4.9. MCC-1 Test Results for the 116-B-6A Crib ISV Block

\begin{tabular}{|c|c|c|c|c|}
\hline \multirow[b]{2}{*}{ Element } & \multicolumn{4}{|c|}{ Normalized Elemental Loss. $\mathrm{g} / \mathrm{m}^{2(a)}$} \\
\hline & $116-B-6 A$ & ISV Glass (b) & ISy Crystals (b) & PNL $76-68(\mathrm{c})$ \\
\hline A1 & 2.72 & 4 & 2 & -- \\
\hline B & 13.72 & & & \\
\hline $\mathrm{Ba}$ & 0.82 & 2 & 2 & $<0.05$ \\
\hline $\mathrm{Ca}$ & 1.82 & 4 & 3 & 0.3 \\
\hline $\mathrm{Cr}$ & & & & \\
\hline $\mathrm{Fe}$ & 0.05 & 0.1 & 0.5 & $<0.01$ \\
\hline$k$ & 21.16 & & & \\
\hline $\mathrm{Mg}$ & 1.51 & 4 & 3 & -- \\
\hline Mn & 0.13 & & & \\
\hline $\mathrm{Na}$ & 5.57 & 5 & 3 & 55 \\
\hline Si & 3.97 & 4 & 3 & 36 \\
\hline $\mathrm{Sr}$ & 1.31 & 3 & 3 & 0.3 \\
\hline $\mathrm{Ti}$ & 0.02 & & & \\
\hline Cs & & 6 & 4 & 64 \\
\hline La & & $<0.01$ & $<0.01$ & $-\cdot$ \\
\hline $\mathrm{Nd}$ & & $<0.02$ & $<0.02$ & -- \\
\hline
\end{tabular}

(a) MCC-1 leach test in $90^{\circ} \mathrm{C}$ deionized water. $S A / V=10 \mathrm{~m}^{-1}$ for 28 days.

(b) Data from Buelt et al. (1987).

(c) Data from Strachan. Turcotte, and Barnes (1980). 
difference between the modified MCC-3 and PCT is that there is no agitation during the PCT test. Approximately $3 \mathrm{~g}$ of crushed glass, in the size range -100 to +200 mesh, is placed in a Teflon test container with approximately 30 $\mathrm{ml}$ of deionized water. The Teflon containers are placed in an oven at $90^{\circ} \mathrm{C}$. and the lids are tightened within 24 hours after being placed in the oven. The PCT results confirm the high chemical durability of the 116-B-6A ISV block seen with the MCC-1 test results.

In addition to testing the chemical durability of the 116-B-6A block, testing was performed to determine the toxicity of the final waste form. Samples of the 116-B-6A block were sent to CEP (Sante Fe. NM) for Toxicity Characteristic Leach Procedure (TCLP) testing. TCLP is used by the EPA to determine the toxicity of a given waste form for classification. Results from the TCLP test are used to classify the waste form as either hazardous or nonhazardous.

For the TCLP test, the 116-B-6A block samples are subsampled to approximately $100 \mathrm{~g}$ amounts and are then size reduced so that the surface area per gram of sample is equal to or greater than $3.1 \mathrm{~cm}^{2}$. The crushed samples are then placed into an extraction vessel containing a weak acid extraction fluid. Analysis of the leachate is performed at the end of the extraction period. Results from the TCLP testing of the 116-B-6A block are provided in Table 4.10. The elements appearing in Table 4.10 are all part of the EPA's target analyte list for metals. As illustrated by Table 4.10, the 116-B-6A block is a stable waste form that passes the EPA's TCLP test criteria. 
IABLE 4.10. TCLP Results for 116-B-6A Block Samples. All values mg/L.

\begin{tabular}{|c|c|c|c|c|c|c|c|c|}
\hline Sample & As & $\mathrm{Ba}$ & Cd & $\mathrm{cr}$ & $\mathrm{Pb}$ & $\mathrm{Hg}$ & $\mathrm{Se}$ & $\mathrm{Ag}$ \\
\hline \multicolumn{9}{|l|}{ Core 非1 } \\
\hline Run 非11 & $<0.01$ & 0.06 & $<0.05$ & $<0.05$ & $<0.05$ & $<0.0004$ & $<0.01$ & $<0.05$ \\
\hline \multicolumn{9}{|l|}{ Core \#1 } \\
\hline Run \#14 & $<0.01$ & 0.05 & $<0.05$ & $<0.05$ & $<0.05$ & $<0.0004$ & $<0.01$ & $<0.05$ \\
\hline \multicolumn{9}{|l|}{ Core 非2 } \\
\hline Run 非9 & $<0.01$ & 0.05 & $<0.05$ & $<0.05$ & $<0.05$ & $<0.0004$ & $<0.01$ & $<0.05$ \\
\hline \multicolumn{9}{|l|}{ Core \#2 } \\
\hline Run 非4 & $<0.01$ & 0.06 & 0.07 & 0.08 & $<0.05$ & $<0.0004$ & $<0.01$ & $<0.05$ \\
\hline \multicolumn{9}{|l|}{ Core 非2 } \\
\hline Run 非4 & $<0.01$ & 0.05 & $<0.05$ & $<0.05$ & $<0.05$ & $<0.0004$ & $<0.01$ & $<0.05$ \\
\hline \multicolumn{9}{|l|}{ Core \#2 } \\
\hline Run \#5 & $<0.01$ & 0.05 & $<0.05$ & $<0.05$ & $<0.05$ & $<0.0004$ & $<0.01$ & $<0.05$ \\
\hline \multicolumn{9}{|c|}{ Detection } \\
\hline Limit & 0.01 & 0.03 & 0.05 & 0.05 & 0.05 & 0.0004 & 0.01 & 0.05 \\
\hline \multicolumn{9}{|l|}{ TCLP } \\
\hline Limit & & 100 & 1.0 & 5.0 & 5.0 & 1.0 & & \\
\hline
\end{tabular}




\subsection{PROCESS PERFORMANCE}

Section 4.0 discussed the various objectives and corresponding results for the 116-B-6A Crib ISV treatability test. To this end, many aspects of the test were discussed as they were directly related to the test objectives. The following sections discuss aspects of the treatability test that, although not directly related to the test objectives, were necessary for ensuring that the test was completed and that the safety of the workers and environment was secure.

\subsection{OFF-GAS TREATMENT SYSTEM}

The off-gas treatment system, including the off-gas confinement hood, is the key element in ensuring that gases and particulate evolved from the ISV melt are not released to the environment until the effluent is adequately treated. As was shown in Figure 4.7, the vacuum within the off-gas confinement hood was maintained within acceptable limits throughout the test. Although the amount of vacuum maintained during the test was lower than desired. it was sufficient to direct the evolved gases and particulate from the melt into the off-gas treatment system. A vacuum is established within the off-gas hood via a primary blower within the off-gas treatment trailer. In the event that the vacuum within the off-gas confinement hood is critically low or lost (either caused by conditions evolving from the melt or difficulties in the off-gas treatment system), a backup blower is engaged to maintain a minimal vacuum in the off-gas hood. In addition. the power to the electrodes is disengaged to slow down or eliminate off-gas evolution from the ISV melt.

Figure 5.1 illustrates the standard volumetric flowrate generated by the primary blower out through the stack of the off-gas treatment trailer. As shown by Figure 5.1, the flowrate out through the stack averaged 76 standard $m^{3} / m i n$. The time periods when the off-gas flowrate was higher than the average flowrate denote times when both of the scrubbing systems were engaged (as discussed previously in section 1.1, the large-scale ISV system uses a parallel off-gas treatment system for added capacity when needed and as a backup). At approximately 56 hours into the test, the primary blower shut down, causing the backup blower to engage (see Table 4.1 for event summary). When the primary blower came back on line, the backup blower disengaged. The 


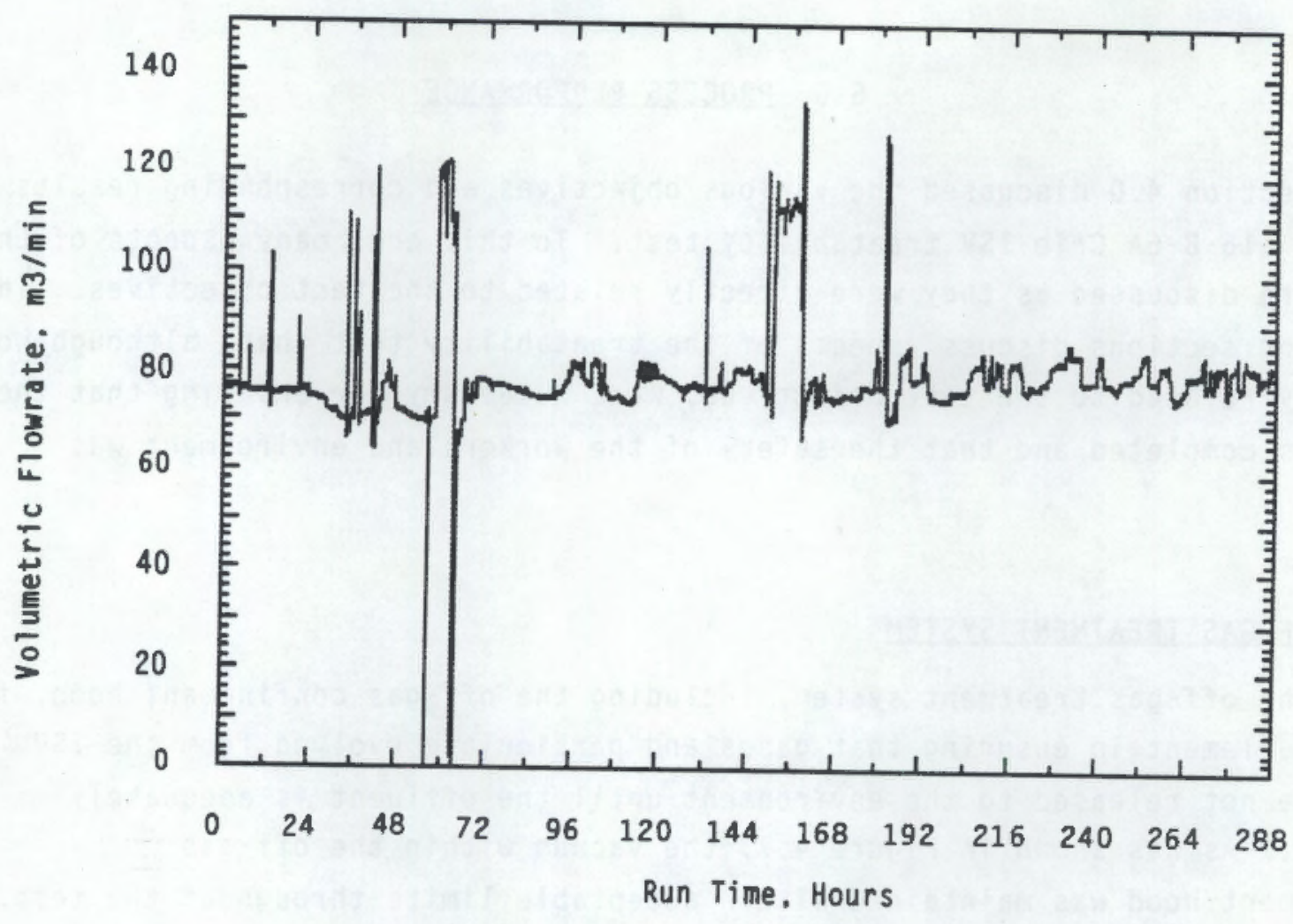

EIGURE 5.1. Standard Volumetric Flowrate through the Off-Gas Treatment Stack

success of this "backup" system is best illustrated by Figure 4.7. Which does not show a loss of hood vacuum at this point in time. At approximately 63 hours into the test, the backup system was again engaged and it performed as designed.

\subsection{LARGE-SCALE POWER SYSTEM}

The power system performed adequately for this test. Several factors affected the level of power that could be supplied to the ISV melt (e.g.. apparent high CO levels, downtime to replace electrodes, and administrative controls on transformer temperatures), but did not affect the level of control that the operators had on the power system. Figure 5.2 illustrates the power input profile for the treatability test. A peak power input of approximately $3200 \mathrm{~kW}$ was achieved with an average power input. including downtime, of $1921 \mathrm{~kW}$. The average power input excluding downtime was 


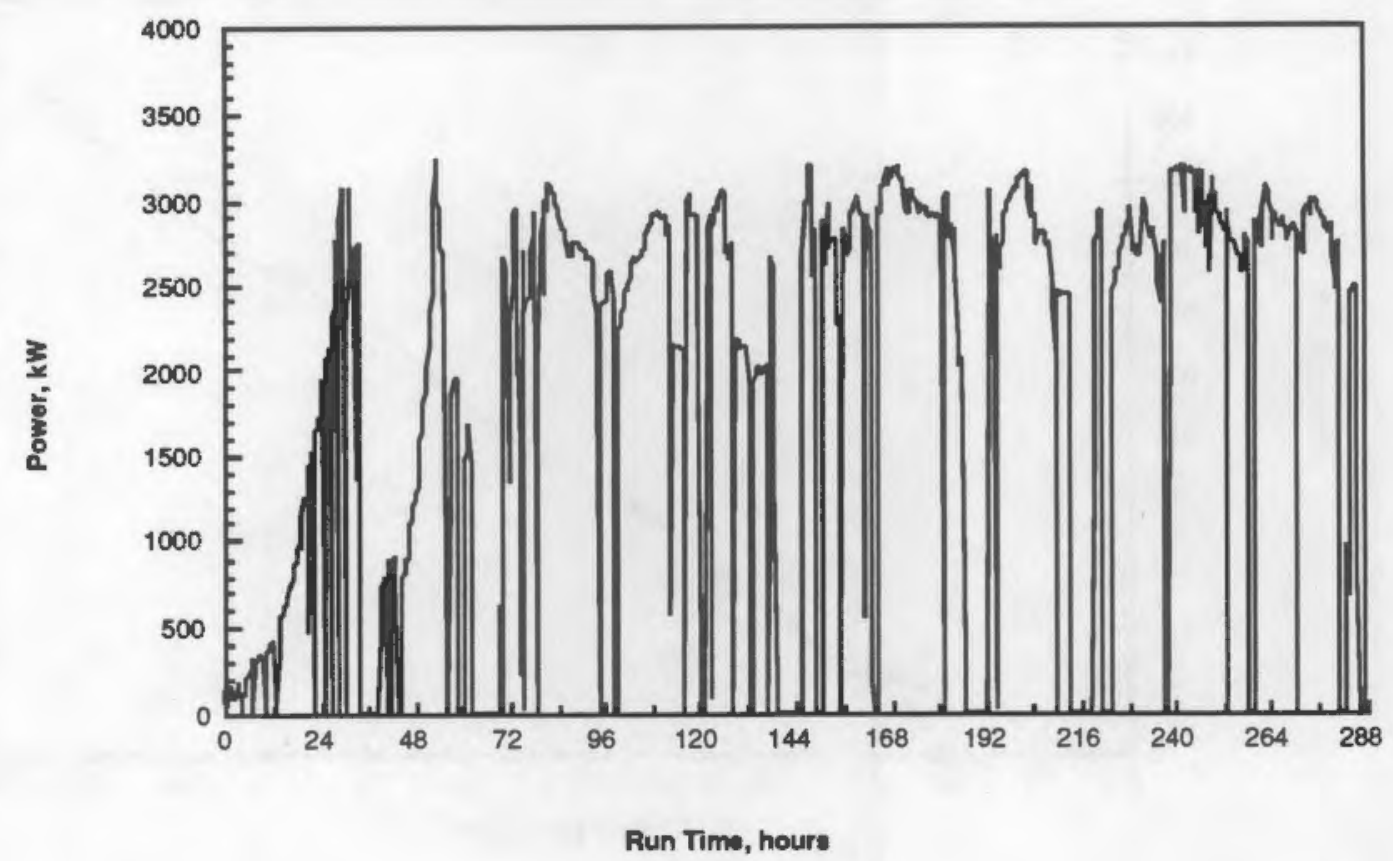

FIGURE 5.2. Power Profile for the 116-B-6A Crib ISV Treatability Test

approximately $2290 \mathrm{~kW}$. Figure 5.3 illustrates the cumulative energy profile for the treatability test and shows that the total energy consumed for the 2-week test was $550 \mathrm{MWh}$. The level portions of the energy profile correspond to periods when power was not being applied to the electrodes (see Table 4.1 for a test event summary, including causes of downtime). An electrode feed system has been developed and successfully tested on all scales of ISV equipment and will aid in reducing the downtime that results from replacing electrodes.

\subsubsection{Power Limitation: Carbon Monoxide Levels}

Although the downtime to replace electrodes was significant relative to the total downtime for the test (approximately 14 hours out of 40 hours). other factors also affected the amount of power input to the ISV melt. As Table 4.1 illustrates, on numerous occasions during the 116-B-6A test power 


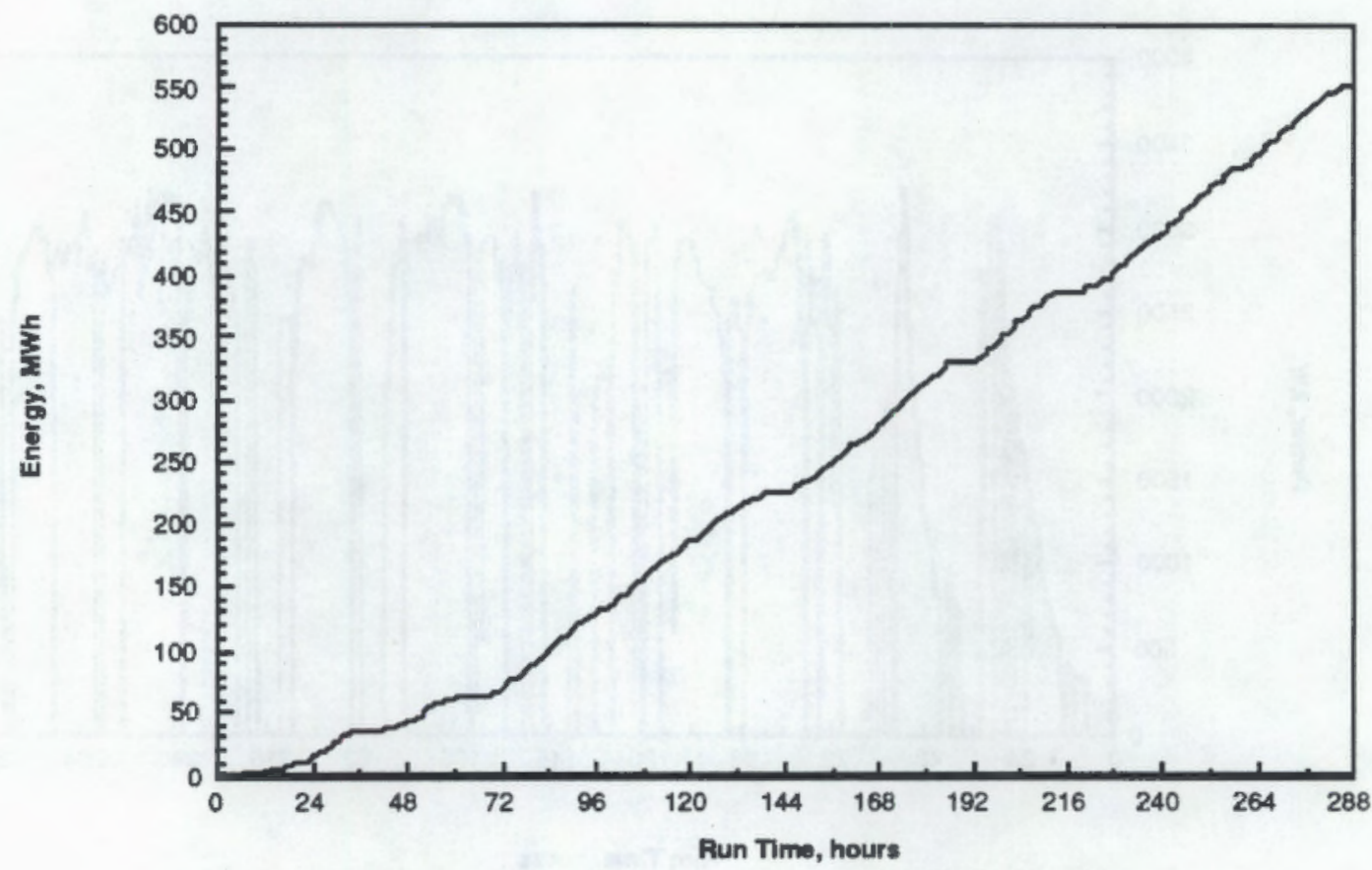

EIGURE 5.3. Cumulative Energy Profile for the 116-B-6A Crib ISV Treatability Test

was either reduced to, or completely disengaged from, the electrodes because of apparent high levels of carbon monoxide $(\mathrm{CO})$ (the $\mathrm{CO}$ levels in the off-gas stream are measured after the stream passes through all of the treatment stages). Figure 5.4 illustrates the CO profile measured at the off-gas treatment trailer stack. Difficulties with the online CO monitor and discrepancies between the online monitor and hand held monitors make the absolute $C O$ concentration levels shown in Figure 5.4 suspect. Figure 5.4 also illustrates the fact that the ISV process is controllable to the point where undesired changes in the off-gas stream can be compensated for by adjusting the operating parameters (in this case, the amount of power input). If the gas had been another material instead of $\mathrm{CO}$, the off-gas treatment process would have been versatile enough to allow compensatory changes (e.g.. pH changes in the scrub tanks, varying gas flows, and varying temperatures). 


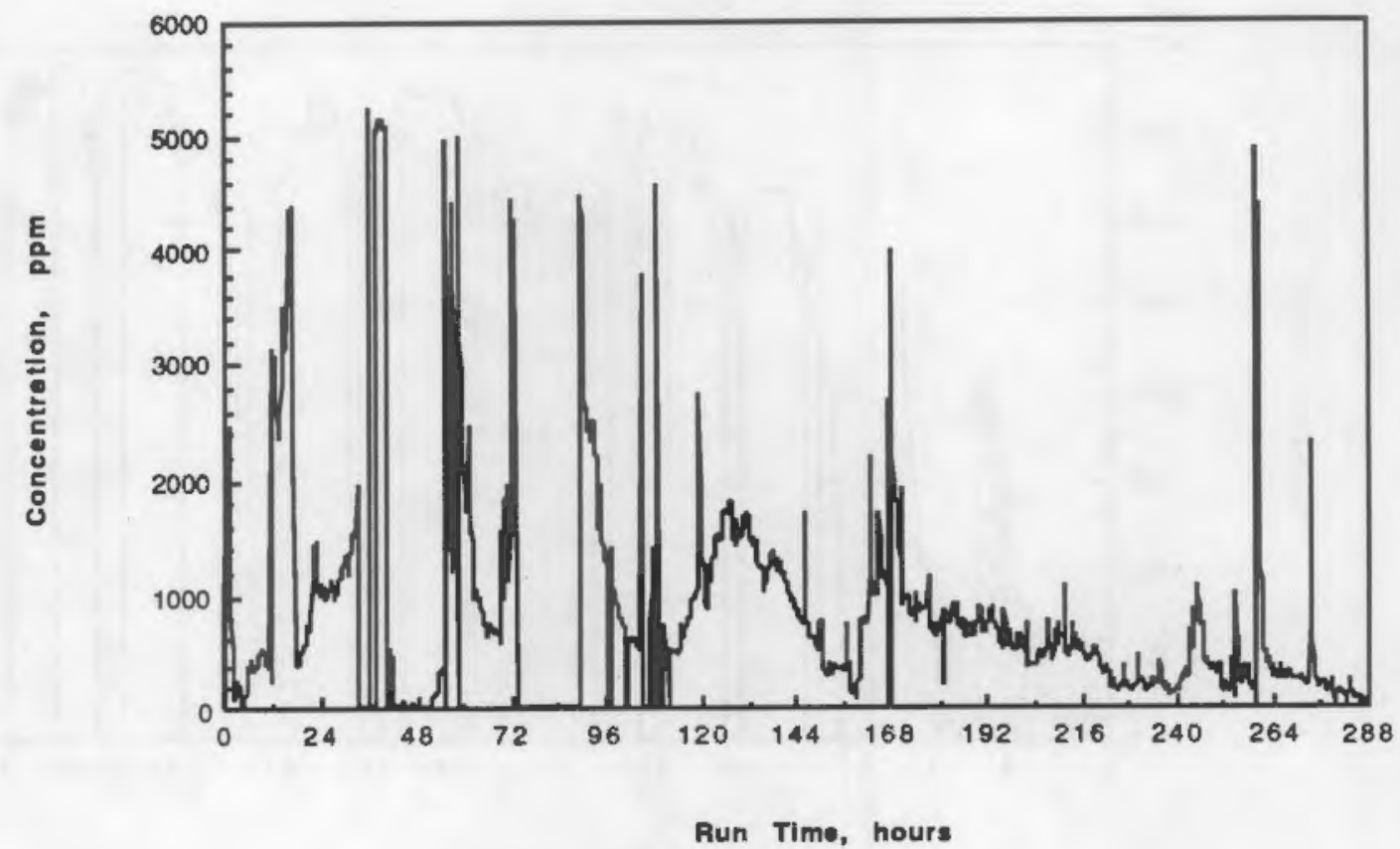

EIGURE 5.4. Carbon Monoxide Concentration Profile: Off-Gas Stack

\subsubsection{Power Limitation: Upper Current Limit}

As the ISV melt progresses, it becomes more conductive because of the increase in the amount of molten soil (molten soil is a significantly greater conductor of electricity than nonmolten soil). Because of this fact, power input into the melt becomes a function of the amount of current that can be supplied to the melt. Figure 5.5 illustrates the current profile for the "A"-phase output of the Scott-Tee transformer (the profile for B-phase follows the same trend as that for A-phase and, as a matter of practice, control of the power system attempts to keep the two phases balanced). Comparing Figures 5.2 and 5.5 shows a relationship early in the test (less than 60 hours) where a current up to 2500 amps was sufficient for a power level of up to $3000 \mathrm{~kW}$. At 84 hours into the test, the A-phase current approached the administratively set upper level of 3200 amps, whereupon operators controlled the power system to maintain the current below this upper limit. During the approximately 8 hours at which the current was maintained at 3200 amps, the power input level into the ISV melt steadily decreased from $3100 \mathrm{~kW}$ to $2700 \mathrm{~kW}$, indicating 


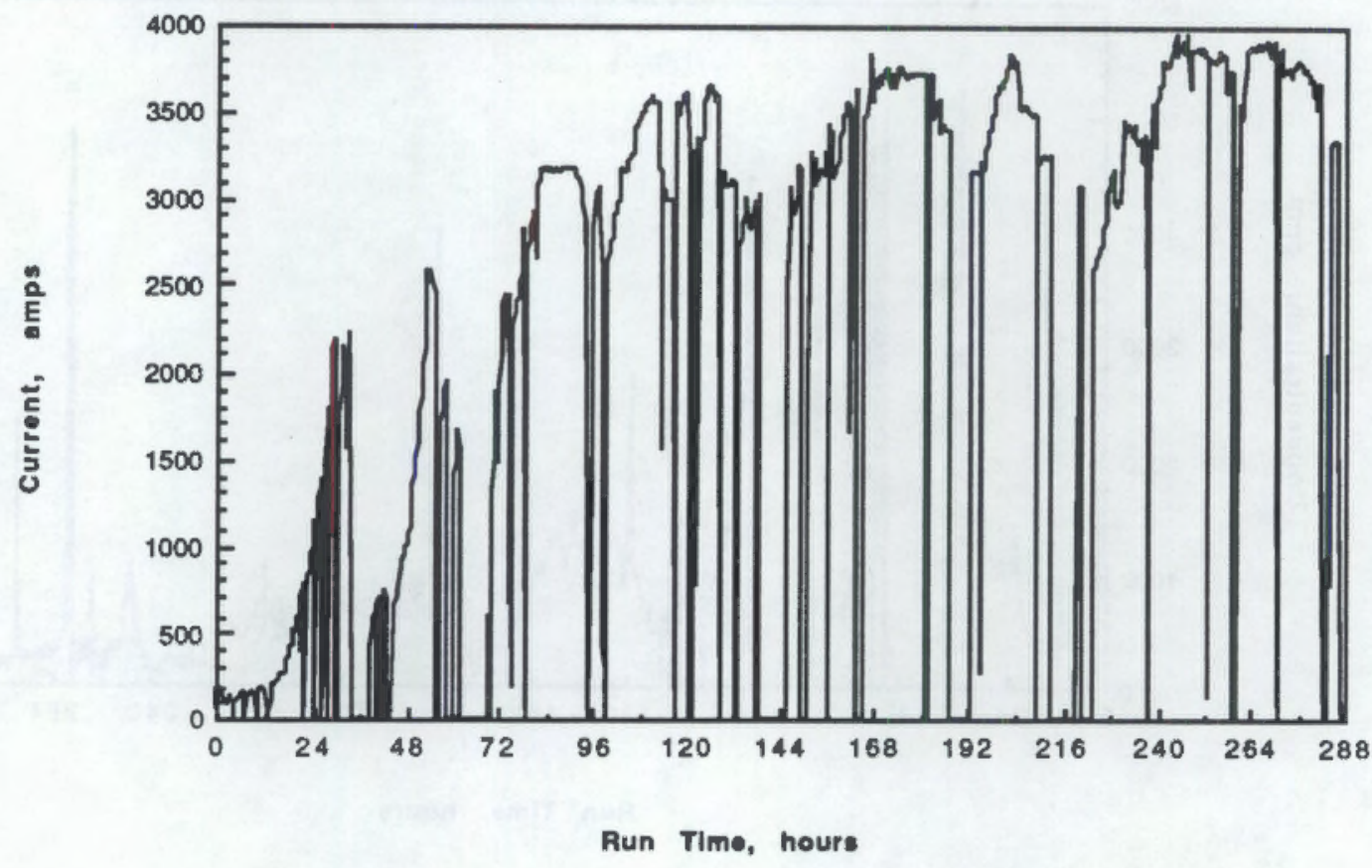

EIGURE 5.5. Current Profile for the "A" Phase Scott-Tee Transformer Output

that the melt required more than the 3200 amps if power levels were to be increased. Discussions with safety personnel at PNL led to an increase in the allowed current to the nameplate value of 4000 amps at approximately 100 hours into the test. This increase is reflected in Figures 5.5 and 5.2 by an increase in current and an increase in power input, respectively. Another point of current limitation did not occur until near the end of the test at hour 252. The upper current limit for subsequent large-scale tests has been raised to 3900-4000 amps to avoid current limitations early in a test run.

\subsubsection{Power Limitation: Transformer Temperature Limit}

In addition to an upper limit on the output current from the transformer, an upper temperature limit existed for the air space around the transformer windings. Thermocouples were placed in the air space between the windings of the transformer to give an indication of whether the transformer was overheating. Figure 5.6 illustrates the temperature profile for the air 
space between a set of transformer windings. The apparent equilibrium temperature for the winding of the air space appears to be about $65^{\circ} \mathrm{C}$; however. the administratively set upper limit was $55^{\circ} \mathrm{C}$. The elevated temperatures seen prior to hour 72 are surprising given the fact that power levels were just beginning to be increased (this observation was a factor in establishing the new monitoring procedure of attaching the thermocouple directly to the winding). After 72 hours, sufficient power was being applied to the melt to warrant concern about the elevated temperatures, and power levels were reduced accordingly to bring the temperature below $55^{\circ} \mathrm{C}$. The $55^{\circ} \mathrm{C}$ upper 1 imit, as with the $3200 \mathrm{amp}$ limit. restricted the amount of power the operating staff could input into the ISV meit. Because of this operational limit, discussions were held with laboratory safety and the temperature 1 imit was raised to $75^{\circ} \mathrm{C}$. As Figure 5.6 illustrates, the change in the upper limit did not affect the temperature in the windings, which equilibrated at approximately $65^{\circ} \mathrm{C}$.

However, the change in the upper limit gave the operating staff more latitude in applying power to the ISV melt.

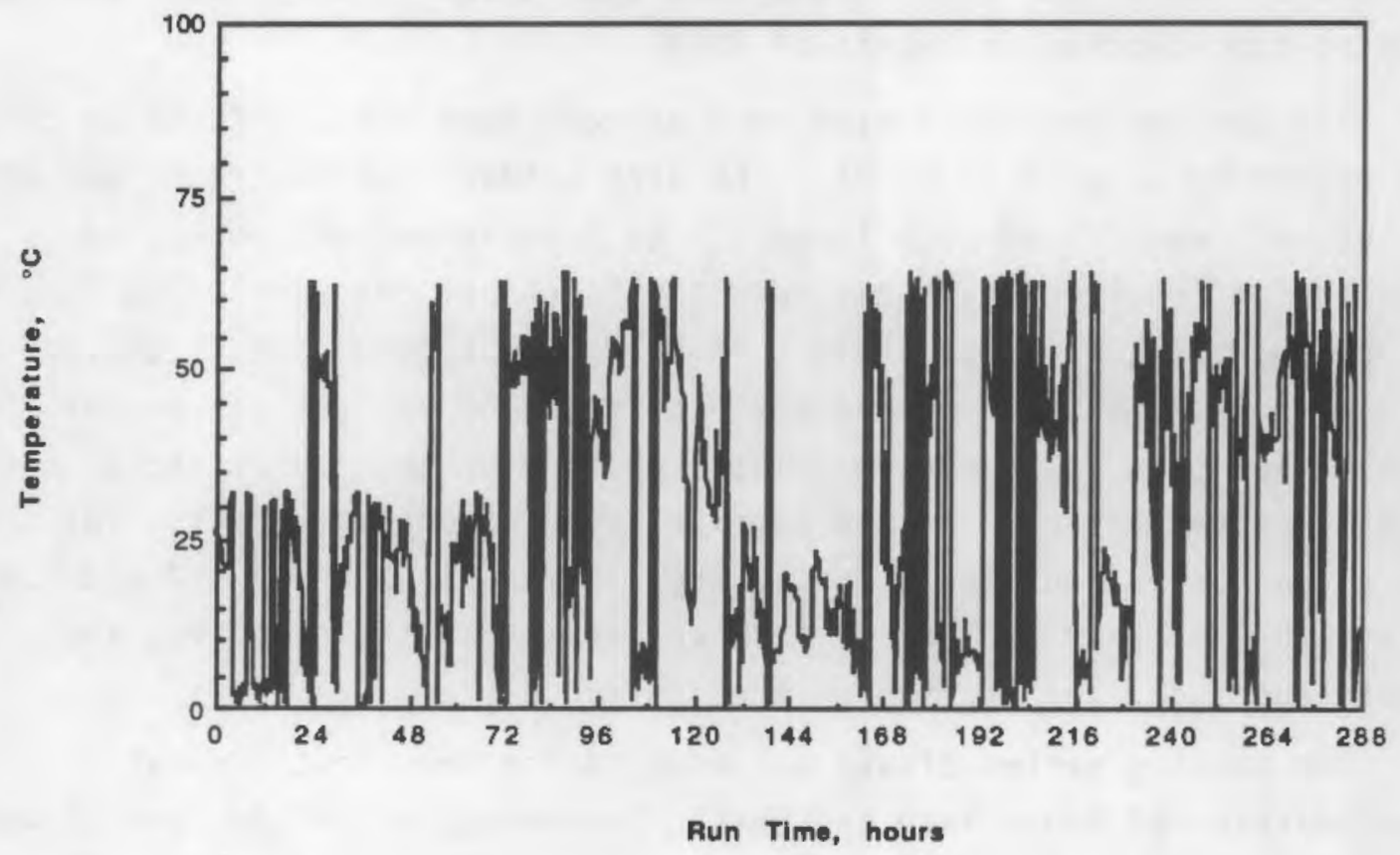

EIGURE 5.6. Air Space Temperature Profile for the Scott-Tee Transformer Winding 


\subsection{CONTROL OF LATERAL GROWTH: BARRIER WALL}

During the normal processing of contaminated soils, the ISV melt progresses downward and laterally. The lateral growth is normally uniform, leading to a final melt boundary that retains a square-like shape with slightly rounded corners. This lateral growth is not usually an unwanted feature, for it leads to the vitrification of a greater volume of soil for a given setting, a factor that affects the number of settings (and cost) required for a given contaminated soil site. However, there are situations where the lateral growth of the ISV melt needs to be controlled to protect adjacent structures.

Figure 5.7 presents a plan view, and Figure 5.8 an elevation view, of the barrier wall and cooling system installed for the 116-B-6A Crib ISV treatability test. This system was installed to protect an underground concrete storage tank that was previously used to store contaminated material. The alumina-silica barrier wall was designed to impede the growth of the ISV melt toward the concrete tank. However, the barrier wall itself was not sufficient to prevent the tank temperature from rising as a result of thermal diffusion. Therefore, a cooling system was installed to prevent the tank from reaching temperatures in excess of $200^{\circ} \mathrm{F}$.

The barrier wall consisted of a plywood form and a 1-ft-thick ceramic wall poured to a depth of $15 \mathrm{ft}$. The area between the concrete tank and the barrier wall was filled with large (2- to 3-in.-diameter) rocks. A distribution (cooling) pipe extended the length of the barrier wall at the base of the rocks (approximately $6 \mathrm{ft}$ below the bottom of the concrete tank). A blower located outside of the ISV hood supplied ambient air to the distribution pipe. The air percolates up through the bed of rocks, cooling the protective zone between the barrier wall and concrete tank. Thermocouples were placed at various locations in the system (see Figures 5.7 and 5.8) to monitor the approach of the ISV melt and establish the need for, and effectiveness of, the startup of the cooling system.

The cooling system blower was engaged for the first time at approximately 124 hours into the test. Thermocouples 13, 14, and 15 were reading 50,70 , and $22^{\circ} \mathrm{C}$, respectively. After slightly more than an hour, the temperatures had all fallen $2^{\circ} \mathrm{C}$ or more, indicating that the cooling system was having an effect on the thermal diffusion from the ISV melt. Review of the thermocouple data (recorded on a chart recorder) indicated that the ISV 


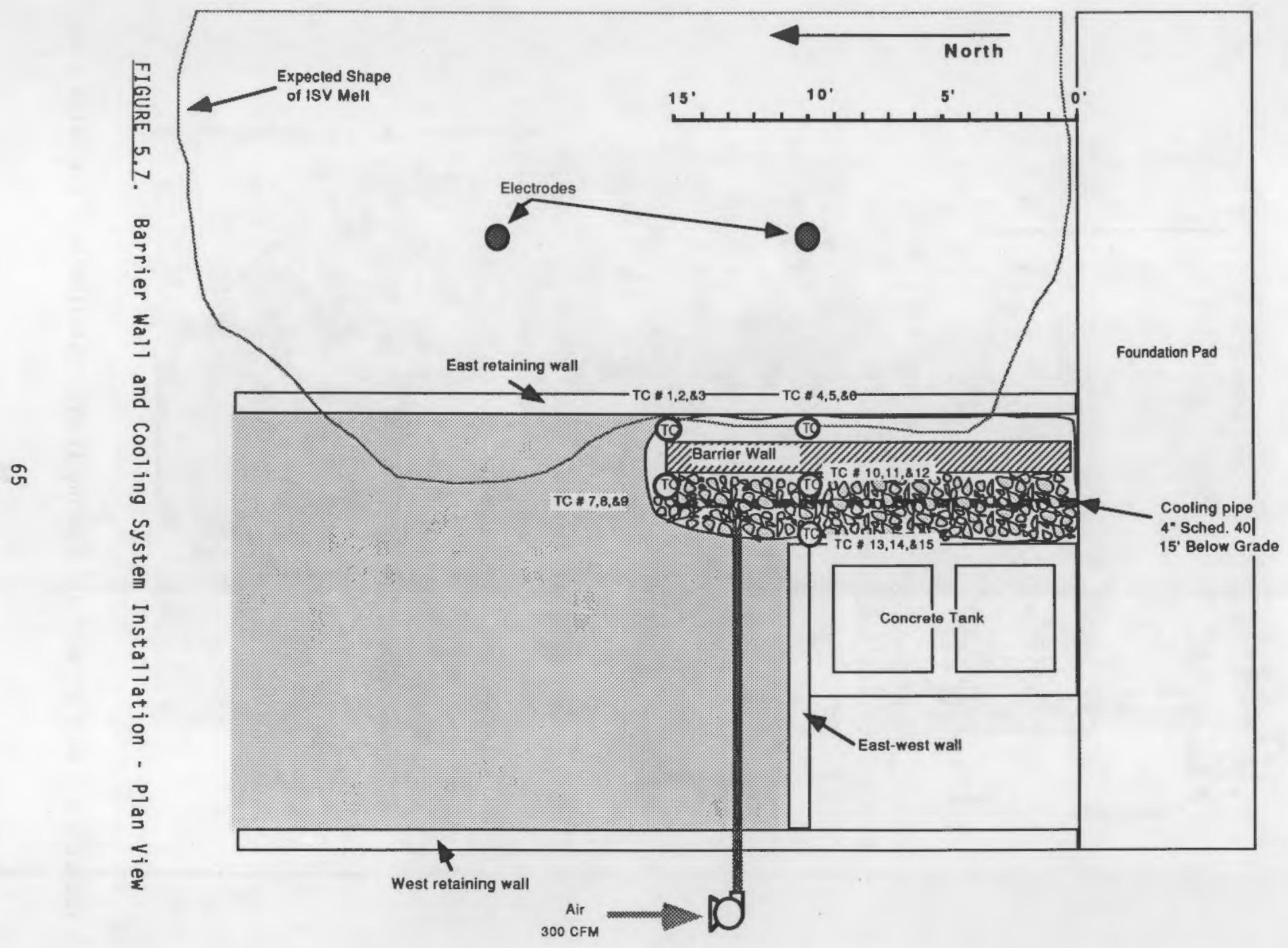




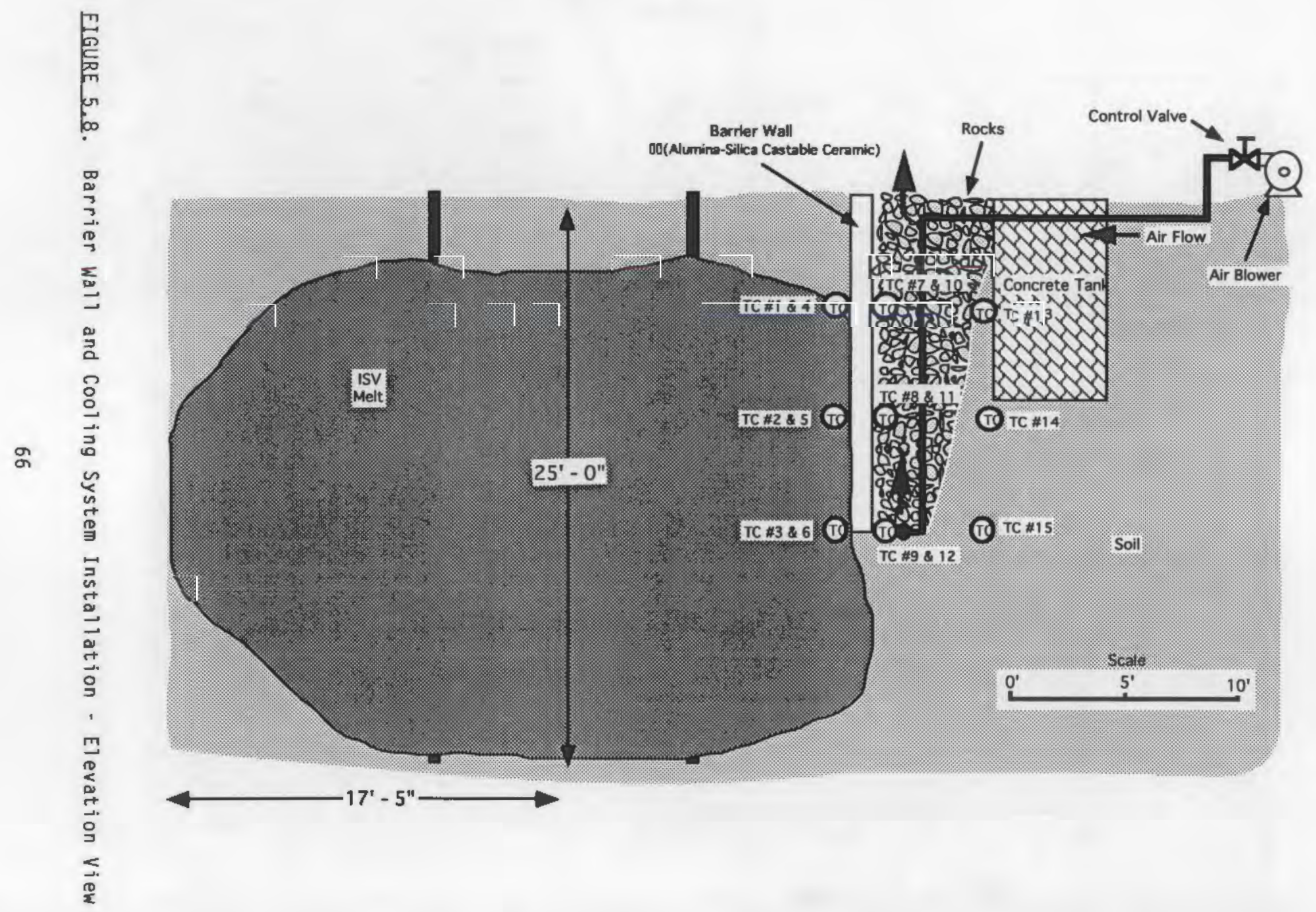


me1t did reach the barrier wall but did not cause a temperature increase to $200^{\circ} \mathrm{F}$ outside of the concrete tank (thermocouples 13.14. and 15 on Figure

5.8). Thermocouples placed on the rock side of the barrier wall indicated that the ISV melt may have penetrated the ceramic barrier in various locations. Confirmation of this hypothesis requires excavation of the rocks, an activity that is not planned. 


\subsection{REFERENCES}

Buelt, J. L., C. L. Timmerman, K. H. Oma, V. F. Fitzpatrick, and J. G. Carter. 1987. In Situ Vitrification of Transuranic Waste: An Update System Evaluation and Application Assessment. PNL-4800. Supplement 1. Pacific Northwest Laboratory, Richland, Washington.

Buelt, J. L.. and J. H. Westsik. 1988. "In Situ Vitrification - Preliminary Results from the First Large-Scale Radioactive Test." PNL-SA-15277. Presented at Waste Management ' 88 Conference, Tucson. Arizona.

Campbel1, B. E.. S. S. Koegler, R. S. Butner, and S. S. Tee1. 1990. Ireatability Investigation Work Plan for the 116-B-6A Crib Isv Demonstration Project. PNL-7284, Pacific Northwest Laboratory, Richland Washington.

Carslaw. H. S., and J. C. Jarger. 1959. Conduction of Heat in Solids. Second Edition. Oxford University Press, London.

Clukey, H. V. 1954. Iabulation of Radioactive Liquid Waste Disposal Facilities. HW-33305. General Electric Company, Richland, Washington.

Clukey, H. V. 1956. Tabulation of Radioactive Liquid Waste Disposal Facilities. HW-43121. General Electric Company. Richland, Washington.

Stanek. J. 1977. Electric Melting of Glass. Elsevier Scientific Publishing Company. Amsterdam. The Netherlands.

Touloukian, Y. S. and C. H. Ho. 1970. Thermophysical Properties of Matter. Thermophysical Properties Research Center (TPRL), Purdue University. West Lafayette, Indiana.

Trent, D. S., L. L. Eyler and M. J. Budden. 1985. A Three-Dimensional TimeDependent Computer Program for HydroThermal Analysis. Volume 1: Numerical Methods and Input Instructions. PNL-4348. Pacific Northwest Laboratory, Richland, Washington. 

APPENDIX $\mathrm{A}(\mathrm{a})$

100 AREA MONITORING WELLS, GEOLOGY, HYDROLOGY, AND WATER CHEMISTRY

(a) Adapted from Campbell et al. 1990. 


\section{A.1 MONITORING WELLS}

There are eight existing ground-water monitoring wells in the 100-B Area: 199-B3-1; 199-B3-2P.Q; 199-B-4-1; 199-B4-2; 199-B4-3; 199-B4-4; 199-B5-1; and 199-B9-1. All of these wells, except well 199-B3-2P,Q. monitor the upper portion of the unconfined aquifer. Well 199-B3-2 is composed of piezometers " $P$ " and " $Q$ " which monitor the base of the unconfined aquifer ( $Q$ ) and the upper confined aquifer $(P)$. The locations of these wells is shown in Figure A.1. The monitoring intervals of these wells are shown in Table A.1.

The wells are all constructed with 8-in carbon steel casing (except for well 199-B4-2 which is constructed with 6-in casing). Perforations in the casing allow water to enter the well from the aquifer. The 1.5 -in screened piezometer pipes were later installed in well 199-B3-2. Only one well. 199B3-2, penetrates deeper than $151 \mathrm{ft}$. This well was drilled to a $790 \mathrm{ft}$ depth and encountered basalt at a depth of $656 \mathrm{ft}$. The nearest existing well to the

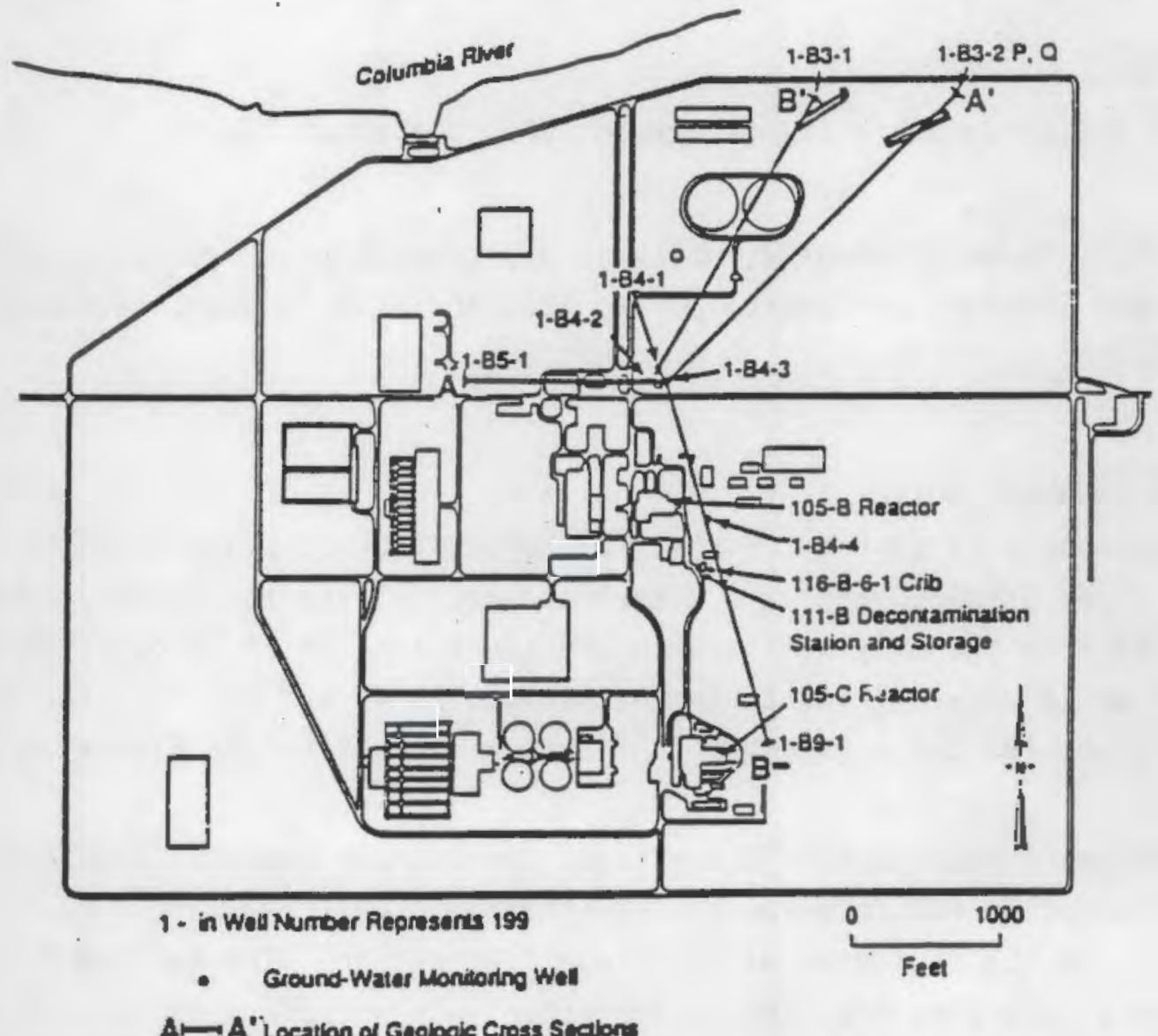

EIGURE A.1. Locations of Existing Wells in the 100-B Area and Locations of Geologic Cross Sections $A-A^{\prime}$ and $B-B^{\prime}$ 
IABLE A.1. Monitoring Intervals of Existing Wells, ft

\begin{tabular}{|c|c|c|c|c|}
\hline & Monitoring & Approx. Depth & Height of & Date \\
\hline Well No. & Interval & to Water & Water Column & Drilled \\
\hline $199-B 3-1$ & $20-60$ & 44 & 19 & $3 / 53$ \\
\hline $199-B 3-2 P$ & $758-778$ & 39 & 739 & $8 / 53$ \\
\hline $199-83-20$ & $632-642$ & 34 & 608 & $8 / 53$ \\
\hline $199-B 4-1$ & $50-90$ & 63 & 27 & $2 / 49$ \\
\hline $199-B 4-2$ & $62-86$ & 63 & 27 & $2 / 49$ \\
\hline $199-B 4-3$ & $60-86$ & 63 & 27 & $2 / 49$ \\
\hline $199-B 4-4$ & $49-102$ & 74 & 28 & $9 / 60$ \\
\hline $199-85-1$ & $40-100 \star$ & 57 & 43 & $8 / 62$ \\
\hline 199-B9-1 & $80-110$ & 97 & 13 & $7 / 52$ \\
\hline
\end{tabular}

* Drilled and screened to $151 \mathrm{ft}$. cement plug placed at $100 \mathrm{ft}$

116-B-6A crib is well 199-B4-4, which is approximately $350 \mathrm{ft}$ away. Wells 199-B9-1 and 199-B4-3 are approximately 1200 and $1250 \mathrm{ft}$ away, respectively. from the crib.

\section{A.2 SITE GEOLOGY}

The Hanford site geology consists of three distinct geologic units: the Columbia River Basalt Group. the Ringold Formation, and the Hanford formation. Well 199-B3-2 is the only well within the 100-B Area which encountered basalt: all other wells were drilled to depths between $63 \mathrm{ft}$ and $151 \mathrm{ft}$. Geologic cross sections for the area shown in Figure A.1 are given in Figures $A .2$ and A.3.

The Columbia River Basalt Group forms the bedrock beneath 100-B Area. It was encountered at $656 \mathrm{ft}$ below ground surface in well 199-83-2. Overlying the basalt are the sediments of the Ringold Formation. The Hanford formation unconformably overlies the Ringold Formation. An unconformity is an erosional surface which separates strata of different ages. Detailed textural and lithologic information would be necessary to accurately distinguish the 


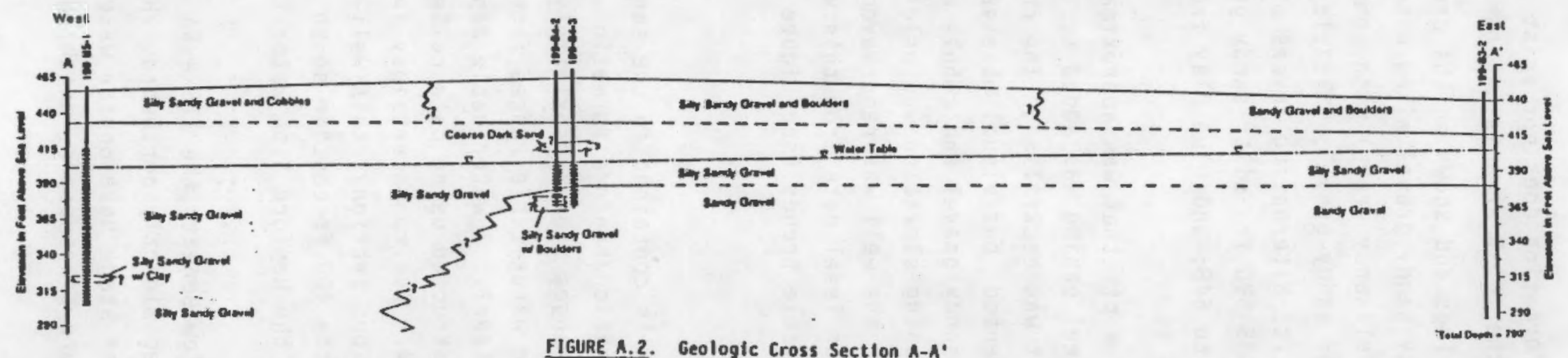

w
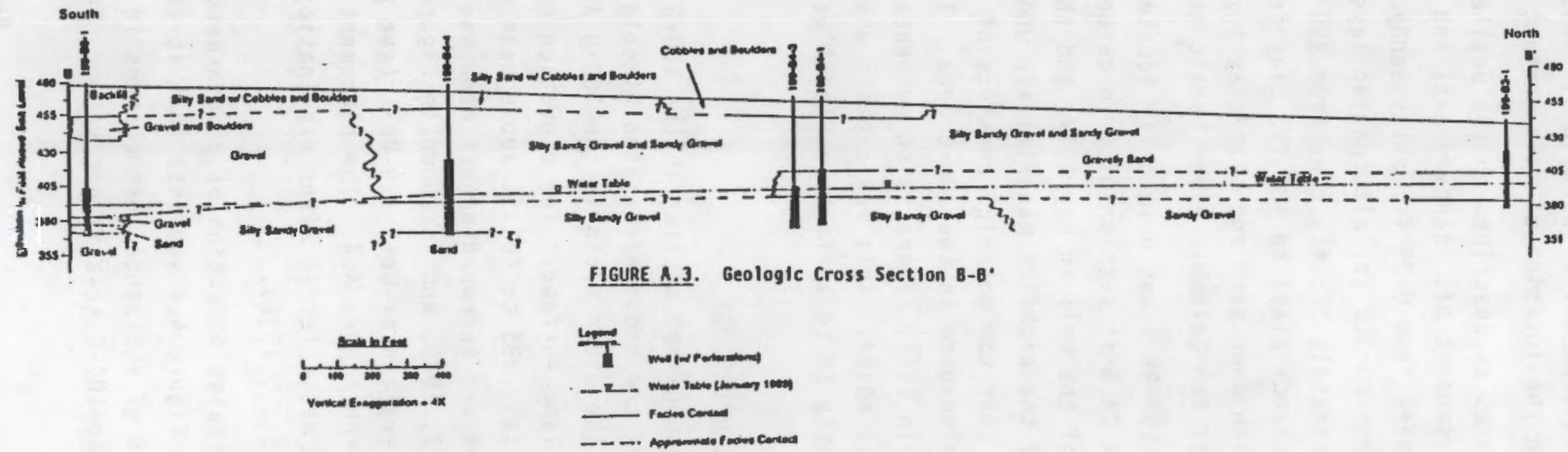
contact between these formations. This information does not exist, and therefore the location of this contact in the 100-B area is unknown.

Textures as described on the drillers' logs and shown on the cross sections consist of: sandy gravel and silty sandy gravel mixed with cobbles and boulders from $0-25 \mathrm{ft}$; silty sandy gravel/sandy gravel with some sand layers from 25-300 ft; alternating layers of sandy gravel. silt/clay, and sand to approximately $385 \mathrm{ft}$ : clay from 390-425 ft: alternating layers of sand and clay (or sandy clay) to $480 \mathrm{ft}$ : clay from 485-590 ft; silty sandy gravel/sandy gravel with some sand and silt/clay layers to 648; and blue clay from 648 to the top of the Columbia River basalt at $656 \mathrm{ft}$.

Well 199-B9-1 was originally located in a pit that was approximately $25 \mathrm{ft}$ deep. A 24.5-ft section of 8-in carbon steel casing was added to the upper portion of the well in May 1974, and the pit was backfilled. The characteristics of the backfill material are undocumented, but visual observations indicate that the material consists of the sandy gravel and cobble mixture present elsewhere in the 100-B Area. The casing elevation was originally surveyed in 1967. There is no evidence that the well was resurveyed after the casing was added. This may explain why water level data from this well are consistently 10 to $12 \mathrm{ft}$ below local water table trends (see Figure A.4).

\section{A.3 SITE HYDROLOGY}

The unconfined aquifer in the 100-B Area is contained in the sands and gravels of the undifferentiated Ringold Formation/Hanford formation. The depth to the water table in the 100-B Area ranges from approximately 41 to 93 $\mathrm{ft}$ below land surface. The elevation of the water table ranges from approximately 395 to $401 \mathrm{ft}$ above mean sea level. A water table map of the 100-B Area and surrounding 600 Area was constructed using data collected on February 7, 1989, and is shown in Figure A.4. Due to uncertainty in the casing elevation of well 199-B9-1 (see previous section), this well was omitted from Figure A.4. The placement of the $400 \mathrm{ft}$ contour south of well 699-63-90 was inferred after examination of the Hanford Site water-table map (Evans, et a1. 1988).

The precise direction of ground-water flow beneath the 116-B-6A crib is unknown. Figure A.4 suggests that it is predominantly northward. However, the extent of influence that changes in river stage have on the water table beneath the 100-B Area is not known. Pressure transducers, which measure 


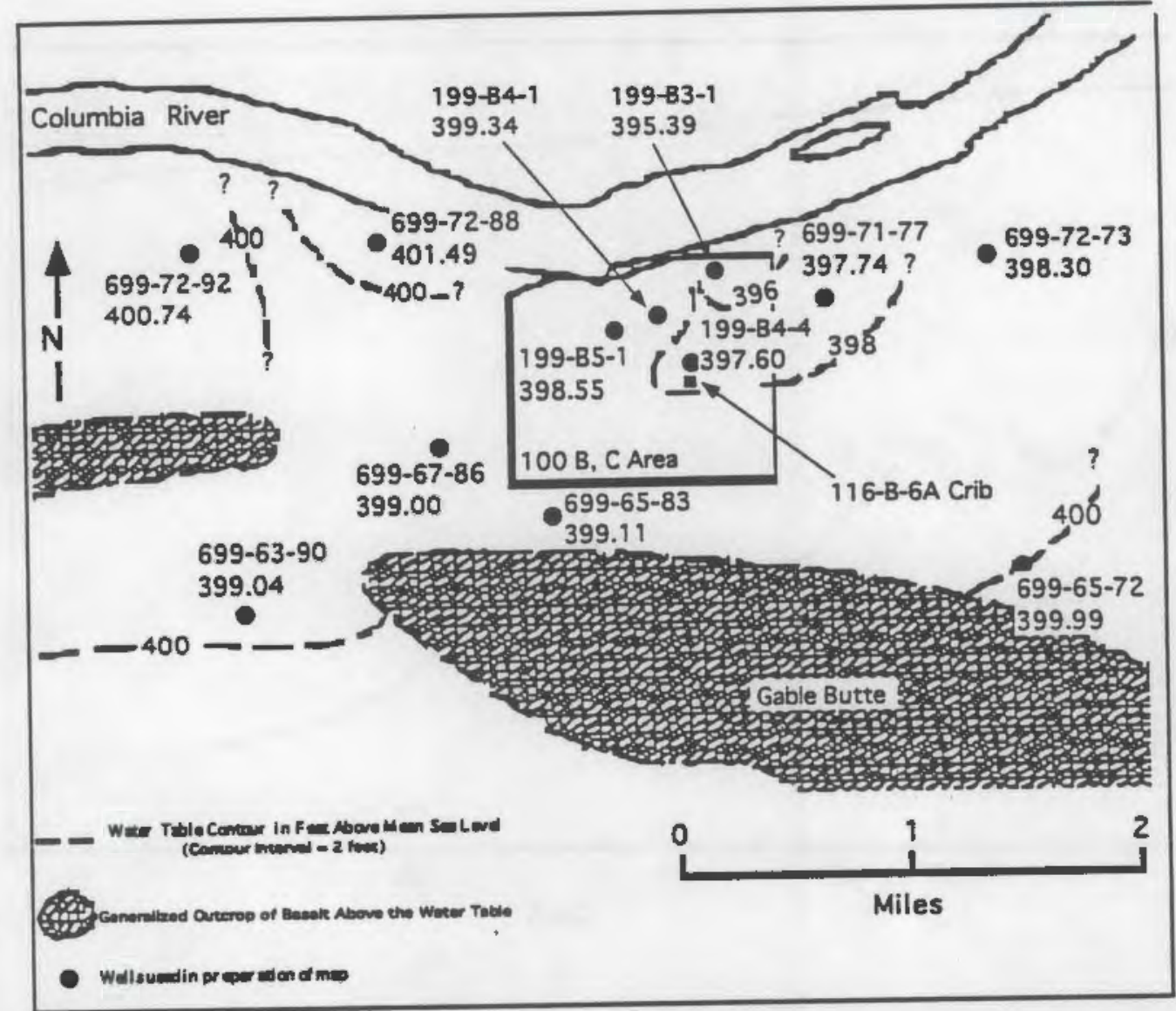

EIGURE A.4. Water Table Map of the 100-B Area Measured on February 7, 1989

changes in water level, have been installed in wells 199-B3-1 (the 100-B Area well closest to the river) and 199-B4-4 (the well closest to the crib). Data from these transducers is shown in Figure A.5. This figure demonstrates that well 199-84-4 is not affected by short-term river stage fluctuations. Therefore, there is no reason to believe that there will be any short term reversals of the regional ground water flow direction (ie, northward) due to changes in river stage in the vicinity of the 116-B-6A crib. Further hydrologic data collection will be done as part of the $100-B C-1$ RI/FS.

\section{A.4 WATER CHEMISTRY}

Table A.2 summarizes the water chemistry data in the 100-B Area for the past 5 years. As the table indicates (by the symbol *), most contaminants were found to be below detection limits. However, six constituents (as shown by the symbol 0 ), exceeded standards in samples taken during this period. 


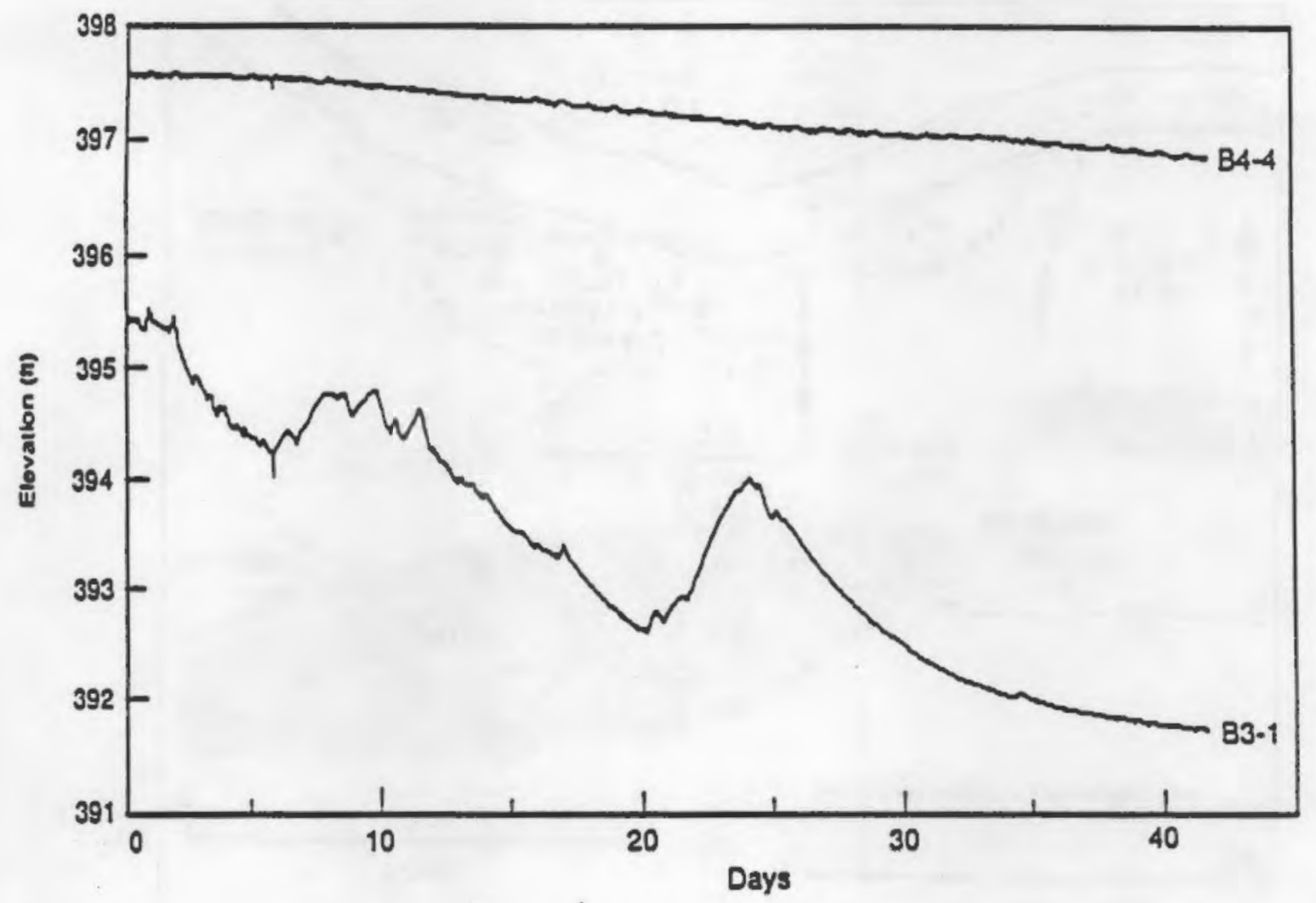

FIGURE A.5 Effect of River Stage (well 199-B3-1) on Aquifer Level as Measured at Well 199-B4-4

The National Interim Primary Drinking Water Regulations (40 CFR 141. July. 1987 as amended by 52 FR 25690) standards for these constituents were gross beta, $50 \mathrm{pCi} / \mathrm{L}$; strontium-90, $8 \mathrm{pCi} / \mathrm{L}$; tritium, $20,000 \mathrm{pCi} / \mathrm{L}$ : chromium,50 ppb: nitrate, $45,000 \mathrm{ppb}$ : and coliform bacteria, 1 count/100 ml MPN (most probable number). The table also gives statistical information including mean, median, maximum, and standard deviation for each constituent which was detectable. The well number at the maximum concentration was measured is also given.

- Gross beta values above the standard occurred in wells 199-B3-1, 199-B32. 199-B4-1, 199-B4-2, 199-B4-3, and 199-B4-4. (See Figure A.6.) The maximum concentration observed was $179 \mathrm{pCi} / \mathrm{L}$ in well 199-B3-1 (4/4/88).

- Strontium-90 values above the standard occurred in wells 199-B3-1, 199-B41. 199-B4-2, 199-B4-3, and 199-B4-4. The maximum concentration observed was $57.5 \mathrm{pCi} / \mathrm{L}$ in well 199-B3-1 (4/488). Values for well 199-B4-4 ranged from $31.0(7 / 30 / 87)$ to $35.4(10 / 19 / 87)$. 
- Tritium concentrations above the $20,000 \mathrm{pCi} / \mathrm{L}$ standard were exceeded in wells 199-B4-1 and 199-B4-3. The maximum concentration observed was $75.500 \mathrm{pCi} / \mathrm{L}$ in well $199-\mathrm{B} 4-1(1 / 12 / 87)$

- Chromium (filtered) was above the standard in one sampling event in one we11, 199-B3-1 (62 ppb, 5/21/87).

- Nitrate concentrations above the standard occurred in wells 199-B3-1, 199B4-1, 199-B4-2, and 199-B9-1. The maximum concentration observed was $73.000 \mathrm{ppb}$ in well 199-B3-1 (5/22/84).

- Two of the samples collected were analyzed for coliform bacteria: 199-B4$1(8 / 5 / 85)$ and $199-B 9-1$ (9/13/85). At least one of these samples was above the drinking water standard of $10 / 1$ MPN ( 40 CFR Part 141. July 1987). The values reported were $<30 / 1 \mathrm{MPN}$ and $40 / 1$ HPN, respectively. The contract required quantification limit (CROL) was $30 / 1$ MPN.

No volatile organic constituents were detected at any well, except possibly 199-B4-4, where a value of $2.4 \mathrm{ppb}$ of trichloroethylene (TCE) was reported on $7 / 30 / 87$. However. the CROL for this constituent was $10 \mathrm{ppb}$ at that time, and the reported value was less than the CRQL. That a result was reported indicates that the laboratory tentatively identified this constituent, but since the value is below the CRQL, the value cannot be confirmed. The maximum contaminant level (MCL) for this constituent is 5 ppb (52 FR 25690-717). 
Iable.A.2. Summary of Ground Water Samples Taken January 1, 1984 to December 31 , 1988 In the 100-B Area.

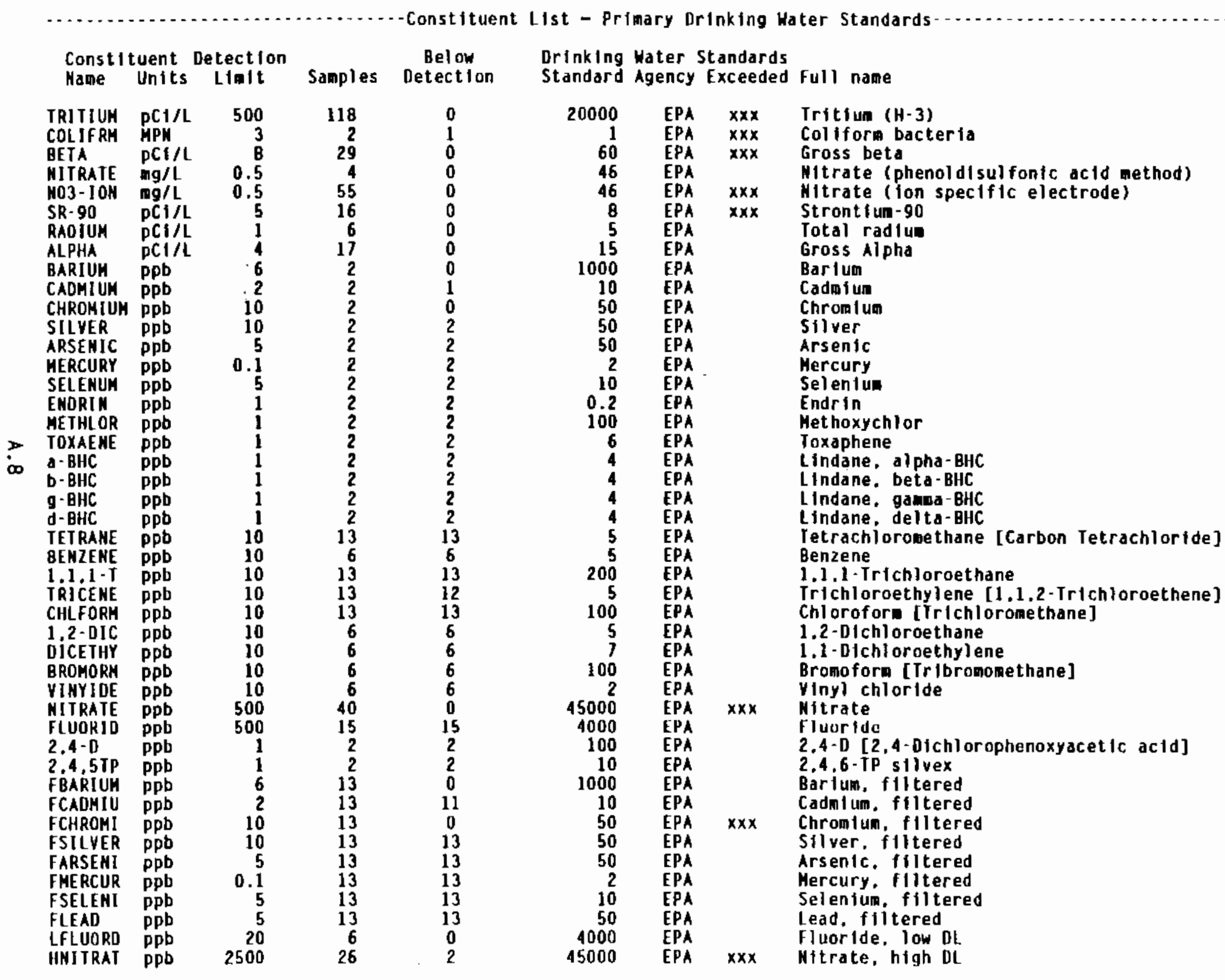


Iable A.2 (con'tl. Summary of Ground Water Samples Taken January 1. 1984 to December 31.1988 In the 100-B Area.

\begin{tabular}{|c|c|c|c|c|c|c|c|}
\hline \multicolumn{2}{|c|}{ Constituent } & $\begin{array}{l}\text { Detection } \\
\text { Liolt }\end{array}$ & Samples & $\begin{array}{l}\text { Below } \\
\text { Detection }\end{array}$ & \multicolumn{2}{|c|}{$\begin{array}{l}\text { Drinking Water Standards } \\
\text { Standard agency Exceeded }\end{array}$} & Full name \\
\hline $\begin{array}{l}\text { CONOFLD } \\
\text { PHFIELD } \\
\text { PH-LAB } \\
\text { TOX } \\
\text { TOC } \\
\text { TOXLDL }\end{array}$ & $\begin{array}{l}\text { ppb } \\
\text { ppb } \\
\text { ppb }\end{array}$ & $\begin{array}{r}1 \\
0.1 \\
0.01 \\
100 \\
1000 \\
20\end{array}$ & $\begin{array}{r}14 \\
13 \\
13 \\
2 \\
15 \\
13\end{array}$ & $\begin{array}{l}0 \\
0 \\
0 \\
0 \\
0 \\
7\end{array}$ & $\begin{array}{r}700 \\
8.5 \\
8.5 \\
. \\
.\end{array}$ & $\begin{array}{l}\text { HDOE } \\
\text { EPAS } \\
\text { EPAS }\end{array}$ & $\begin{array}{l}\text { Specif Ic conductance, field } \\
\text { pH. fleld } \\
\text { pH. Laboratory } \\
\text { Total organic halogen } \\
\text { Total organic carbon } \\
\text { Total organic halogens, low OL. }\end{array}$ \\
\hline $\begin{array}{c}\text { Constit } \\
\text { Nane }\end{array}$ & $\begin{array}{l}\text { uent } \\
\text { Untts }\end{array}$ & $\begin{array}{l}\text { Detection } \\
\text { Linit }\end{array}$ & Sauples & $\begin{array}{c}\text { Below } \\
\text { Detection }\end{array}$ & $\begin{array}{l}\text { ent List } \\
\text { Drinking } \\
\text { Standard }\end{array}$ & $\begin{array}{l}\text { - Qual Ity Charact } \\
\text { Hater Standards } \\
\text { Agency Exceeded }\end{array}$ & $\begin{array}{l}\text { teristics } \ldots \ldots \ldots \ldots \ldots \\
\text { Full nane }\end{array}$ \\
\hline $\begin{array}{l}\text { SOOIUH } \\
\text { MANGESE } \\
\text { IRON } \\
\text { PIIENOL } \\
\text { SULFATE } \\
\text { CHLORID } \\
\text { FSODIUH } \\
\text { FHAHGAN } \\
\text { FIRON }\end{array}$ & $\begin{array}{l}\mathrm{ppb} \\
\mathrm{ppb} \\
\mathrm{ppb} \\
\mathrm{ppb} \\
\mathrm{ppb} \\
\mathrm{ppb} \\
\mathrm{ppb} \\
\mathrm{ppb} \\
\mathrm{ppb}\end{array}$ & $\begin{array}{r}200 \\
5 \\
50 \\
10 \\
500 \\
500 \\
200 \\
5 \\
50\end{array}$ & $\begin{array}{r}2 \\
2 \\
2 \\
8 \\
16 \\
16 \\
13 \\
13 \\
13\end{array}$ & $\begin{array}{l}0 \\
1 \\
1 \\
0 \\
0 \\
0 \\
0 \\
9 \\
12\end{array}$ & $\begin{array}{r}5 \dot{5} \\
300 \\
25000 \dot{0} \\
250000 \\
5 \dot{0} \\
300\end{array}$ & $\begin{array}{l}\text { EPAS } \\
\text { EPAS } \\
\text { EPAS } \\
\text { EPAS } \\
\text { EPAS } \\
\text { EPAS }\end{array}$ & $\begin{array}{l}\text { Sodiua } \\
\text { Hanganese } \\
\text { Iron } \\
\text { Phenol } \\
\text { Sulfate } \\
\text { Chlorlde } \\
\text { Sodfun, filtered } \\
\text { Hanganese. filtered } \\
\text { lron, filtered }\end{array}$ \\
\hline \multicolumn{2}{|c|}{$\begin{array}{l}\text { Const } 1 \text { tuent } \\
\text { Hane Units }\end{array}$} & $\begin{array}{l}\text { Detection } \\
\text { Linit }\end{array}$ & Samples & $\begin{array}{c}\text { Below } \\
\text { Detection }\end{array}$ & $\begin{array}{l}\text { Drinking } \\
\text { Standard }\end{array}$ & $\begin{array}{l}\text { Hater Standards } \\
\text { Agency Exceeded }\end{array}$ & Full name \\
\hline $\begin{array}{l}\text { C0.60 } \\
\text { CS-137 } \\
\text { RU-108 } \\
U \\
\text { TC-99 } \\
\text { LEAD } \\
\text { NICKEL } \\
\text { COPPER } \\
\text { VAHADUH } \\
\text { AHTIOHY } \\
\text { ALUHNUH } \\
\text { POTASUH } \\
\text { DIOXAHE } \\
\text { METHONE } \\
\text { PYRIDJH } \\
\text { TOLUENE } \\
1,1.2-T \\
\text { PERCENE } \\
\text { OPXYLE }\end{array}$ & $\begin{array}{l}\mathrm{pC1} 1 / \mathrm{L} \\
\mathrm{p} C 1 / \mathrm{L} \\
\mathrm{pC1} / \mathrm{L} \\
\mathrm{pC1/L} \\
\mathrm{pC1/L} \\
\mathrm{ppb} \\
\mathrm{ppb} \\
\mathrm{ppb} \\
\mathrm{ppb} \\
\mathrm{ppb} \\
\mathrm{ppb} \\
\mathrm{ppb} \\
\mathrm{ppb} \\
\mathrm{ppb} \\
\mathrm{ppb} \\
\mathrm{ppb} \\
\mathrm{ppb} \\
\mathrm{ppb} \\
\mathrm{ppb}\end{array}$ & $\begin{array}{r}22.5 \\
20 \\
172.5 \\
0.5 \\
15 \\
30 \\
10 \\
10 \\
5 \\
100 \\
150 \\
100 \\
500 \\
10 \\
500 \\
10 \\
10 \\
10 \\
10\end{array}$ & $\begin{array}{r}44 \\
37 \\
37 \\
12 \\
9 \\
2 \\
2 \\
2 \\
2 \\
2 \\
2 \\
2 \\
6 \\
13 \\
6 \\
6 \\
13 \\
13 \\
13\end{array}$ & 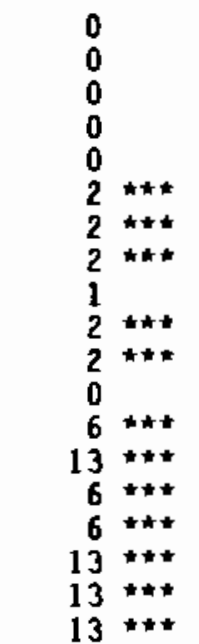 & 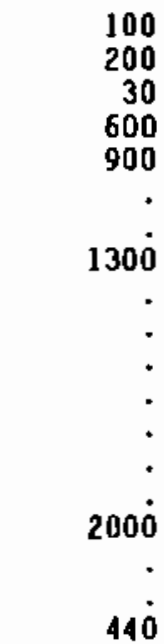 & $\begin{array}{l}\text { EPAR } \\
\text { EPAR } \\
\text { EPAR } \\
\text { DOE } \\
\text { EPAR } \\
\text { EPAP }\end{array}$ & 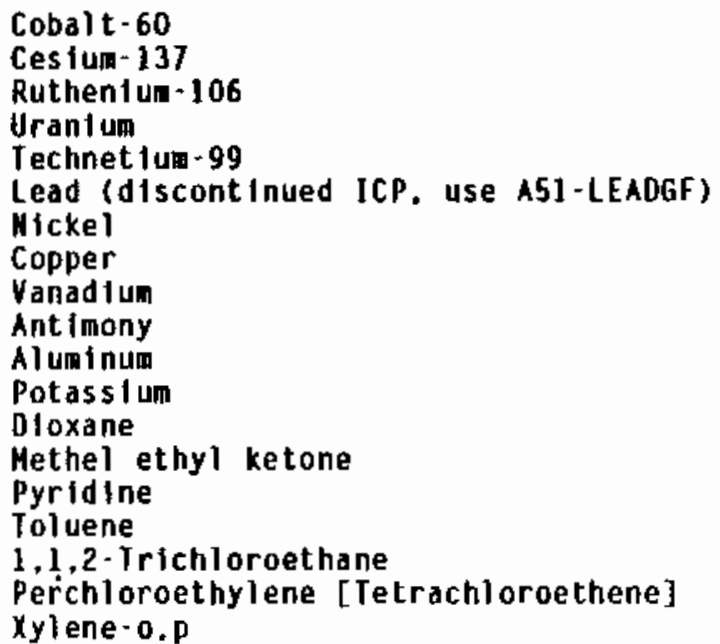 \\
\hline
\end{tabular}


IABLE A.2 (Con't). Summary of Ground Water Samples Taken January 1. 1984 to December 31 . 1988 1n the 100-B Area.

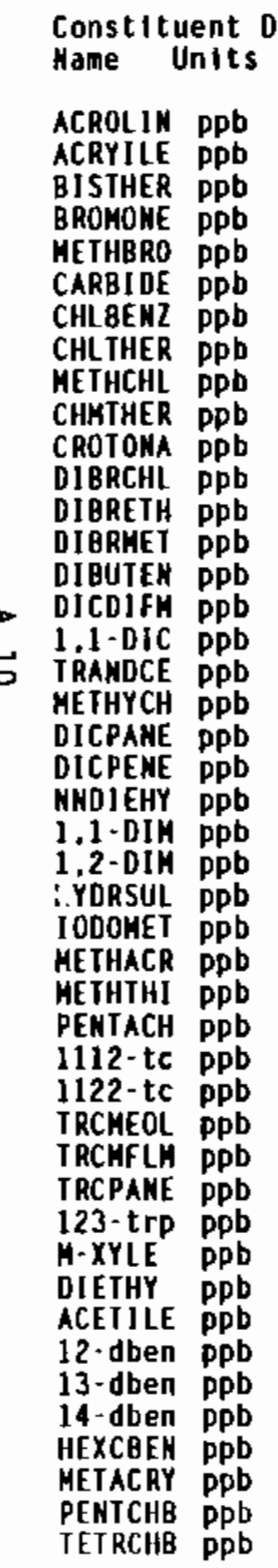

\section{Samples}

10
10
10
10
10
10
10
10
10
10
10
10
10
10
10
10
10
10
10
10
10
10
3000
3000
10
10
10
10
10
10
10
10
10
10
10
10
10
300
10
10
10
10
10
10
10

Below Detection

$6 * * *$

6

$6 \pm \pm$

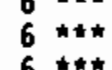

6 t**

6 t**

$6 \pm$

$6 * \star \star$

$6 \neq t$

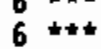

$6 \hbar \star \star$

$6 \star * t$

$6 \pm+4$

6 *t*

6 tak

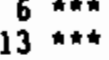

6 *t*

$6 * \pi *$

6 titk

$4 * \pi$

$4 * * *$

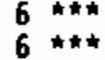

$6 \pm \pm$

$6+\hbar \star$

$6 * \pi *$

$6 * \hbar *$

6 ***

$6 * \pm$

6 **

6 tht

6 t*

$13 * \star \star$

6 *t*

8 kะ

$B+t$

$8 * \star *$

$8 * \pm *$

$6 * t+$

$8 * n *$

$8 \neq * *$
Drinking Water Standards

Standard Agency Exceeded full name

Acrolein

Acrylonitrile

Bis(chloronethyl) ether

Bromoacetone

Methyl bromide

Carbon disulfide

Chlorobenzene

2-Chloroethvi vinyl ether

Methyl chlorlde [Chloromethane]

Chloromethyl nethyl ether

Crotonal dehyde

1.2-01brono-3-chloropropane

1,2-Dibronoethane

Dibromonethane

1.4-0ichloro-2-butene

Dichlorodifluoronothane

1,1-Dichloroethane

trans-1,2-Dichloroethene

Methylene chloride [Dichloronethane]

1.2-Dichloropropane

1.3-Dichloropropene

M.N-diethylhvdrazine

1.1-D1methylhydrazine

1.2-Dimethylhydrazine

HYdrogen sulfide

Iodome thane

Methacrylonitrile

Methanethiol

Pentachloroethane

1.1.1.2-Tetrachl orethane

1,1.2,2-Tetrachlorethane

Irichl or onethanethiol

Irlchloromonofluoromethane

Irichloropropane

1,2.3-Trichloropropane

Xylene-a

Diethylars ine

Acetonitrile

1,2-D1chlorobenzene

1,3-D1chlorobenzene

1,4-Dichlorobenzene

Hexach lorobenzene

Methyl methacrylate

Pentachlorobenzene

1.2.4,6-Tetrachl orobenzene 
IABLE A.2 (Con't). Summary of Ground Water Samples Taken January 1, 1984 to December 31 . 198B in the 100-B Area.

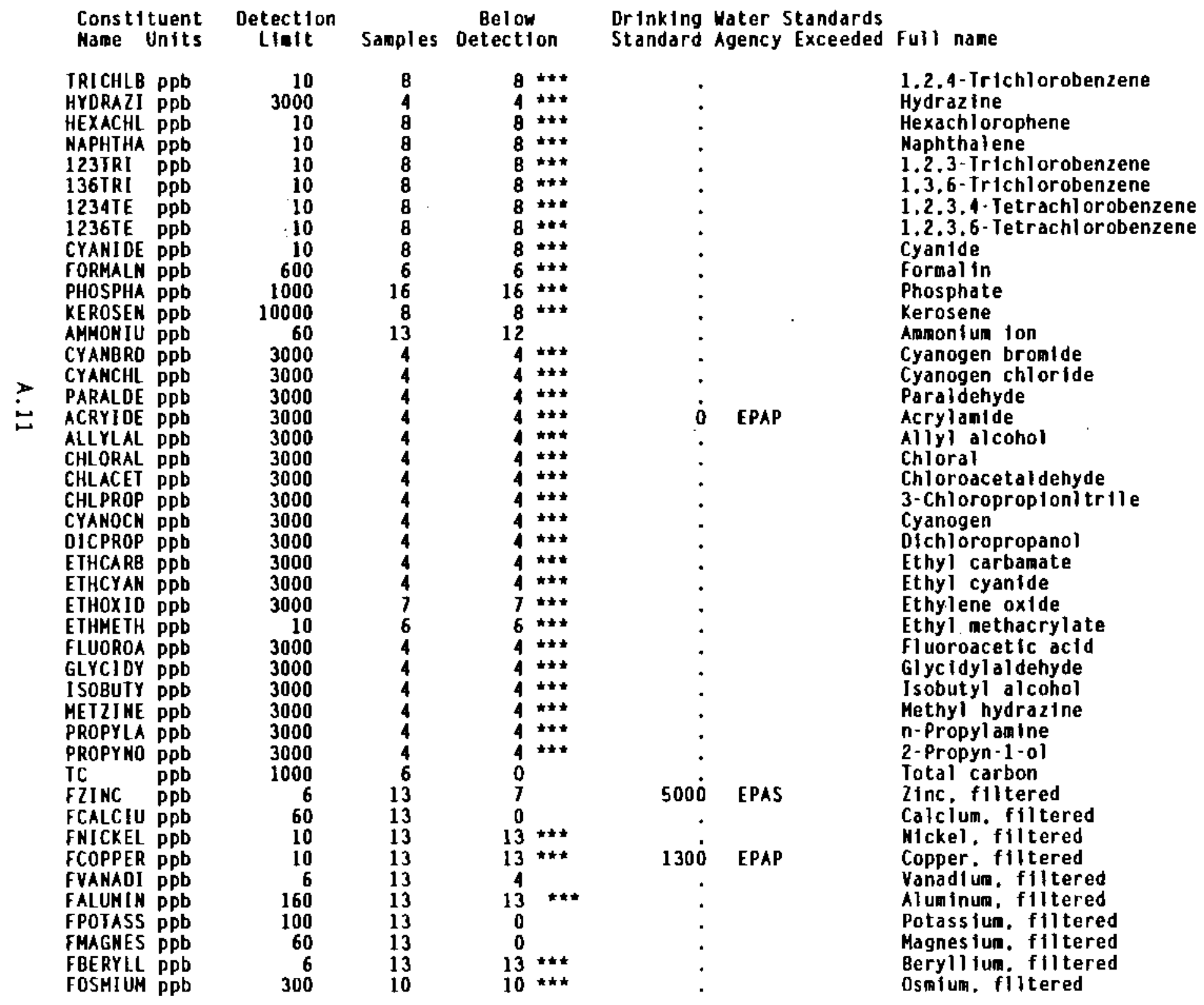


IABLE A.2 (COn't). Summary of Ground Water Samples Taken January 1. 1984 to December 31 . 1988 in the $100-\theta$ Area.

- Const 1tuent LIst - other Const1tuents

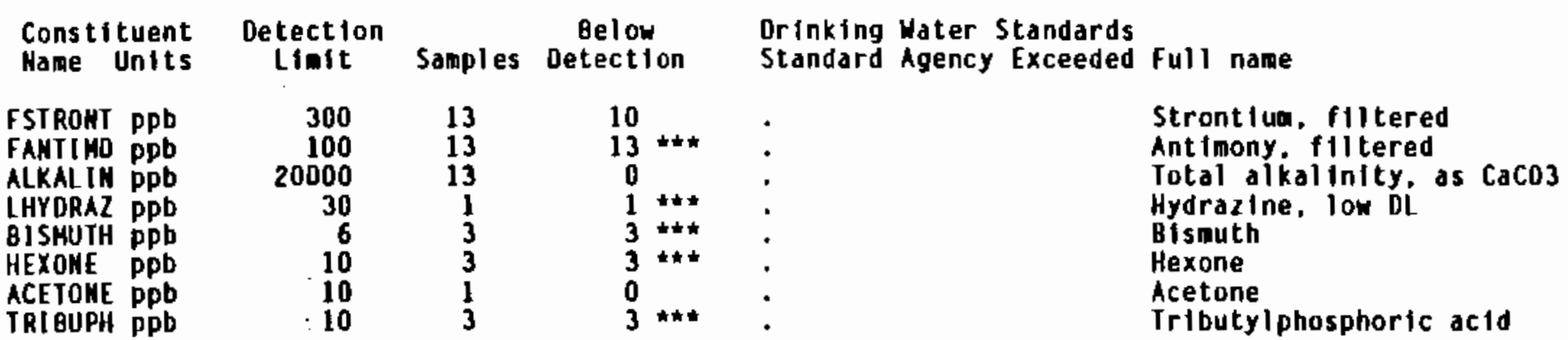

t** - Indicates all sanples were reported as belowe contractual detection lialts

$x x x$ - Indicates that Drinking Water Standards were exceeded

EPA - Based on Haxisum Contaninant Levels given in 40 CFR Part 141 (July. 1987)

Mational Primary Drinking Hater Regulations as anended by 52 FR 25690

EPAR - Based on Hational Interin Primary Drinking Hater Regulations.

Append IX IV. EPA-570/9-76-003

EPAS - Based on Secondary Maxinue Contaninant Levels given in 40 CFR Part 143

$\sim \sim \sim$ National Secondary Drinking Water Regulations

HDOE - Based on additional Seconoary Haximun Contaninant Levels given in HAC 248-54. Public Mater Supplies 
APPENDIX B

EVALUATION OF FACTORS THAT MAY INFLUENCE MELT DEPTH AND SHAPE 
APPENDIX 8

\section{EVALUATION OF FACTORS THAT MAY INFLUENCE MELT DEPTH AND SHAPE}

Results from core drilling of the vitrified glass and crystaliine product from a 1987 large-scale test of In Situ Vitrification (ISV) showed that insufficient depth and extensive lateral growth was obtained. As a result of this observation. a task force was convened to determine the causes of lateral growth and decreased downward growth. The findings of the task force in regard to postulating and identifying the cause of lateral growth of the ISV block are discussed here.

Based on evaluations conducted by the task force, it was determined that numerous factors can contribute to lateral growth of the vitrified product. However. the cause for insufficient depth during the 1987 test was attributed primarily to the presence of an artificial rock layer near the bottom of the setting. Although not primary contributors during the 1987 large-scale test. the following factors have the potential to contribute to lateral growth of an ISV block:

- heterogenous layers of higher melting soil or sludge compositions.

- scale-up effects.

- use of graphite collars.

- presence of a permeable water recharge layer, and

- broken electrodes.

The task force aiso determined that the following factors have no potential for creating a lateral growth effect:

- differences in thermal conductivity of varying soil or rock layers.

- presence of disturbed, noncompacted soil.

- effects of downtime during an operation. and

- suspension of particles in the glass during processing.

A1 1 of these potential factors have been evaluated and determined not to have had an influence on melt shape during the 1987 large-scale test. In addition. these factors were considered and found not to have had an influence during the 116-B-6A Crib ISV Dmeonstration.

The follow sections discuss each of the postulated factors identified by the task force. 


\section{PARTICLE SIZE EFFECTS}

The ISV process has been observed routinely to melt into soil heavily laden with large stones and gravel. Electrical energy is converted to heat. which accumulates in the melt. The temperature rises until the melting rate proceeds fast enough to consume the heat as fast as it is generated. This result is attained irrespective of the loading of stones or gravel because an equilibrium must ensue between the rate of heat generation, the rate of consumption (by melting) of heat, and the rate of heat loss to the surrounding soil and off gas hood (through the meit top surface).

However, the large-scale radioactive test conducted in 1987 at Hanford had the unexpected result of the downward melting process being impeded at a layer of large gravel (on the order of $2.5 \mathrm{~cm}$ dia.). At the same time. the process continued to melt laterally into the sandy soil above the gravel. This evaluation of particle size effects concludes that the unexpected behavior is not simply because of the presence of gravel or stones in soil, but instead the presence of discrete heterogeneous layers of sand and gravel.

The ISV process involves heat transfer from an electrically heated molten region to a surrounding shell of unmelted particles. As a layer of these particles is incorporated into the melt, the melt can move to the next layer of particles. The melting rate is then the product of the frequency at which particles are incorporated into the melt and the distance moved at each step. which is the diameter of a particle. The frequency of incorporating particles is the reciprocal of the time required to incorporate a particle into the melt. Incorporating a particle into the melt is assumed to increase the particle's temperature to the point that it is fluid enough to allow convective motion to extend through it and to the next particle to be heated. Also, some particles become hot enough to undergo density changes, allowing such particles to be removed by floating to the surface.

A very crude idea of the effect of particle size can be developed by combining the effect of particle size on the time to melt (or float) particies with the effect on the melting rate for a given particle melting time. The time for the average temperature of a spherical particle to change from an initial value to some temperature that is imposed suddenty over its surface is on the order of $R^{2} / \alpha$, where $\alpha$ is the thermal diffusivity of the particle and $R$ is the particle radius. The thickness of soil added to the melt by melting a particle is on the order of $2 R$. Hence, the melting rate expressed as the velocity of the advancing melting front is $(2 R) /\left(R^{2} / \alpha\right)$, which is proportional 
to $1 / R$. Therefore, if the temperature applied at the surface of particle does not depend on the particle size, the melting rate should be roughly inversely proportional to the particle size.

This relationship illustrates that the particle size is expected to affect the melting rate for a given temperature in the melt. However, if the particle size is uniform over the boundary of the melt, ultimately the effect of a large particle size is to increase the temperature of the melt so that the melting rate balances the rate of generation of heat in the melt. In order to estimate the effect of particle size on the temperature of the melt. or to estimate the consequences of a melt contacting different particle sizes simultaneously, a more complete analysis is required.

The following model of the processes in the melt boundary is used to develop a relationship between the temperature at the boundary of the melt. $T_{i}$, and the melting rate expressed as the advancing velocity of the melt boundary, V. For the sake of simplicity. we ignore the heat of vaporization of water. We assume that molten glass at a temperature $T_{\mathfrak{j}}$ contacts and envelops a layer of spherical particles, instantly raising the temperature at the surface of the particles to $T_{i}$, and begins to heat the particles by spherically symmetric conduction within the particles. The boundary of the melt receives heat from the mixed molten glass at temperature $T_{g}$ and transfers it to the particles at a lower temperature $T_{j}$, with the rate of heat transfer being proportional to a heat transfer coefficient in the melt, $h_{g}$, and to the temperature difference $T_{g}-T_{\mathfrak{j}}$. Simultaneously, the melt heats the next layer of particles at a rate in proportion to a contact heat transfer coefficient. $h_{c}$. and with the temperature difference $T_{f}-T_{c}$, where $T_{c}$ is the temperature of the particies just beyond those enveloped by the melt.

Particles beyond the plane of contact are assumed to be part of a homogeneous and continuous earth, ranging in temperature from $T_{a}$ far from the melt to $T_{c}$ at the plane of contact.

Finally, we assume that a particle becomes fluid suddenly when its average temperature becomes $T_{m}$. a melting temperature. We assume that at that point the volume of the particle mixes instantly with the melt enveloping it. and its temperature rises from $T_{m}$ to $T_{j}$ as the fluid particle at the interface 
receives heat from the mixed molten glass. As heating occurs, the average temperature in the particles is described by

$$
\left(T-T_{0}\right) /\left(T_{1}-T_{0}\right)-\phi .
$$

where $T_{0}$ is the temperature of the particle at the moment it is enveloped by the melt, and $\phi$ is a function of timea. Since it's assumed that prior to this moment the particle was at the plane of contact with the melt, its initial temperature is assumed to be Tc. Hence, $T_{0}-T_{C}$. The function $\phi$ is of the form $\phi-\phi(y)$, where $y-\sqrt{ }\left(\alpha_{p} t / a^{2}\right)$ and $\alpha_{p}-k_{p} / \rho C_{p}$. where $\alpha_{p}$ and $k_{p}$ are the thermal diffusivity and thermal conductivity. respectively. of the particle (which is assumed to have the same $p$ and $C_{p}$ as the melt), $t$ is the time the particle is contacted by the melt, and a is the radius of the particle. The function $\phi$ is such that if $y\langle<1 / K$, then $\phi=k y$, where $k-6 / \mathrm{J}$. and if $y>$ $1 / k$, then $\phi \approx 1$.

The time for the average temperature of the particle to reach $T_{m}$ is the time required to incorporate the particle into the melt. If the melt is advancing at velocity $V$ and the diameter of the particie is $\delta$. then this time is $\delta / V$. Therefore. since a $-\delta / 2$. then $y-V\left(2 \alpha_{p} / V \delta\right)$. The value of $y$ causing the particle to become fluid is then found from

$$
\left(T_{m}-T_{c}\right) /\left(T_{i}-T_{c}\right)=\phi(y) .
$$

The term $y$ depends on $V$. and $\phi$ depends on $y$, so the temperatures $T_{c}$ and $T_{j}$ depend on $V$ as well as on $T_{a}$ and $\rho C_{p}$. Conversely, $V$ is a function of $\delta, T_{i}$. $T_{m} . T_{a} \cdot p C_{p} \cdot h_{c}$, and $h_{g}$. The temperature $T_{g}$ must adjust to cause the power consumed by the melting process to match the electrical power provided.

The effect of particle size can be estimated apart from any effect of natural convection heat transfer if one assumes no heat transfer resistance between the center and boundary of the melt. Then $T_{g}-T_{1}$. The remaining heat transfer coefficient. $h_{c}$. can be made dimensionless in the form $h_{c} \delta / k_{p}$.

(a) See Equations A.14 - A.16, which follow under "Detailed Analysis of Particle Size Effect." 
where $k_{p}$ is the thermal conductivity of the particles of diameter $\delta$; this form is termed a "Biot number". It can be shown(a) that the Biot number is on the order of 1 , so it is treated as a constant. The heat flux at the melting interface. $q_{1}$, can be made dimensionless in the form $q^{\prime}=q_{i} \delta / k_{p}\left(T_{m}-T_{a}\right)$, where $\delta$ is the diameter of the particles, $k_{p}$ is the thermal conductivity of the particles. $T_{m}$ is the melting temperature and $T_{a}$ is the ambient temperature far from the melt. The melting rate can be made dimensionless in the form $V *$ $v \delta / \alpha$, where $v$ is the melting velocity and $\alpha$ is the thermal diffusivity of the particles. Finally, the interface temperature $T_{\mathfrak{j}}$ can be made dimensionless in the form $\beta-\left(T_{j}-T_{m}\right) /\left(T_{m}-T_{a}\right)$.

If the heat $f 1$ ux is small enough that $q^{\circ} \ll 1$, then from an asymptotic analysis(b) one finds that $q^{*}=V^{\star} \approx \beta / 2$. This means that as $q^{\prime}$ and $v^{*}$ become small, then the interface temperature becomes the melting temperature. Since both $q^{*}$ and $V *$ are proportional to $\delta$. this condition is approached as either the melting rate or the particle size decreases.

If the melting rate is large enough that $\gamma * \gg 72 / \pi$, then $(1+\beta) \approx$ $\left(q^{*} / 2 K^{2}\right)^{1 / 3}$ and $V^{*}=2 K^{2}(1+\beta)^{2}$. For this case the interface temperature is greater than the melting temperature and, since $q^{\circ}$ is proportional to $\delta$, depends on the particle size.

A typical value for $q^{*}$ can be estimated given an estimate of $k_{p}\left(T_{m}{ }^{-}\right.$ $\left.T_{a}\right) / \delta$, which we denote as $q_{m}$ ( $i . e . . q^{\prime}=q_{i} / q_{i}$ ). We assume the thermal conductivity and specific heat of the particles are the same as for the glass. $1 \mathrm{~W} / \mathrm{m}^{\circ} \mathrm{C}$ and $1088 \mathrm{~J} / \mathrm{Kg}^{\circ} \mathrm{C}$, respectively. and that the melting temperature is $\mathrm{T}_{\mathrm{m}}$ $=1200^{\circ} \mathrm{C}$. Then for $1-\mathrm{mm}$ particles (sandy $50 i \mathrm{l}$ ), $q_{\mathrm{m}}=1.2 \times 106 \mathrm{~W} / \mathrm{m}^{2}$, and for $2.5-\mathrm{cm}\left(1-i n\right.$.) particles (stones). $q_{m}-4.7 \times 10^{4} \mathrm{~W} / \mathrm{m}^{2}$.

Taking the characteristic power for a large-scale ISV application as 3.5 MW and the area of the boundary of the melt as five faces (four sides and bottom) of a cube with an edge the length of the electrode spacing, which is taken to be $3.5 \mathrm{~m}$. then $q=3.5 \times 10^{6} /\left[5(3.5)^{2}\right]-5.7 \times 10^{4} \mathrm{~W} / \mathrm{m}^{2}$. Hence, values of $q^{\prime}=q_{i} / q_{m}$ are .05 for $1-m m$ particles and 1.2 for $2.5-c m$ particles. Hence. it appears that $q^{\circ} \ll 1$ for "soit," while $q^{\prime} \approx 1$ for "stones." Therefore. we

(a) See text following Equation A.25.

(b) See text accompanying Equation A.26. 
expect that the interface temperature will be the melting temperature when melting only soil. but, if melting only stones, that the interface temperature will exceed the melting temperature and depend non-linearly on the flux and the size of the stones.

Now we can consider the case where the ISV melt simultaneously includes two boundaries with different values of the convective heat transfer coefficient, $h_{g}$, and the contact heat transfer coefficient. $h_{c}$. If the dimensionless heat $f 1 u x q^{*}$ is small enough and the value of the contact heat transfer coefficient $h_{c}$ is large enough at both boundaries, as would be expected for small particles, then the ratio of melting rate at boundaries " 1 " and $" 2 "$ will be controlled by the $h_{g}$ values: $V_{2} / V_{1}=h_{g 2} / h_{g 1}$.

On the other hand, suppose that, as melting proceeds, boundary "2" involves large particles of size. $\delta_{2}$. Assume that $\delta_{2}$ is large enough that the dimensionless heat flux $q^{\prime}$ at boundary 2 depends on $\delta_{2}$. Suppose further that the ISV melt has just begun to contact the larger particles and that the melt is not particularly flattened. Then $h_{g 1}$ and $h_{g 2}$ should be commensurate, and for the sake of simplicity we assume they are both equal to a nominal value, $h_{g}$.

The ratio of melting rates is given by $V_{2} / V_{1}-q_{2} / q_{1}$ which is estimated(a) to be

$$
V_{2} / V_{1} \rightarrow q^{\star 2} /\left[q^{\star 2}+1\right]
$$

where $q^{*}$ is a dimensionless term that is proportional to $\delta_{2}-1 / 2$. As $B_{g}$ becomes large, then asymptotically the ratio of melting rates becomes inversely proportional to $\delta_{2}$.

Using the rough estimate obtained from the "Dimensional Analys is of Convective Currents" section of this appendix. $h_{g}=140 \mathrm{~W} / \mathrm{m}^{2}{ }^{\circ} \mathrm{C}$. and noting that if $\delta-1 \mathrm{in}$. $(0.0254 \mathrm{~m})$, and using $k_{p}-1 \mathrm{w} / \mathrm{m}^{\circ} \mathrm{C}$, then $h_{g} \delta_{2} / k_{p}-B_{g}=3.56$. This value is not large enough to justify use of an asymptotic analysis for large $\delta_{2}$. It does suggest, however, that this asymptotic analysis is more

(a) See text preceding Equation A.47. 
accurate than assuming that $\delta_{2}$ is very small. Therefore, it is instructive to draw inferences from the asymptotic analysis for large $\delta_{2}$. Also, as is discussed above, for $\delta=1 \mathrm{in}$, we find $q^{\circ} \approx 1$. This also does not satisfy the condition $q^{\prime} \gg 2 K^{2}=72 / \pi=22.92$. However. since it is also not true that $q^{\prime} \ll<1$, we can expect the asymptotic approximation of the effect of particle size on the ratio of melting rates to provide a rough idea of the behavior of the melt. To do this requires a computation of the term(a)

$$
q / q_{g}=\left(5.7 \times 10^{4} \mathrm{~W} / \mathrm{m}^{2}\right) /\left[\left(140 \mathrm{~W} / \mathrm{m}^{2} \mathrm{C}\right)\left(1200^{\circ} \mathrm{C}\right)\right]-0.34
$$

where $q$ is the average heat $f l u x$ over the entire boundary (known from the rate of power generation). and $q_{g} \equiv h_{g 2}\left(T_{m}-T_{a}\right)$ where $h_{g 2}$ is the heat transfer coefficient in the melt adjacent to boundary " 2 ." which is in contact with the larger particles of diameter $\delta_{2}$. This computation is used to calculate a term $q^{*} \equiv\left(q / q_{g}\right) / \Gamma l / 3 \sqrt{ } B_{g}$. where $\Gamma$ is the fraction of the boundary area contacting small particles. The value of $\Gamma$ is $4 / 5$ if we consider the ISv melt to be a cube with the four sides contacting small particles, the bottom contacting large particles, and no melting occurring at its top surface. Using $B_{9} \approx$ 3.56. we can estimate $q^{*} \approx 0.34 \sqrt{ }(3.56)(4 / 5)^{1 / 3}-0.6$. Finally. the ratio of melting rates at the two boundaries is estimated(b) to be $v_{2} / v_{1}=q^{* 2} /\left[q^{* 2}+1\right]$ -0.26 . or about $1 / 4$. That is, the lateral melting rate would be four times the downward melting rate.

This approximation, although very rough. suggests that the effect of melting through sand and then contacting a bed of $2.5-\mathrm{cm}$ gravel would be a substantial decrease in the downward melting rate, even if the convective heat transfer within the melt was uniform. The behavior observed during the 1987 large-scale radioactive test supports the results of this evaluation. Consequently. the presence of the artificial rock layer is thought to be the primary reason for the observed lateral growth.

(b) See text accompanying Equation A.48.

(a) See text following Equation A.48. 


\section{DETAILED ANALYSIS OF PARIICLE SIZE EFFECTS}

An approximate heat transfer analysis of the behavior associated with melting at the advancing front of an isV melt is presented. The analysis is developed first for melting into a region of particles of "earth" of uniform size, and then for melting simultaneously into two regions of substantialiy different particle size. Qualitative results and the formulation of a boundary condition for numerical analysis of convective heat transport are presented. Conclusions based on asymptotic results of the anaiysis and on limited comparison of theory with observations are presented at the end.

\section{ISV Process Background}

The ISV process involves heat transfer from an electrically heated molten region to a surrounding shell of unmelted particles. As a layer of these particles is incorporated into the melt, the melt can move to the next layer of particles. The melting rate is then the product of the frequency at which particles are incorporated into the melt and the distance moved at each step, which is the diameter of a particle. The frequency of incorporating particles is the reciprocal of the time required to incorporate a particle into the melt. Incorporating a particle into the melt amounts to increasing the particle temperature to the point that it is fluid enough to allow convective motion to extend through it and to the next particle to be heated.

The approximate analysis presented here addresses (1) the use of a pseudo-steady-state approximation to address temperature profiles near an advancing melting front. (2) spherically symmetric conduction of heat into particles in a uniform region of "earth" (soil, sand. rocks, etc.) followed by a particle becoming part of the melt when its average temperature reaches a "melting" temperature. (3) boundary conditions for describing melting that can be used in numerical models of convective heat transport in an ISV melt, (4) a partial comparison of theory with observations, including an estimate of an apparent natural convection heat transfer coefficient, and (5) melting occurring simultaneously into regions of vastly different particle size.

\section{Pseudo-Steady-State Temperature Profiles}

Once the ISV process is underway, pseudo-steady-state temperature profiles will exist in front of the advancing melt. Specifically. if we observe the temperatures within a coordinate system moving with the advancing 
melt boundary, we see a heat flux outward and the earth moving inward. At constant pressure, the conservation of energy becomes

$$
\rho V(d H / d x)=d q_{x} / d x
$$

where $\rho$ is the local density, $V$ is the velocity of the advancing melt boundary. $H$ is the local enthalpy per unit mass, $x$ is the distance outward from the melt boundary. and $q_{x}$ is the local outward heat flux. This applies to the porous earth as well as in the melt outside regions of significant electrical heat generation, such as the static shell imagined above to constitute heat transfer resistance near the boundary.

There is a direct relationship between the temperature rise from the ambient earth at the melt boundary, the heat flux from the melt to the boundary, and the velocity at which the boundary moves into the earth. For the sake of simplicity, we ignore the heat of vaporization of water. Setting $d H=C_{p} d T$, where $C_{p}$ is the specific heat, we have

$$
\rho C_{p} V(d T / d x)=d q_{x} / d x \text {. }
$$

Integrating this from $x \rightarrow \infty$, where $T \rightarrow T_{d}$ and $q_{x} \rightarrow 0$. to $x$ gives

$$
\rho C_{p} V\left(T-T_{a}\right)-q_{x}
$$

Also for the sake of simplicity. we have assumed that $\rho$ and $C_{p}$ are constant with $x$. This is obviously not true for $\rho$, e.g. comparing the melt with the earth that is melted. However, the approximation will suffice for the purpose of this analysis.

If the heat flux to the boundary were constant over the boundary, it would be determined by the power $P$ divided by the area $A$ of the boundary. Denoting the temperature in the mixed molten giass as $T_{g}$. we would have

$$
V=(P / A) /\left[\rho C_{p}\left(T_{g}-T_{a}\right)\right]
$$


We assume that the effect of $T_{g}$ on $V$ is strong enough that $V$ becomes large enough to satisfy this relationship for some value of $T_{g}$.

In the earth near the melt, the temperature profile referred to the coordinate system moving with the advancing melt reaches a "pseudo-steadystate" profile, at which point the profile satisfies

$$
-V(\partial T / \partial x)=\alpha\left(\partial^{2} T / \partial x^{2}\right)
$$

which has the solution $T-T_{c} \exp \left(-V_{x} / \alpha\right)$, where $T_{c}$ is the temperature in the earth next to the melt. Here $\alpha$ is the thermal diffusivity in the earth. The ratio $\alpha / V$ is a characteristic length scale for the temperature profile. If we assume $P-3.5 \times 10^{6} \mathrm{~W} . \mathrm{A}-5\left(3.5^{2}\right) \mathrm{m} 2$ ( 5 sides of a cube whose edge is the electrode spacing), $\rho=2238 \mathrm{~kg} / \mathrm{m}^{3}, C_{p}-1088 \mathrm{~J} / \mathrm{Kg}$, and $\left(\mathrm{T}_{g}-\mathrm{T}_{a}\right)-1600^{\circ} \mathrm{C}$, then the velocity $V$ would be $1.5 \times 10^{-5} \mathrm{~m} / \mathrm{s}$. Also, $\alpha=k / \rho C_{p}-4 \times 10^{-7}$. so the characteristic length for this situation would be $0.03 \mathrm{~m}$, and $90 \%$ of the temperature change would occur within $0.07 \mathrm{~m}$ of the melt.

The time required to achieve the pseudo-steady-state temperature profile is found from the unsteady state heat balance:

$$
\partial T / \partial \mathrm{t}-\mathrm{V}(\partial \mathrm{T} / \partial \mathrm{X})=\alpha\left(\partial^{2} \mathrm{~T} / \partial \mathrm{X}^{2}\right) .
$$

A dimensional analysis shows that the characteristic time for the behavior described by this equation is $\alpha / v^{2}$. Using the value of $V$ assumed above, this gives 0.5 hour. Therefore, for the nominal conditions assumed here, the temperature profile would be narrow compared to the size of the melt. and the time required to attain this profile would be small compared to the time required to generate the melt. This supports the use of a pseudo-steady-state approximation for the analyses presented below.

\section{Analysis for Uniform Boundary Conditions}

If the temperature at the interface between the melt and the melting 
earth (soil, gravel, or other material) is $T_{j}$, and the heat flux across this interface is $q_{1}$, then we have

$$
\begin{gathered}
\rho C_{p} V\left(T_{i}-T_{d}\right)-q i \text {, or } \\
V=q_{i} /\left(\rho C_{p}\left(T_{i}-T_{a}\right) .\right.
\end{gathered}
$$

The heat flux $q_{f}$ will depend on the difference between the temperature of the mixed molten glass. $T_{g}$, and $T_{1}$, and on the heat transfer coefficient in the molten glass at the interface. $h_{g}$. Since by definition of $h_{g}$ we have also $q_{i}$ $=h_{g}\left(T_{g}-T_{f}\right)$. then overall we must have

$$
T_{j}=\left(h_{g} T_{g}+p C_{p} V T_{a}\right) /\left(h_{g}+\rho C_{p} V\right)
$$

so that $T_{j}$ depends on $V$. Therefore, a relationship between $V$ and $T_{i}$ must be developed before a boundary condition is available for solving the convective heat transfer problem in the molten glass. Also, such a relationship is needed to estimate differences in melting that could occur when the melt encounters earth with different particle sizes simultaneously.

The following model of the processes in the melt boundary is used to develop a relationship between $T_{i}$ and $V$. For the sake of simplicity, we have ignored the heat of vaporization of water. We assume that molten glass at temperature $T_{j}$ contacts and envelops a layer of spherical particles, instantly raises the particle surface temperatures to $T_{1}$, and begins to heat the particles by spherically symmetric conduction within the particles. The melt accepts heat from the mixed molten glass at temperature $T_{g}$ and passes it onto the particles at temperature $T_{1}$. Simultaneously, the melt heats the next layer of particles in accordance with a contact heat transfer coefficient $h_{c}$ and with the temperature difference $\left(T_{j}-T_{c}\right)$, where $T_{c}$ is the temperature of the particles just beyond those enveloped by the meit. 
Particles beyond the plane of contact are assumed to be part of a homogeneous and continuous earth, ranging in temperature from $T_{a}$ far from the melt to $T_{c}$ at the plane of contact. The conservation of energy between these two locations becomes

$$
q_{c}=\rho C_{p} V\left(T_{c}-T_{o}\right)
$$

where $q_{c}$ is the conductive heat flux across the plane of contact. By definition of $h_{c}$, this is also $q_{c}-h_{c}\left(T_{1}-T_{c}\right)$. so that overall we have

$$
T_{c}=\left(h_{c} T_{i}+\rho C_{p} V T_{o}\right) /\left(h_{c}+\rho C_{p} V\right) .
$$

Since $h / \rho C_{p}$ has units of velocity, it is convenient to put $h_{c}=\rho C_{p} V_{c}$ and $h_{g}=$ $\rho C_{p} V_{g}$. so that

$$
\begin{aligned}
& T_{f}-\left(V_{g} T_{g}+V T_{d}\right) /\left(V_{g}+V\right) \\
& T_{c}=\left(V_{c} T_{f}+V T_{a}\right) /\left(V_{c}+V\right) .
\end{aligned}
$$

Finally. We assume that a particle becomes fluid suddenly when its average temperature becomes $T_{m}$, a "melting" temperature. We assume that at that point the volume of the particle mixes instantly with the melt enveloping $i t$, and its temperature rises from $T_{m}$ to $T_{j}$ as the fluid particle at the interface receives heat from the mixed molten glass, which is at temperature $T_{g}$. As heating occurs. the average temperature in the particles is described by

$$
\left(T-T_{0}\right) /\left(T_{1}-T_{0}\right)-\phi
$$

where $T_{0}$ is the temperature of the particle at the moment it is enveloped by 
the melt, and $\phi$ is a function(a). Since prior to this moment the particle was at the plane of contact with the melt. its temperature was Tc. Therefore, we set $T_{0}=T_{c}$. The function can be approximated as

$$
\begin{gathered}
\phi(y) \approx 1-\exp \left[-K\left(y+1.32 y^{2}\right)\right] . \\
y=\sqrt{ }\left(\alpha_{p} t / a^{2}\right), k-6 / \sqrt{ } \pi \\
a_{p}-k_{p} / \rho C_{p} .
\end{gathered}
$$

where $\alpha_{p}$ and $k_{p}$ are the thermal diffusivity and thermal conductivity of the particle. Which is assumed to have the same $\rho$ and $C_{p}$ as the melt, $t$ is the time the particle is contacted by the melt, and a is the radius of the particle. If $y \ll 1 / k$. then $\phi \approx k y$; if $y \gg 1 / k$, then $\phi=1$. However, the above approximation cannot be used to estimate the value of 1- $\phi$ for large $y$.

The time for the average temperature of the particle to reach $T_{m}$ is the time required to incorporate the particle into the melt. If the melt is advancing at velocity $\vee$ and the diameter of the particle is $\delta$, then this time is $\delta / V$. Therefore, since a $-\delta / 2$, then $y-\sqrt{ }\left(2 \alpha_{p} / V \delta\right)$. Finally, setting $T-$ $T_{m}$ gives

$$
\left(T_{m}-T_{c}\right) /\left(T_{i}-T_{c}\right)-\phi(y)
$$

Hence, this ratio depends on $V$ through the function $\phi$, and also the temperatures $T_{c}$ and $T_{i}$ depend on $V$ as well as on $T_{a}, T_{g}$. and $p C_{p}$. Conversely, $V$ is a function of $\delta . T_{g}, T_{m}, T_{a}, \rho C_{p}, h_{c}$, and $h_{g}$. The temperature $T_{g}$ must adjust to cause the power consumed by the melting process to match the electrical power provided.

The effect of $h_{c}$ and $h_{g}$ can be most easily considered by introducing dimensionless variables and parameters. Using the relationships between $T_{j}$

(a) Carsiaw and Jaeger (1959) 
and $T_{c}$ and $T_{g}$ and $T_{a}$, and retaining the definitions of $V_{g}$ and $V_{c}$, we can write the ratio $\left(T_{m}-T_{c}\right) /\left(T_{j}-T_{c}\right)-\phi$ as

$$
\left\{\left[\left(T_{m}-T_{a}\right) /\left(T_{f}-T_{a}\right)\right]\left(V_{c}+V\right)-V_{c}\right\} / V=\phi .
$$

Then we have

$$
\begin{gathered}
\left(V_{c}+V\right) /\left(V_{c}+\phi V\right)=\left(T_{1}-T_{a}\right) /\left(T_{m}-T_{b}\right) \\
=\left[V_{g} /\left(V_{g}+V\right)\right]\left(T_{g}-T_{b}\right) /\left(T_{m}-T_{a}\right)
\end{gathered}
$$

We put

$$
\left(T_{g}-T_{a}\right) /\left(T_{m}-T_{a}\right)-1+\beta, \beta \equiv\left(T_{g}-T_{m}\right) /\left(T_{m}-T_{a}\right)
$$

where $\beta$ can be thought of as a dimensionless driving force for melting. Next, we make $V$ dimensionless by putting $V_{*}-V \delta / \alpha_{p}=2 / y^{2}$. Finally, we similarly make $V_{g}$ and $V_{c}$ dimensionless. which leads to dimensionless groups known as Biot numbers: $B_{g}-V_{g} \delta / \alpha_{p}-h_{g} \delta / k_{p}$ and $B_{c}-V_{c} \delta / \alpha_{p}-h_{c} \delta / k_{p}$.

Substituting $V_{*}, B_{c}, B_{g}$, and $\beta$ into the expression involving $V . V_{c}, V_{g}$. and $\left(T_{g}-T_{m}\right) /\left(T_{m}-T_{0}\right)$ gives

$$
\left(B_{c}+V_{*}\right)\left(B_{g}+V_{*}\right)-B_{g}\left(B_{c}+\phi V_{*}\right)(1+\beta)
$$

Consider the case of no significant thermal resistance in the molten glass. such that $B_{g} \rightarrow \infty, T_{i}-T_{g}$, and hence $\beta=\left(T_{i}-T_{m}\right) /\left(T_{m}-T_{a}\right)$. Then we have

$$
\left(B_{c}+V_{*}\right)=\left(B_{c}+\phi V_{\star}\right)(1+\beta)
$$


Since from a heat balance from the interface, where $T=T_{i}-T_{g}$, to the ambient earth we have $q_{i}=\rho C_{p} V\left(T_{g}-T_{a}\right)$, and $T_{g}-T_{a}(1+\beta)\left(T_{m}-T_{a}\right)$, and $V_{\star} \equiv$ $v \delta \rho C_{p} / k_{p}$ then

$$
q_{i}-V_{*}\left[k_{p}\left(T_{m}-T_{a}\right) / \delta\right](1+\beta)
$$

If we define $q_{m} \equiv k_{p}\left(T_{m}-T_{a}\right) / \delta$ and $q^{*} \equiv q / q_{m}$, then

$$
(1+\beta)=q^{\cdot} / V_{*}
$$

Therefore, substituting for $(1+\beta)$ gives

$$
\begin{aligned}
& \left(B_{c}+V_{\star}\right)=\left(B_{c}+\phi V_{\star}\right) q^{*} / V_{\star} \text { or } \\
& V_{\star} 2+V_{*}\left(B_{c}-q^{\prime} \phi\right)-q^{\prime} B_{c}=0 .
\end{aligned}
$$

The value of $B_{c}$ is $V_{c} \delta / \alpha_{p}-h_{c} \delta / k_{p}$. The value of $h_{c}$ will be the apparent thermal conductivity of the packed particles constituting the earth divided by the particle spacing $\delta$. Therefore, $h_{c}-k_{c} / \delta$, and so $B_{c}=k_{c} / k_{p}$. Assuming the earth consists of particles with the same thermal conductivity as the particles being melted, then $k_{c}$ is $k_{p}$ modified to account for the porosity in the earth. At low temperatures. where radiation is not important, then based on correlations for packed beds of spheres we can expect $k_{c}=k_{p} / 2$. On the other hand, at high temperatures radiation will cause thermal equilibrium over the interior of interstices in the earth, making the earth behave as particles imbedded in a continuum of very high thermal conductivity. The thermal resistance of the earth then becomes that of solid particles with the conduction path length reduced by a factor (1-E). where $E$ is the porosity of the earth. This would give $k_{c}=k_{p} /(1-E)$. Considering both low and high temperature, we would expect $B_{c}=k_{c} / k_{p}$ to fall in the range 0.5 to perhaps 1.5. which is to say $B_{c}=1$. 
An asymptotic form is obtained if $q^{\prime} \ll B_{c} / 4$. Then

$$
\begin{gathered}
V_{*}=\left(B_{c} / 2\right)\left[\sqrt{ }\left(1+4 q^{\prime} / B_{c}\right)-1\right] \\
=q^{\circ}-2 q^{\prime} 2 / B_{c} .
\end{gathered}
$$

and $(1+\beta)-q^{*} / V_{*} \approx 1+2 q^{\circ} / B_{c}$, or $q^{\circ} \approx B_{c} \beta / 2$. As $q^{\prime} \rightarrow 0, \beta \rightarrow 0$. or $T_{g} \rightarrow T_{m}$ and, since we have assumed $B_{g} \rightarrow \infty, T_{j}-T_{g}$. That is, for sufficiently small heat flux the interface temperature becomes the melting temperature and is independent of the particle size $\delta$.

As $q^{*}$ becomes large so does $V_{*}$. A second asymptotic form is obtained if $V_{\star}$ is large enough that $y \ll 1 / K$, i.e. $V_{*} \gg 2 K^{2}$. Then $\phi=k y=k \sqrt{ }\left(2 / V_{\star}\right)$, and

$$
V_{*} 2+V_{*}\left[B_{c}-q^{\prime} K \sqrt{ }\left(2 / V_{*}\right)\right]-q^{\prime} B_{c}=0
$$

Putting $x \equiv V V_{\star}$ and rearranging gives

$$
x^{3}-q^{\cdot}\left(K \sqrt{ } 2+B_{c} / x\right)-B_{c} x
$$

Since $V_{*}-x^{2} \gg 2 K^{2}$ and $B_{c} \approx 1$, then $B_{c} x \ll k \sqrt{ } 2$. If we assume $B_{c} x \ll q^{\prime} k \sqrt{ } 2$, then $x^{3}=q^{\prime} k \sqrt{ } 2$. But then the assumption is $B_{c} x \ll x^{3}$, and this is already satisfied since we have already assumed $x^{2} \gg 2 K^{2}$. Solving for $V_{\star}$ gives $V_{\star}=$ $\left(q^{\prime} K \sqrt{ } 2\right)^{2 / 3}$, and hence $(1+\beta)-q^{\prime} / V_{*}=\left(q^{*} / 2 K^{2}\right)^{1 / 3}$. Finally, the condition that $V_{*} \gg 2 k^{2}$ becomes $q^{\prime} \gg 2 K^{2}$. So, if $q^{\prime} \gg 2 k^{2}$, then $V_{*}=\left(q^{\prime} k \sqrt{2}\right)^{2 / 3}, q^{\prime}=$ $2 K^{2}(1+\beta)^{3}$, and $(1+\beta)=\left(q^{\circ} / 2 K^{2}\right)^{1 / 3}$. Since $q^{\prime}$ is proportional to the particle size $\delta$, then for this case the interface temperature is greater than the melting temperature and depends on the particle size.

\section{Boundary Conditions for Numerical Analysis of Convective Heat Iransport}

A functional relationship between the interfacial heat flux, $q_{i}$. and the interfacial temperature. $T_{\mathfrak{f}}$. is needed to conduct numerical modeling studies of convection and heat transfer in the molten glass. To obtain this, we 
continue to assume that $B_{g} \rightarrow \infty$ so that $T_{j}-T_{g}$ and $\beta=\left(T_{j}-T_{m}\right) /\left(T_{m}-T_{a}\right)$. or $T_{j}$ $=T_{m}+\left(T_{m}-T_{a}\right) \beta$. Also. $q_{i}=q_{m} q^{*}=q^{\prime} k_{p}\left(T_{m}-T_{a}\right) / \delta$ and $q^{*}=V_{*}(1+\beta)$. Therefore, a functional relationship between $V_{\star}$ and $\beta$ will provide a relationship between $q_{i}$ and $T_{j}$. Since we have assumed $h_{g} \rightarrow \infty$ so that $T_{i} \rightarrow T_{g}$ the asymptotic expressions of the form $q^{\prime}-F[\beta]$ provide boundary conditions of the form $q=$ $F\left[T_{i}\right]$. The asymptotic boundary conditions become

$$
\begin{gathered}
q-h_{c}\left(T_{i}-T_{m}\right)=\left(k_{c} / \delta\right)\left(T_{i}-T_{m}\right) \text {, smalt } q^{\prime} \\
q-2 K^{2}\left(k_{p} / \delta\right)\left[\left(T_{i}-T_{a}\right) /\left(T_{m}-T_{a}\right)\right]^{3}\left(T_{m}-T_{a}\right) \text {. large } q^{\prime} .
\end{gathered}
$$

For either asymptotic case the heat flux is predicted to depend inversely on the particle size for a given value of $T_{\mathfrak{i}}$.

A general relationship is available from the expression

$$
\begin{gathered}
\left(B_{c}+V_{*}\right)=\left(B_{c}+\phi V_{*}\right)(1+\beta) \text {, with } \\
\phi=\phi\left(V_{\star}\right) .
\end{gathered}
$$

This is an explicit function of the form $\beta=f\left(V_{*}\right)$. Unfortunately, since $V_{*}=$ $q^{\prime} /(1+\beta)$ is a function of both $q_{j}$ and $T_{1}$. the solution for either $q_{i}$ or $T_{j}$ is implicit. To implement the functional relationship as part of a numerical model will require either an explicit approximation of the implicit function. or inclusion of a solution algorithm in the numerical model.

\section{Partial Comparison of Model with Observations}

A typical value for $q^{\circ}-q_{/} q_{m}$ can be estimated from estimates of $q_{m}$. We assume the thermal conductivity and specific heat of the particles are the same as for the $\mathrm{glass}, 1 \mathrm{~W} / \mathrm{m}^{\circ} \mathrm{C}$ and $1088 \mathrm{~J} / \mathrm{kg}^{\circ} \mathrm{C}$, and that the melting 
temperature is $T_{m}=1200^{\circ} \mathrm{C}$. Then for $1-m m$ particles (sandy soil). $q_{m}=1.2 \times 10^{6} \mathrm{~W} / \mathrm{m}^{2}$, and for 1 -inch $(0.0254 \mathrm{~m})$ particles (stones), $q_{m}=4.7 \times 10^{4} \mathrm{~W} / \mathrm{m}^{2}$.

Taking the power as $3.5 \mathrm{MW}$ and the area of the boundary of the melt as five faces (four sides and bottom) of a cube with an edge the length of the electrode spacing. which is taken to be $3.5 \mathrm{~m}$, then $\mathrm{q}=3.5 \times 10^{6} /\left[5(3.5)^{2}\right]=$ $5.7 \times 10^{4} \mathrm{~W} / \mathrm{m}^{2}$. Hence, values of $q^{\prime}$ are .05 for $1-\mathrm{mm}$ particles and 1.2 for l-in. particles. Hence, it appears that $q^{\circ} \ll 1$ is satisfied for "soil." such that $\beta \rightarrow 0$, while $q^{\prime}=1$ for "stones." Therefore, we expect that the interface temperature will be the melting temperature when melting only soil, but if melting only stones the interface temperature at constant heat flux will depend nonlinearly on the flux and the size of the stones.

For the case of soil, since $q^{\prime} \ll 1$, we expect $\beta \rightarrow 0$. so that $T_{g} \rightarrow T_{m}$. However, we observe $T_{m}=1200^{\circ} \mathrm{C}$ and $T_{g} \approx 1600^{\circ} \mathrm{C}$. Evidently this difference is between $T_{g}$ and $T_{i}$; that is. $B_{g}$ is small enough to have an effect. If we assume that $T_{g}-T_{i} \approx 400^{\circ} \mathrm{C}$, and using $q_{1}=5.7 \times 10^{4} \mathrm{~W} / \mathrm{m}^{2}$. then we estimate $h_{g}=$ $\mathrm{q}_{i} /\left(\mathrm{T}_{\mathrm{g}}-\mathrm{T}_{\mathrm{i}}\right) \approx 140 \mathrm{~W} / \mathrm{m}^{2}{ }^{\circ} \mathrm{C}$. Converting this to a Nusselt number, we have Nu = $h_{g} L / k=\left(140 \mathrm{~W} / \mathrm{m}^{\circ} \mathrm{C}\right)(3.5 \mathrm{~m}) /\left(1 \mathrm{~W} / \mathrm{m}^{\circ} \mathrm{C}\right)-40$.

For free convection from vertical plates, Nu $=0.6(\mathrm{GrPr})^{1 / 4}$. where $\mathrm{Gr}$ and $\mathrm{Pr}$ are the Grashof and Prandtl numbers, respectively. so we would have $\mathrm{GrPr}=2 \times 10^{7}$. The Prandtl number is $\mathrm{Pr} \equiv \mu \mathrm{C}_{\mathrm{p}} / \mathrm{k}-(10 \mathrm{~kg} / \mathrm{m}-\mathrm{sec})(1088$ $\left.\mathrm{J} / \mathrm{Kg}^{\circ} \mathrm{C}\right) /\left(1 \mathrm{~W} / \mathrm{m}^{\circ} \mathrm{C}\right) \approx 10^{4}$, so then $\mathrm{Gr}=2000$. This is expected to be proportional to the Reynolds number when convection is driven only by buoyancy forces; the Reynolds number would be something like an order of magnitude smaller. Estimating $\operatorname{Re} \approx G r / 10$. then the velocity in the glass would be $V=$ $\mu R e / p L / 10=(10 \mathrm{~kg} / \mathrm{m}-\mathrm{sec})(2000) /\left(2240 \mathrm{Kg} / \mathrm{m}^{3}\right)(3.5 \mathrm{~m}) / 10=.26 \mathrm{~m} / \mathrm{s}$.

For free convection caused by a temperature difference imposed across a horizontal cell. where the width and length of the cell are the same. then $\mathrm{Nu}=0.075(\mathrm{GrPr}) 1 / 3$. This gives $\mathrm{GrPr} \approx 1.5 \times 10^{8}$, or $\mathrm{Gr}=1.5 \times 10^{4}$, and hence $V=2 \mathrm{~m} / \mathrm{sec}$.

These estimates are about 2 and 3 orders of magnitude greater than velocities predicted to date by numerical modeling. One explanation is that heat transfer processes in the melt are more efficient based on the maximum velocity than is characteristic of natural convection with simple flow 
patterns. However, the analysis presented here is too primitive to allow more than speculation.

One other important interpretation of the estimated value of $\mathrm{h}_{\mathrm{g}}$ is obtained if we imagine that the heat transfer coefficient corresponds to a stagnant layer of glass surrounding a perfectly mixed region. Then in accordance with classical "film" theory for heat transfer we would have $h_{g}=k_{p} / \delta$. or $\delta=k_{p} / h_{g}=\left(1 W / m^{\circ} \mathrm{C}\right) /\left(140 w / m^{2}{ }^{\circ} \mathrm{C}\right)-0.007 m=1 / 4$ inch. Roughly, this means that for this situation heat transfer is predominately conductive within $1 / 4$ inch of the boundary of the melt, or equivalently that substantial convection occurs as close as within $1 / 4$ inch of the boundary. This means that if the particles being melted are much 1 arge than $1 / 4$ inch in size, then the region of predominately conductive heat transfer is significantly increased. since convection between the particles would be severely impeded and the heat transfer there must be predominately conductive. It shouldn't matter much whether the region surrounding the large particles is a void that must be filled by the melt or sand that must be melted, since in either case significant convection cannot occur there until the large particles are made fluid by melting them.

\section{Analysis for Simultaneous Contact with Two Particle Sizes}

Consider the case where the ISV melt simultaneously contacts two regions with different values of $h_{g}$ and $h_{c}$. Suppose that $q^{*} \ll<$, as would be the case for soil. Then $q \approx\left(h_{c} / 2\right)\left(T_{1}-T_{m}\right)$. Also, $q-h_{g}\left(T_{g}-T_{j}\right)$. Solving for the value of $T_{i}$ that satisfies these relations simultaneously and substituting the value of $T_{j}$ into either relation gives

$$
q=\left(T_{g}-T_{m}\right) /\left(2 / h_{c}+1 / h_{g}\right)
$$

Denoting the two regions of the boundary as " 1 " and " 2 " the total power transferred across the boundary is $p-A_{1} q_{1}+A_{2} q_{2}$. Where $q_{1}$ and $q_{2}$ are found from the above relation with the " 1 " and " 2 " values for $h_{g}$ and $h_{c}$ inserted. 
The result is

$$
P=\left(T_{g}-T_{m}\right)\left[A_{1} /\left(2 / h_{c 1}+1 / h_{g 1}\right)+A_{2} /\left(2 / h_{c 2}+1 / h_{g 2}\right)\right] \text {. }
$$

This expression determines the value of $T_{g}$. which must adjust such that the generated power $P$ is exactly expended by the melting process (for simplicity, other heat losses, such as at the top of the melt, have been ignored). The local melting rate $V$ is found from the local heat $f 1 u x: q-\rho C_{p} V\left(T_{g}-T_{0}\right)$. The ratio of melting rate at boundaries " 1 " and ${ }^{2} 2$ " is then the ratio of heat fluxes (in this case, where we have assumed $q^{\prime} \ll 1$ ). Hence.

$$
v_{2} / v_{1}=q_{2} / q_{1}-\left(2 / h_{c 1}+1 / h_{g 1}\right) /\left(2 / h_{c 2}+1 / h_{g 2}\right)
$$

and the ratio does not depend on $T_{g}$. If the particle size is 5 mall, $2 / h_{c}=$ $2 \delta / k_{c}$ will be small, and the ratio will be controlled by the hi values: $V_{2} / V_{1}$ $=h_{\mathrm{g} 2} / h_{g 1}$.

On the other hand, suppose that, as melting proceeds, boundary " 2 " encounters a large particle size, $\delta_{2}$. Assuming that, because $\delta_{2}$ is large, $q^{\prime}$

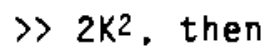

$$
q_{2}=2 K^{2}\left(k_{p} / \delta_{2}\right)\left[\left(T_{i}-T_{a}\right) /\left(T_{m}-T_{a}\right)\right]^{3}\left(T_{m}-T_{a}\right)
$$

and, as before, $q_{2}-h_{92}\left(T_{g}-T_{1}\right)$. Combining these relations for $q_{2}$ gives

$$
\begin{aligned}
& q_{2} / q_{g}=\left(2 K^{2} / B_{g 2}\right)\left[1+\beta-q_{2} / q_{g}\right]^{3} \text {. or } \\
& 1+\beta=\left(q_{2} / q_{g}\right)+\left[\left(B_{g 2} / 2 K^{2}\right)\left(q_{2} / q_{g}\right)\right]^{1 / 3} .
\end{aligned}
$$


where $q_{g} \equiv h_{g 2}\left(T_{m}-T_{a}\right), B_{g 2}=h_{g 2} \delta_{2} / k_{p}$, and $\beta \equiv\left(T_{g}-T_{m}\right) /\left(T_{m}-T_{a}\right)$. Also, the power must satisfy the condition

$$
P=A_{1} h_{g 1}\left(T_{m}-T_{a}\right)[1+\beta]+A_{2} h_{g 2}\left(T_{m}-T_{a}\right)\left(2 K^{2} / B_{g 2}\right)\left[1+\beta-q_{2} / q_{g}\right]^{3} \text {. }
$$

Substituting for $1+\beta$ from above gives

$$
\begin{gathered}
P=A_{1} h_{g 1}\left(T_{m}-T_{b}\right)\left\{\left(q_{2} / q_{g}\right)+\left[\left(B_{g 2} / 2 K^{2}\right)\left(q_{2} / q_{g}\right)\right]^{1 / 3}\right] \\
+A_{2} h_{g 2}\left(T_{m}-T_{g}\right)\left(q_{2} / q_{g}\right)
\end{gathered}
$$

Dividing $P$ by the total area gives an average heat $f l u x$ over the boundary. $q$. Dividing this by $q_{m} \equiv k_{p}\left(T_{m}-T_{a}\right) / \delta_{2}$ gives $q^{\circ}$, an average value of $q^{\prime}$ for the boundary. Making $P$ dimensionless in this way gives

$$
q^{\prime} \equiv P /\left[\left(A_{1}+A_{2}\right) q_{m}\right]-\Gamma B_{g 1}\left\{\left(q_{2} / q_{g}\right)+\left[\left(B_{g 2} / 2 K^{2}\right)\left(q_{2} / q_{g}\right)\right]^{1 / 3}\right]+(1-\Gamma) B_{g}\left(q_{2} / q_{g}\right)(A .40)
$$

where $\Gamma \equiv A_{1} /\left(A_{1}+A_{2}\right)$ and $B_{g 1}$ is now based on $\delta_{2}: B_{g 1} \equiv h_{g 1} \delta_{2} / k_{p}$. The value of $q_{2} / q_{g}$ and $\beta$ must adjust to satisfy this. Therefore, $q / q_{g}$ is an implicit function of $q^{\cdot}, \Gamma, B_{91}$, and $B_{92}$. If we imagine the ISV melt has just begun to contact the larger particles and that the melt is not particularly flattened. then $h_{g 1}$ and $h_{g 2}$, and hence $B_{g 1}$ and $B_{g 2}$, would be similar, and for the sake of simplicity we can assume they are both equal to a nominal value $B_{g}=h_{g} \delta_{2} / k_{p}$. This gives

$q^{\prime} \equiv P /\left[\left(A_{1}+A_{2}\right) q_{m}\right] \approx \Gamma B_{g}\left[\left(q_{2} / q_{g}\right)+\left[\left(B_{g} / 2 K^{2}\right)\left(q_{2} / q_{g}\right)\right]^{1 / 3}\right]+(1-\Gamma) B_{g}\left(q_{2} / q_{g}\right)$

By putting $x \equiv q_{2} / q_{g}$ and $z-\sqrt{ }\left(2 K^{2} / B_{g}\right) x$. the above equation can be simplified to give

$$
q^{\prime}\left(2 K^{2} / B_{g}\right)^{1 / 2}=z+\Gamma z^{1 / 3} \text {. }
$$


Re-expanding the term $\mathrm{G}^{\circ}\left(2 \mathrm{~K}^{2} / \mathrm{Bg}^{3}\right)^{1 / 2}$ gives

$$
\left[(P / A) / h_{g}\left(T_{m}-T_{a}\right)\right]\left(k_{p} / \delta_{2} h_{g}\right) 1 / 2 \approx z+\Gamma z^{1 / 3} .
$$

If $B_{g}$. which is proportional to $\delta_{2}$. is large, the left hand side of this expression, which is $2 K^{2} / B_{g}{ }^{3}$. will be small. Considering the asymptotic case of the left hand side decreasing to zero, then we must also have $z \rightarrow 0$, and hence the right hand side $\rightarrow \Gamma z^{1 / 3}$. Solving for $z$, expanding $z$ in terms of $q_{z}$. and rearranging gives

$$
\left(q_{2} / q_{g}\right) \rightarrow\left(q / q_{g}\right)^{3} / \sqrt{ }\left(2 K^{2}\right) \Gamma B_{g} .
$$

where $q \pm P / A$. Substituting this into the approximate expression for $1+\beta$ gives

$$
1+\beta \rightarrow\left(q / q_{g}\right) 3 / \sqrt{ }\left(2 k^{2}\right) \Gamma B_{g}+\left(q / q_{g}\right) /\left[\Gamma 1 / 3 \sqrt{ }\left(2 K^{2}\right)\right]
$$

Substituting this into the expression $q_{1}-h_{g}\left(T_{m}-T_{0}\right)(1+\beta)$ gives

$$
\left(q_{1} / q_{g}\right) \rightarrow\left(q / q_{g}\right)^{3} / \sqrt{ }\left(2 k^{2}\right) \Gamma B_{g}+\left(q / q_{g}\right) /\left[\Gamma 1 / 3 \sqrt{ }\left(2 k^{2}\right)\right]
$$

The ratio of melting rates is given by $v_{2} / v_{1}-q_{2} / q_{1}$. Substituting for $q_{2}$ and $q_{1}$ gives

$$
\begin{gathered}
V_{2} / V_{1} \rightarrow\left[\left(q / q_{g}\right)^{3} / \sqrt{ }\left(2 k^{2}\right) \Gamma B_{g}\right] /\left[\left(q / q_{g}\right)^{3} / \sqrt{ }\left(2 k^{2}\right) \Gamma B_{g}+\left(q / q_{g}\right) / \Gamma 1 / 3 \sqrt{ }\left(2 k^{2}\right)\right] \text {. or } \\
V_{2} / V_{1} \rightarrow q^{* 2} /\left[q^{* 2}+1\right] .
\end{gathered}
$$

where $q^{\star} \equiv\left(q / q_{g}\right) / \Gamma^{1 / 3} \sqrt{ } B_{g}$. Therefore, as $q^{\star}$ becomes sma $11, V_{2} / V_{1}$ becomes proportional to $q^{\star 2}$. The value of $q^{\star}$ is proportional to $\left(B_{g}\right)^{-1 / 2}$, and hence to $\delta_{2}^{-1 / 2}$. Therefore. as $\delta_{2}$ becomes large, $q^{*}$ becomes small, and the ratio of 
melting rates becomes inversely proportional to $\delta_{2}$. However. it is the size of $\delta_{2}$ compared to $k_{p} / h_{g}$ (i.e.. the value of $B_{g}$ ), and not the ratio $\delta_{2} / \delta_{1}$ that is important. All of this is based on the assumptions made that both $\delta_{1}$ is small enough that $\delta_{1} / k_{c} \ll 1 / h_{g}$ at boundary " 1 " and $\delta_{2}$ is large enough that $q$ " 〉 $2 K^{2}$ at boundary " 2 ".

Using the rough estimate obtained above that $h_{g} \approx 140 \mathrm{~W} / \mathrm{m}^{2} \mathrm{C}$, and noting that if $\delta=1 \mathrm{in}$. $(0.0254 \mathrm{~m})$, and using again $k_{c}=k_{p}-1 \mathrm{~W} / \mathrm{m}^{\circ} \mathrm{C}$, then $h_{g} \delta_{2} / k_{p}=$ $B_{g}=3.56$. Then $\left[\left(2 K^{2} / B_{g}\right)^{3}\right]^{1 / 2}=0.7$. which does not satisfy the condition < 1. However, it is less than unity, and so we can try to draw inferences from the asymptotic analysis.

As is discussed above, for $\delta=1$ in. we find $q^{*}=1$. This does not satisfy the condition $q^{\prime} \gg 2 K^{2}=72 / \pi=22.92$. However, since it is also not true that $q^{\prime} \ll 1$, we can expect our asymptotic analysis of the effect of particle size on the ratio of melting rates to describe the trend, if not the quantitative effect. for the system of interest. Thus proceeding. We can estimate

$$
q / q_{g}=\left(5.7 \times 10^{4} \mathrm{~W} / \mathrm{m}^{2}\right) /\left[\left(140 \mathrm{~W} / \mathrm{m}^{2} \mathrm{C}\right)\left(1200^{\circ} \mathrm{C}\right)\right]-0.34
$$

The value of $\Gamma$ is $4 / 5$ if we consider the ISV melt to be a cube with the four sides contacting small particles, the bottom contacting large particles, and no melting occurring at its top surface. Using the above estimate of $B_{9}=$ 3.56, we can estimate $q^{\star} \approx 0.34 \sqrt{ }(3.56)(4 / 5) 1 / 3=0.6$. This is small enough that the ratio of melting rates is substantially influenced by $q^{\star}$, and hence by the l-in. particle size. The asymptotic ratio would be given by $q^{\star 2} /\left[q^{\star 2}+\right.$ 1] -0.26 , or about $1 / 4$. That is. the lateral melting rate would be four times the downward melting rate.

This result, although fraught with the danger of over-interpreting what are approximate results derived for limiting conditions, suggests that the effect of melting through sand and contacting a bed of 1 -in. gravel would be a substantial decrease in the downward melting rate. 
COMPOSITIONAL DIFEERENCES

The findings associated with encountering layers of larger size rocks can also be applied to heterogeneous layers of varying soil compositions. Even if the particle size of the soil throughout the vitrified depth is uniform, encountering a layer of higher melting temperature soil after a melt has been established with a lower melting point soil will slow the downward vitrification rate. Just as with encountering a rock layer, the vitrification zone will then grow primarily outward.

Even though layers of varying soil or sludge types may affect the downward growth rate, this effect was not encountered during the 1987 largescale radioactive test. Approximately $75 \%$ of the rocks encountered were basaltic, which have a composition and melting properties that are identical to that of the vitreous material produced from the soil above the rock layer. The remaining rocks are quartzite rocks, with silica concentrations up to $98 \mathrm{wt} \%$. Although the melting point of the quartzite is $1600^{\circ} \mathrm{C}$ to $1700^{\circ} \mathrm{C}$, the rocks undergo a change in density when exposed to temperatures of about $1400^{\circ} \mathrm{C}$, changing from a specific gravity of 2.6 to 2.17 . Since the specific gravity of glass is about 2.6. the rocks will float without being exposed to the higher melting temperature. Therefore. the compositional differences of the rocks are not thought to have contributed to the lateral growth of the vitrified mass; the lateral growth is due instead to a layer of larger particle sizes.

\section{THERMAL CONDUCTIVITY DIFFERENCES}

The rock layer is expected to have a lower thermal conductivity than the overlying sandy soil because it has a high void volume. Materials with a high void content generally have lower thermal conductivities. Even so, thermal conductivity is not thought to have a significant effect in downward melting rate. A lower thermal conductivity would result in less thermal stratification of the melt since the bottom would more closely approach adiabatic conditions. When the temperature is less stratified, an improved downard melting rate would be expected. Consequently the lower thermal conductivity of the rock layer would have acted to promote downard growth. Since the opposite effect was observed. the differences in thermal conductivity can be largely discounted as contributing to downard or lateral growth. 


\section{SCALE-UP EFFECTS}

Two approaches were taken to determine whether the ISV process inherently tends to promote lateral growth as the process is scaled up. The first approach is a theoretical dimensional analysis of convection currents. The second approach involves conducting a series of fluid dynamic models at various geometric configurations. The fluid dynamic modeling was more conclusive than the theoretical dimensional analysis: its results revealed a correlation of enhanced lateral growth with larger scales. This scale-up effect must be incorporated into the existing ISV predictive model used to predict melt shapes and time and energy requirements. However. scale-up alone did not account for the lateral growth observed during the large-scale radioactive test. The depth was inhibited primarily by the presence of the rock layer. Nevertheless. until a larger hood is available to support the wider blocks achieved with the large-scale system, engineering techniques are recommended to enhance downward growth for applications in excess of $5 \mathrm{~m}$.

\section{Dimensional Analysis of Convective Currents}

A dimensional analysis of the convection currents in the $15 V$ melt shows that substantial convective heat transfer must occur. It also suggests that the apparent "film thickness" of stagnant glass outside the central convection zone in the ISV melt may be on the order of only $0.5 \mathrm{~cm}$ thick. However, the analysis is only approximate and cannot yet be validated against the results of numerical computation of convection in the melt. No definitive conclusions could be made as to the effects of scale-up on melt shape by this analysis. The dimensional analysis is developed in the following discussion.

No temperature difference is imposed in the ISV process; instead, power is imposed. Which results in a temperature increase from the meit boundary to its core. If we imagine the melt is a sphere heated uniformly with total power $P$ and where the melt is static, then the temperature rise would be

\section{$\Delta T-P / 8 \pi k R$}

where $R$ is the radius of the sphere and $k$ is the thermal conductivity of the melt. If the melt is actually a cube inscribing the electrodes. its volume would be $L^{3}$, where Le is the electrode spacing. Using Le $-3.5 \mathrm{~m}$, the radius 
of a sphere containing the same volume is $R=2.17 \mathrm{~m}$. and using $P-3 \times 10^{6} \mathrm{~W}$ and $k=1 \mathrm{~W} / \mathrm{m}^{\circ} \mathrm{C}$, then $\Delta T=5 \times 10^{\circ}{ }^{\circ} \mathrm{C}$. The observed temperature rise from the melting point to the melt temperature is about $1600^{\circ} \mathrm{C}-1200^{\circ} \mathrm{C}-400^{\circ} \mathrm{C}$. This is smaller than the temperature difference predicted from conduction alone by 2 orders of magnitude, so convective heat transfer must be important.

Since the velocity is zero at the boundaries of the melt, heat must be removed by conduction across the boundaries. Convection near the boundary is not in the direction (i.e.. normal to the boundary) of heat transport. The effect of convection is to decrease the temperature gradient within a mixed region in the cavity, thereby increasing the gradient near the boundaries and hence increasing the rate of removal of heat. If we now imagine that heat is conducted across a spherical shell of stagnant melt surrounding a mixed and electrically heated region, the relation between the power generated and the temperature drop across the shell is

$$
\Delta T=(P / 4 \pi r k)\left(R_{2}-R_{1}\right) / R_{1} R_{2}
$$

If we set $\Delta T=400^{\circ} \mathrm{C}$ and use $R_{2}-2.17 \mathrm{~m}$, we find the thickness of the conduction shell would be only $1 \mathrm{~cm}$. In effect, the temperature of the melt must increase until the buoyancy driving force for natural convection and the fluidity of the melt are sufficient to extend convective heat transfer close enough $(e . g . .=1 \mathrm{~cm})$ to the boundary that the conductive heat transfer step occurs as fast as heat is generated in the melt. However, if for half of the effective heat transfer area the effective conduction thickness were $0.5 \mathrm{~cm}$, then no conduction at all would be required over the remaining area. Hence a) though the convective heat transfer coefficient must attain some minimum value. it need not be uniform over the boundary.

For the case of ISV in soil, typical values for the melting temperature of the soil and the temperature in the melt are $T_{m} \approx 1200^{\circ} \mathrm{C}$ and $T_{g}=1600^{\circ} \mathrm{C}$. respectively. Assuming that the boundary of the melt is at the melting temperature, then the $400^{\circ} \mathrm{C}$ difference is associated with a convective heat transfer resistance in the melt near the boundary. If we assume $\Delta T=400^{\circ} \mathrm{C}$. and using a typical heat flux at the interface between the melt and the soil of $q_{i}=5.7 \times 10^{4} \mathrm{~W} / \mathrm{m}^{2}$. then we estimate the convective heat transfer coefficient in the melt to be about $140 \mathrm{~W} / \mathrm{m}^{2}{ }^{\circ} \mathrm{C}$. Converting this to a 
dimensionless form using the electrode spacing. the Nusselt number would be about 40 .

If we imagine that the heat transfer coefficient corresponds to a stagnant layer of glass surrounding a perfectly mixed region, then in accordance with classical " $f \mathbf{i l m}$ " theory for heat transfer we would estimate the thickness of a stagnant " $\mathrm{film}$ " of molten glass at the edge of the melt to be $0.5 \mathrm{~cm}$. Hence, it would appear that for this situation heat transfer is predominately conductive within $0.5 \mathrm{~cm}$ of the boundary of the melt, or equivalently that substantial convection occurs as close as within $0.5 \mathrm{~cm}$ of the boundary. This means that if the particles being melted are much larger than $0.5 \mathrm{~cm}$ in size, then the region of predominately $y$ conductive heat transfer is significantly increased. since convection between the particles would be severely impeded and the heat transfer there would have to be predominately conductive. It should not matter much whether the region surrounding the large particles is a void that must be filled by the melt. or sand that must be melted, since in either case significant convection cannot occur there until the large particles are made fluid by melting them.

If the apparent Nusselt number of 40 is compared with correlations for natural convective heat transfer at vertical plates or within a horizontal cavity, crude estimates of the corresponding velocity in the melt can be made. However, these estimates are about 2 and 3 orders of magnitude greater than velocities predicted by numerical modeling. Drawing conclusions from this simple analysis on the effects of scale with such a discrepancy from more sophisticated fluid dynamic modeling results is not recommended. Therefore, the results obtained from numerical modeling are used to determine the effects of scale-up on melt shape.

\section{Fluid Dynamic Modeling Results}

A series of computer simulations were performed to assess the thermoand fluid-dynamic response to the imposed electric field for each of three scales of $15 V$ (i.e., engineering-. pilot-, and large-scale units). The information obtained in these computer simulations serves to enhance our understanding of the processes at work in ISV. The computer simulations were performed using the EL7 version of the TEMPEST code (Trent et al. 1985). 


\section{Material Properties}

The thermodynamic, transport, and electrical properties of the soil were obtained from Buelt et al. (1987). The data for Hanford soil was chosen for these studies. The electrodes used in these ISV facilities were composed of a molybdenum core encased in a graphite collar. The thermal and electrical properties associated with these materials were obtained from Toulouklan and Ho (1970). The densities for the molybdenum and graphite are essentially constant over the temperature range of interest in these studies. A density of $10,230 \mathrm{~kg} / \mathrm{m}^{3}$ was used for the molybdenum, and $1620 \mathrm{~kg} / \mathrm{m}^{3}$ was used for the graphite.

\section{Summary of Fluid Dynamic Modeling Results}

The important parameters appear to be scale, power level, power-tosurface area ratio (governed by power level and/or electrode spacing), and, to a lesser degree, electrode diameter-to-spacing ratio. As the scale increases, the percentage of bottom heat transfer and relative downard growth decreases. Increasing the power supplied to the electrodes tends to produce a hotter melt region. larger flow speeds, promotes mixing. and consequently, enhances the percentage of total heat loss passing through the bottom surface of the vitreous zone.

Thus, higher power levels would enhance downward growth. Similarly. increasing the power-to-surface area ratio with a narrower electrode spacing produces a more uniform temperature for the core region, thereby enhancing heat transfer to the bottom surface of the melt. Also. as lateral growth is increased, the temperature profiles become less stratified, indicating a limit in lateral growth exists before downard melting becomes more prominent. The task force recommends that these results be accounted for in future updates of the ISV model used to predict melt shapes and time and energy requirements.

\section{DIFFERENCES IN ELECTRODE TYPE}

The current reference electrode design uses a $5-\mathrm{cm}-\mathrm{dia}$. molybdenum core inside a 30-cm-dia. graphite collar(a). Previous ISV experience was based on

(a) Advances in the ISV technology since the time of the Task Force's work have demonstrated the utility of using all-graphite electrodes. Hence. the pure graphite electrode is now the current reference electrode design. 
pure molybdenum electrodes. The two electrode types have a significant difference in melting behavior. Use of pure molybdenum electrodes was abandoned because of extensive growth of a porous cold cap on the surface of the vitrified product. Graphite collars promote cold cap subsidence because their larger diameter transmits more heat to the surface, the molten glass does not wet the graphite surface, and graphite reduces the oxidation state of molten glass. All of these factors contribute to the release of gases generated during the process, which reduces or eliminates the porous cold cap on the surface of the melt. With the cold cap eliminated, the surface soil sloughs into the subsidence void and melts. The energy required to melt the surface soil that sloughed onto the melt surface reduces the amount of energy available to melt downward, thus slowing the downard melting rate. Largescaie test data with molybdenum and molybdenum/graphite electrodes demonstrate that processing efficiency is not affected. maintaining an energy-to-mass rate of about $0.7 \mathrm{kWh} / \mathrm{kg}$. When predicting the energy and time to achieve a required depth. the electrode types and amount of soil sloughing from the surface must be considered.

A comparison of two pilot-scale tests using two different electrode types under otherwise similar conditions demonstrated the influence of graphite collared electrodes. Tests with graphite collared electrodes eliminated the cold cap and allowed sloughing of soil at the surface. a phenomenon that does not occur with pure molybdenum electrodes. The extra energy required to melt the sloughed surface material reduced the achieved depth to $2.4 \mathrm{~m}$ for the graphite collared electrodes, as compared to $3.6 \mathrm{~m}$ for pure molybdenum electrodes. No discernible difference in melt shape was observed. For a given processing time. the lower achieved depth for graphite electrodes is expected due to the fact that the energy and time required to melt the sloughed surface soil diminished that available for downard melting.

The influence of using graphite collared electrodes is also demonstrated through the predictions of the ISV mathematical model. The model had been upgraded to account for surface sloughing as recommended by this Task Force. Model runs demonstrated that for the same time and energy, the depth that would have been achieved with molybdenum electrodes without surface sloughing is $5.8 \mathrm{~m}$, whereas with graphite collars and surface sloughing at a $45^{\circ}$ angie of repose, the depth was $5 \mathrm{~m}$. Melt shape was not appreciably affected.

Although the use of graphite electrodes impacts the amount of depth achieved in a given amount of time, it was clearly not responsible for the 
amount of lateral growth observed from the 1987 large-scale radioactive ISV test. Negating the rock layer effects, the old version of the predictive mode1. Which did not account for surface sloughing. estimated 360 MWh were needed to achieve the $7.1 \mathrm{~m}$ depth. The amount of energy necessary to achieve the $7.1 \mathrm{~m}$ depth at a $45^{\circ}$ sloughing angle would have been $490 \mathrm{MWh}$. The amount of energy dissipated in the large-scale run was $460 \mathrm{MWh}$, far in excess of the predicted $240 \mathrm{MWh}$ needed for the $5 \mathrm{~m}$ depth that was achieved. The upgraded model, that accounts for surface sloughing, should be used for predicting the ISV melt shape and energy requirements for future applications.

An important aspect of using graphite collars. Which contribute to surface sloughing, is that they improve the overall effectiveness of ISV by eliminating unvitrified portions of soil near the surface. Molybdenum electrodes did not contribute to surface sloughing. leaving unvitrified portions near the surface between electrode settings.

\section{EFFECT OF OISTURBED. NONCOMPACTED SOIL}

The 1987 large-scale radioactive test was performed near the edge of a backfilled crib constructed in the 1950s. The effect on melt shape of vitrifying through a partially disturbed soil region was evaluated. The evaluation concluded that the undisturbed soil did not influence the melt shape of the vitrified block. Since the vitrification process was conducted near the edge of the crib, the lateral growth into the undisturbed region was compared with the growth rate into the disturbed soil. The effect of disturbed soil was discounted because probes inserted around the edges of the radioactive test block showed the block to be symmetrical. The process melted into the disturbed and undisturbed soil regions equally. with no discernibie difference in melt shape.

\section{MOISTURE EFFECTS}

The Task Force considered the possibility that recharge of moisture through the rock layer slowed the downard melting rate. Recharge was considered from two sources: 1) free liquid flow toward the vitrified zone through the rock layer from other areas of the crib and 2) reflux of moisture due to an evaporation. condensation, and capillary recharge cycle within the rock layer. 
Moisture effects were largely discounted in the evaluation. Moisture could not have accumulated in the rocks because the crib is designed to drain. The insertion and removal of electrode casings prior to the test would further promote draining. In addition, mass balances show that the soil moisture was completely recovered by the off-gas system. A water recharge layer would have resulted in a greater amount of water recovery. Reflux within the rock layer is highly unlikely because rock is a capillary barrier. Capillary action is the only known mechanism available to draw moisture back to the vitreous zone (Buelt 1988).

\section{DOWNTIME EFFECTS}

The large-scale radioactive test operated at $46 \%$ of total operating efficiency (46\% of maximum production rate) (Buelt and Westsik 1988). The primary reason for the loss in operating efficiency was 68 hours of downtime for transformer repairs during the middle of the test. The Task Force evaluated the effects of this downtime on the shape of the melt and concluded that downtime was not the cause of the lateral growth.

When the power to the electrodes is shutdown or reduced, the equilibrium temperature in the melt begins to decrease. Growth in the outward and downward directions slows, and the thermal gradients outside the block become less pronounced. Observations of crystalline growth in the lower half of the pilot-scale vitrified blocks indicate more rapid cooling occurs in the upper half of the block. This observation is explained by the fact that the surface is exposed to air with only a thin layer of insulation. whereas the bottom and sides are surrounded by highly insulative soil. When power is restored, the current will be directed preferentially to the lower half of the molten soil. This will concentrate higher temperatures near the bottom. promoting downward growth until equilibrium temperatures are re-established in the molten soil. The effect appears to be insignificant since it did not overcome the latera growth imposed by the rock layer. Therefore, in conclusion, the Task Force concluded that the downtime during operation has no discernible effect on the shape of the melt.

\section{BROKEN_ELECTRODES}

Nonradioactive tests conducted prior to the 1987 large-scale radioactive test demonstrated the significance that broken electrodes have on melt shape. 
Broken electrodes do not generally protrude to the bottom of the melt, which prevents power from being distributed near the bottom of the electrodes. The vitrified block formed during a large-scale test conducted in February 1986 exhibited lateral growth because of the broken electrode effect (Buelt et al. 1987). The actual block shape was obtained from measurements after partial excavation of the vitrified block and illustrated a melt shape shallower and wider than predicted by the ISV model.

Fluid dynamic modeling explains this behavior. For the case of a broken eiectrode, the power generation curve is skewed away from the bottom of the melt. Consequently, the downward melting rate is expected to be inhibited for this case. Results from the melt shape observations from the 1986 large-scale test and fluid dynamic modeling illustrate the importance of extending the electrodes to the bottom of the melt at all times to avoid lateral growth. However, since all four electrodes remained intact during the 1987 large-scale radioactive test, broken electrodes were not the cause of lateral growth exhibited.

\section{ENTRAINMENT OR SUSPENSION OF PARTICLES}

One of the postulations examined by the Task Force was the ability of the convective currents within the molten glass to sweep soil particles from the sides of the molten soil preferentially to those from the bottom. The Task Force evaluated whether the convective currents would be strong enough to sweep soil particles into the melt without fully melting them. Fluid dynamic modeling results indicate that convective current velocities are greater on the sides. and that upward velocities would be insufficient to sweep particles from the bottom. Suspension of particles from the sides would have the effect of preferentially melting outward.

The Task Force examined numerous cross sections of vitrified blocks to determine if this behavior was occurring during the ISV process. Examination of the cross sections revealed that the grains of soil fuse together before coming in contact with the convective currents. The edge of the fused soil particles are also protected from being swept into the molten glass by a thin layer $(\approx 1 \mathrm{~cm})$ of highly viscous molten soil. No discernible difference was evident between the melting behavior downward and the melting in the lateral direction. No evidence of sweeping of soil particles in the lateral or downward directions in any of the cross sections could be found. 
Consequently, the Task Force concluded that melting rates in the downward and outward directions are dependent on heat $f l u x$ and that no physical entrainment of soil particles occurs. Thus, this effect was discounted. 

PNL -8281

UC -602

\section{DISTRIBUTION}

No. of

Copies

OFFSITE

12 DOE/Office of Scientific and Technical Information

21 DOE Office of Environmental Restoration and Waste Management Trevion II Building 12800 Middlebrook Road Germantown. MD 20874

ATTN: W. W. Alexander

T. D. Anderson

J. E, Baublitz

D. L. Biancasino

J. 0 . Boda

J. Coleman

S. P. Cowan

J. J. Fiore

C. W. Frank

K. O. Hain

J. M. Lankford

J. C. Lehr

S. C. Lein

J. E, Lytle

S. A. Mann

S. M. Prestwich

M. Shupe

C. H. Sink

L. H. Taylor

H. F. Walter

R. P. Whitfield

2 DOE Albuquerque Operations Office

P.0. Box 5400

Albuquerque, NM 87115

ATTN: P. A. Saxman

D. H. Bandy

W. Holman

DOE San Francisco Field Office

1333 Broadway

Oakl and, CA 94612
No. of

Copies

J. Haugen

DOE Chicago Field office

9800 South Cass Avenue

Argonne. IL 60439

J. Hall

DOE Nevada Field Office

P.0. Box 98518

Las Vegas, NV 89193-8518

R. Tyler

DOE Rocky Flats office

DOE Building 116

Golden, CO 80402-0928

S. Ketola

DOE West Valley Project

P.0. Box 191

West Valley. NY 14171

W. Fitch

DOE Idaho Operations Office

785 DOE P1ace

Idaho Falls, ID 83402

M. O'Rear

DOE Savannah River Operations Office

P.0. Box A

Aiken, SC 29801

4 DOE Oak Ridge Office

P.0. Box 2001

Oak Ridge. TN 37831

ATTN: J. Moore (2)

J. Sweeney (2)

3 Battelle Memorial Institute

$505 \mathrm{King}$ Avenue

Columbus, $\mathrm{OH} 43201$

ATTN: W. A. Carbeiner

R. A. Nathan

Technical Library 
PNL- 8281

UC -602

No. of

Copies

Jesse L. Yow, Jr.

Lawrence Livermore National Laboratory

7000 East Avenue

Livermore, CA 94550

M.A.H. Reimus

Los Alamos National

Laboratory

P.0. Box 1663

Los Alamos. NM 87545

J. Koger

Martin Marietta Energy Systems

P.0. Box 2009

Oak Ridge. TN 37831-8097

P. T. Owen

Martin Marietta Energy Systems

P. 0 . Box 2003

Oak Ridge, TN 37831-7256

5 Oak Ridge National Laboratory

P.0. Box $Y$

Oak Ridge. TN 37830

ATTN: G. K. Jacobs (2)

M. T. Naney

B. P. Spalding (2)

K. Nuhfer

Westinghouse Materials Co. of ohio

P.0. Box 398704

Cincinnati, OH 45239-8704

5 Sandia Laboratories

P.0. Box 5800

Albuquerque, NM 87185

ATTN: D. Berry

R. Knowlton

J. Phelan

L. D. Tyler

Technical Library
No. of

Copies

5

EG\&G Idaho

P.0. Box 1625

Idaho Falls, ID 83415

ATTN: J. L. McAnnaly

5. K. Merrill

D. F. Nickelson

R. L. Norland

R. R. Stiger

L. Rogers

EG\&G Energy Measurements. Inc.

P.0. Box 1912. MS RSL-11

Las Vegas. NV 89125

B. Haas

Ames Laboratory

7 Spedding $\mathrm{Hall}$

Iowa State University

Ames, IA 50011

6 Westinghouse Savannah River Company

P.0. Box 616

Aiken, SC 29801

ATTN: J. S. Hasel ow

C. M. Jantzen

M. J. Plodinec

J. F. Sproull

J. L. Steele

T. Walton

J. M. Pope

West Valley Nuclear

Services Co.

P.0. Box 191

West Valley, NY 14171 
PNL-8281

UC -602

No. of

Copies

4 Geosafe Corporation

Port of Benton Building

2950 George Washington Way

Richland. WA 99352

ATTN: C. L. Timmerman (2)

B. E. Campbell

J. E. Hanson

\section{QNSITE}

2 DOE Richland Field Office

E. A. Bracken, A6-95

D. E. Trader, A5-90

13 Westinghouse Hanford Company

W. C. Alaconis, L4-92

H. Babad, B3-68

J. D. Berger. L0-18

J. W. Cammann, H4-54

K. R. Fecht, H4-56

R. E. Lerch, B2-35

R. L. Gilchrist, L5-63

H. E. McGuire, B2-35

J. W. Shade, R4-03

D. A. Turner, R1-10

D. D. Wodrich, R1-48

R. D. Wojtasek, B2-15

B. A. Wolfe, L5-61

No. of

Copies

25 Pacific Northwest Laboratory

K. A. Borgeson, P7-46

J. L. Buelt, P7-41

H. C. Burkholder, P7-41

W. L. Kuhn, P8-38

P. A. Lowery, K7-15

J. Luey, P7-34 (5)

J. L. MCElroy, P7-46

M. E. Peterson, P7-41

T. D. Powel1, P7-34

S. C. Slate, K1-25

S. L. Stein, K1-25

L. E. Thompson, P7-34

J. S. Tixier, P7-34

C. L. Widrig, P7-34

S. L. Woosley. P7-34

Publishing Coordination

Technical Report Files (5) 
